\title{
ERUDICIÓN, MAGIA Y ESPECTÁCULO: EL JUICIO DE LA REPÚBLICA DE LAS LETRAS SOBRE ATHANASIUS KIRCHER*
}

\author{
Carlos Solís Santos \\ Facultad de Filosofía. UNED
}

"Quante smorfie, quante buffonerie!"

(Don Alfonso en Cosi fan tutte)

ABSTRACT: Athanasius Kircher was commonly addressed with courtliest reverence by his contemporaries, but he was frequently criticized and even despised in private correspondence. We examine here the evolution of the negative appraisal of his work by the members of the Republic of Letters in France, Italy, Germany and England, and we identify Kircher's shortcomings with the ideological attitude of Jesuit science aimed at uprooting the scientific world view.

El lector ingenuo que ojee hoy las obras de Athanasius Kircher S.J (16021680) se sentirá tentado a concluir que se halla ante un majadero cuando no ante un charlatán mistificador. En efecto, lo verá entregado a fabricar linternas para proyectar demonios en pasillos lóbregos (Figura 1$)^{1}$; a construir máquinas basadas

* Este escrito se inició gracias a una discusión con Susana Gómez y se ha beneficiado de sus críticas, así como de las de Antonio Beltrán. También estoy en deuda con Esther Artigas, Sylvia García Gil, Eloy Rada y Juan Vicente Mayoral.

1 "El bueno de Kircher siempre anda haciendo aquí mil pases de prestidigitación con el imán en la galería del Colegio Romano; si dispusiese del invento de la linterna, se dedicaría a espantar a los cardenales con espectros". Carta de P. Guisony a C. Huygens del 25 de Marzo de 1660, en Oeuvres complètes de Christiaan Huygens, La Haya: Martinus Nijhoff, 1888-1950 (22 vols.), III: 48. Huygens había tenido el año anterior la idea de la linterna mágica de la que se apropió Kircher doce años más tarde, en la segunda edición del Ars magna lucis et umbrae (1671). Sin embargo, según se desprende del oscuro texto y de la Figura 1, Kircher no tenía una idea nada clara de su funcionamiento, pues no recoge la inversión de la imagen y la transparencia se coloca después del objetivo. Por el contrario, el diseño de Huygens de 1659 consta de un espejo parabólico, la fuente de luz, un condensador, la transparencia y un objetivo regulable compuesto por dos lentes biconvexas, como un proyector de diapositivas actual. Véase el Capítulo 3 de T. L. HANkInS y R. J. Silverman, Instruments and the Imagination, Princeton University Press, 1995, especialmente las páginas 43-46. 
en la correspondencia entre macrocosmos y microcosmos activadas ora por ciertas semillas que un árabe misterioso trajo del Oriente, ora por un vulgar mecanismo de relojería escondido en un doble fondo; a interpretar antiquísimas inscripciones egipcias como loas cifradas a la Santísima Virgen María; o a describir con seriedad experimentos fantasiosos cuyos resultados nadie era capaz de reproducir.

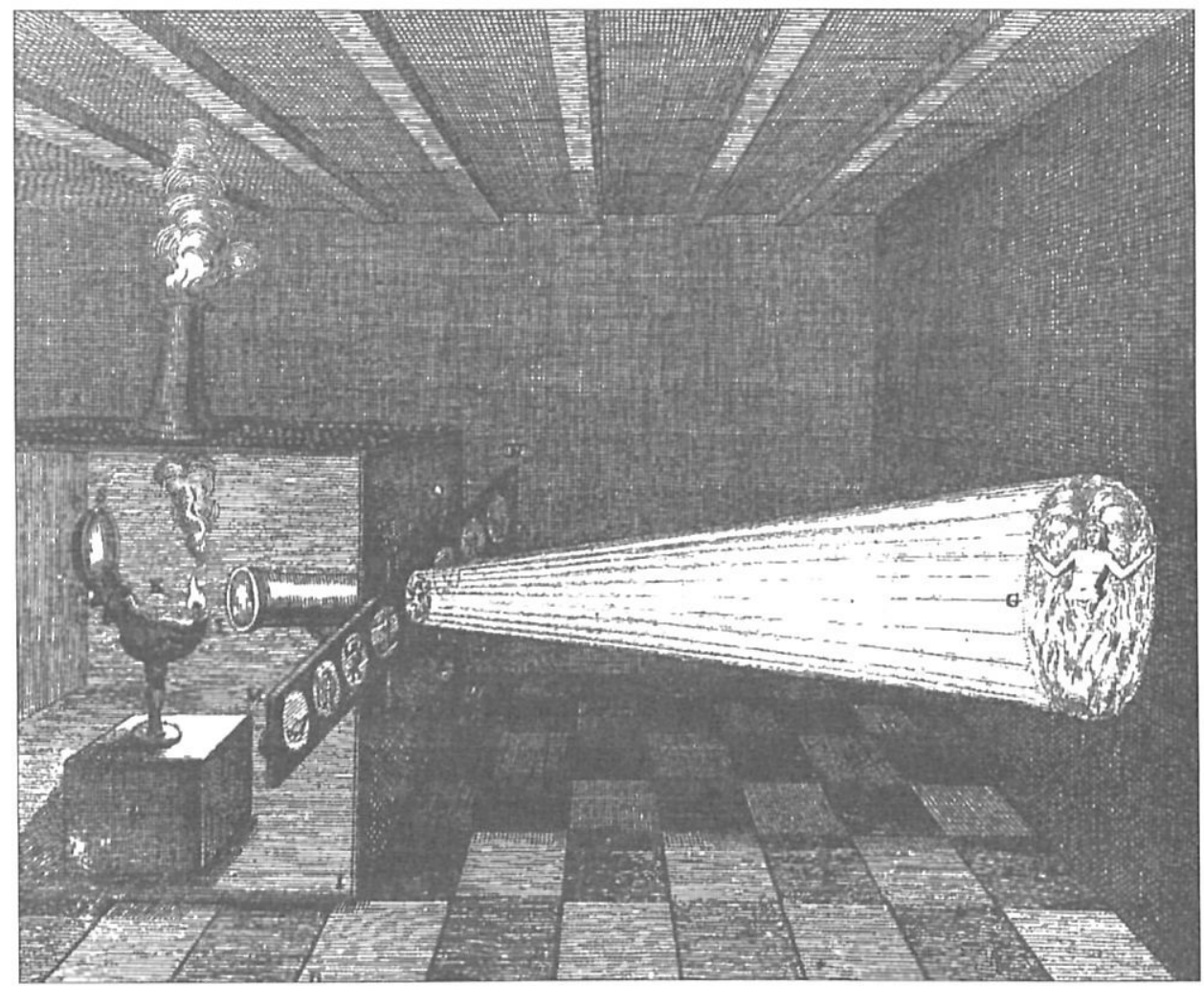

Figura 1. Proyección de un ánima en el fuego del Purgatorio (Georgius de Sepibus, Romani colegii Societatus Jesu musaeum celeberrimum (Amsterdam 1678), página 39. Se pueden ver más proyecciones en las páginas 125 y 126 de S. J. Kestler, Physiologia kircheriana experimentalis (Amsterdam, 1680)

No obstante, Kircher fue un notable miembro de la comunidad científica jesuita que pasó su vida madura en el Collegio Romano dedicado a redactar sus libros. Desde los años treinta hasta su muerte, las ediciones y nuevas ediciones de sus obras se sucedieron a un ritmo de casi una al año. Incluso se vio liberado de las obligaciones de dar clase, lo que quiere decir que sus libros eran respaldados 
por la Compañía dentro de sus planes de abrumar con su erudición y ciencia a las elites europeas divididas entre el Protestantismo y la Contra-Reforma. Sus obras estaban dedicadas a los diversos Príncipes europeos (según las malas lenguas, llegó dedicar la misma obra a diferentes personas notables para matar varios pájaros de un tiro ${ }^{2}$ y se adornaban con grabados magníficos de una belleza inquietante. Mantuvo asimismo una correspondencia voluminosa (casi 2.500 cartas) con cerca de un millar de corresponsales entre los que se contaban misioneros de ambas Indias, emperadores, príncipes y papas, no menos que sabios y curiosos como G. W. Leibniz, N. C. Fabri de Peiresc, P. Gassendi, M. Mersenne, R. Moray o R. Southwell. ${ }^{3}$

Decía T. S. Kuhn que cuando alguna doctrina pretérita nos sorprende por absurda, ello se debe a que no entendemos cabalmente el texto, por lo que esa extrañeza debe ponernos en la pista acerca de qué nos falta por tomar en consideración para que las actitudes y opiniones que expresa se revelen como coherentes y razonables ${ }^{4}$. Tal vez sí y tal vez no. Cuando Kuhn comenzó a estudiar historia de la ciencia a final de los años cuarenta se fijó preferentemente en los grandes personajes, acerca de los cuales su reflexión es en general correcta; pero no sería justo pensar que no había idiotas «sobresalientes» en siglos pasados, por lo que es posible que lo que nos parece hoy injustificado estuviese entonces también injustificado.

${ }^{2}$ H. Oldenburg, "Of the Mundus Subterraneus of Athanasius Kircher", Philosophical Transactions, N. 6 (6-XI-1665): 109-117, página 109. El Volumen I de Mundus subterraneus (1665) estaba dedicaddo al Papa Alejandro VII y el segundo, al Emperador Leopoldo I. Pero la verdadera orgla dedicatoria se había producido en el Oedipus Aegyptiacus (1652-4). Amén de la consagración general de la obra al Emperador Fernando III, las divisiones de los tomos II y III se dedicaban a no menos de cuarenta personas: emperadores, príncipes, cortesanos, cardenales, obispos, eruditos y médicos que abarcaban a una buena parte de la corte vienesa no menos que a los Barberini (familiares del Papa Urbano VIII) y a los Medici.

${ }^{3}$ Cf. J. FleTCHER, "Athanasius Kircher and His Correspondence", en J. FletCHER (Ed.), Athanasius Kircher und seine Beziehungen zum gelehrten Europa seiner Zeit, Wiesbaden: Herzog August Bibliotek, 1988, páginas 139-178. Está en marcha un Athanasius Kircher Correspondence Project (http://www.stanford.edu) para recoger y editar en la red toda la correspondencia, partiendo de los 14 volúmenes procedentes del museo de Kircher en el Collegio Romano, conservados hoy en los Archivos de la Universidad Gregoriana.

4 «Para transmitir a los alumnos estas lecciones, les propongo a menudo la siguiente máxima: al leer las obras de un pensador sobresaliente, fijese antes que nada en los absurdos aparentes del texto y pregúntese cómo es que una persona razonable pudo haber escrito tales cosas". T. S. KuHN, The Essential Tension, The University of Chicago Press, 1977, página xii. 
Es posible que Kircher fuese una persona que empezase a estar ya claramente fuera de época a mediados del siglo XVII. Para no incurrir en proyecciones de categorías y valores actuales sobre el pasado, en este artículo examinaremos la opinión que los principales estudiosos contemporáneos de Kircher tenían de sus obras, pues si bien lo acompañaba fama de sabio, muchos se desengañaron de sus promesas y expresaron hacia él juicios poco halagüeños. Con todo, era persona relevante y bien conectada con el patrocinio de nobles, por lo que dichas críticas aparecían no tanto en las obras publicadas, comúnmente respetuosas con el jesuita, cuanto en la correspondencia privada. En la segunda parte de este escrito pondremos algunos ejemplos de las opiniones sobre diversos aspectos de su obra tras exponer brevemente en la primera el contexto institucional del la práctica científica de la Compañía.

\section{La ciencia de los jesuitas}

La Compañia de Jesús, ingeniada en 1534 por un militar guipuzcoano, Iñigo de Loyola (1491-1556), fue aprobada por el Papa seis años más tarde como una unidad militar a su servicio, útil para la lucha contra la Reforma protestante, organizada en el Concilio de Trento (1545-1563). Estos acontecimientos coincidieron también con el nacimiento del copernicanismo (1543), doctrina que el ejército de Loyola atacaría como un solo hombre en la cabeza de Galileo setenta años más adelante, a partir del Decreto de 1616 que declaraba herético el heliocentrismo.

Los dos campos de batalla predilectos de los jesuitas fueron la conversión de los habitadores de las Indias y la reconversión de los herejes europeos. Para esta última misión centraron sus esfuerzos en las elites a las que pretendían deslumbrar con su superioridad intelectual para luego adularlas y atraerlas al buen camino. Como el árbol, que se endereza bien de joven aunque llegado a la madurez no dobla, así el hombre. Por tanto prestaron primordial atención a la educación de la juventud para que, reafirmada en la recta doctrina, se tornase luego en bastión inexpugnable ante las ideas reformistas. La fundación de colegios se inició con el de Mesina en 1548, alcanzando la cifra de 33 para la muerte del guipuzcoano. A finales de siglo tenían ya 245, los cuales ascendieron a 441 a comienzos del segundo cuarto del siglo XVII. Esto significa un ritmo de 5 ó 6 fundaciones anuales. Los colegios pequeños acogían unos 500 alumnos, mientras que los grandes superaban los 1.500 , de manera que para mediados del siglo XVII los Padres labraban anualmente las mentes de cerca de medio millón de jóvenes de Europa, de las Indias Orientales y de las Occidentales. 
Tan importante como la creación de colegios fue la organización de la enseñanza. Se comenzó a discutir en la década de 1580 con la activa participación del Padre C. Clavio y se hizo publica en la Ratio atque institutio studiorum de 1599 que ya habla conocido en 1586 una edición privada para su discusión interna. Una de las más comentadas novedades de la ensefianza de los jesuitas es la importancia concedida a las matemáticas que Clavio ponía en pie de igualdad con la física, frente a la oposición de los filósofos como el Padre B. Pereira. Según el aristotelismo tradicional, sólo la física ofrecía explicaciones causales verdaderas, frente a las matemáticas que sólo presentaban relaciones accidentales y superficiales. ${ }^{5} \mathrm{La}$ reivindicación de Clavio significó sacar a las matemáticas de los primeros cursos propedéuticos para enseñarla en el segundo o tercer curso del ciclo superior de Filosofía en tres años. ${ }^{6}$ La idea era que las matemáticas suministran un procedimiento efectivo de transmitir la verdad partiendo de principios verdaderos, que es en lo que consiste la ciencia demostrativa según los Segundos Analíticos de Aristóteles. Esos principios no se pueden demostrar dentro de la disciplina; pero eso ocurre asimismo con la física, la cual obtiene los primeros principios de la experiencia acumulada y hecha general en la memoria al abstraer los rasgos accidentales de las sensaciones repetidas. En este punto se produjo la segunda innovación jesuítica.

${ }^{5}$ Sobre la reinterpretación jesuítica de las matemáticas a modo de disciplina susceptible de ofrecer explicaciones efectivas como la física, y sobre la elaboración de la ufísico-matemática* como unión del método deductivo de la matemática con la relevancia causal de la física, véase P. DEAR, "Jesuit Mathematical Science and the Reconstitution of Experience in the Early Seventeenth Century», Studies in the History and Philosophy of Science, 18 (1987): 133-175, y cl Capitulo 2 de P. DEAR, Discipline and Experience, University of Chicago Press, 1995. Sobre el papel de Clavio y el Collegio Romano en la elaboración de la Ratio, véase U. BALDINI "The Academy of Mathematics of the Collegio Romano from 1553 to 1612*, en M. FEINGOLD (Ed.), Jesuit Science and the Republic of Letters, Cambridge, Massachusetts: The MIT Press, 2003: 47-98. Sobre la cultura jesuítica general tanto en Europa como en tierra de misiones, véase J. W. O'Malley et al. (Ed.), The Jesuits: Cultures, Sciences, and the Arts 1540-1773. Buffalo, N. Y.: University of Toronto Press, 1999. Sobre el uso jesuítico de la ciencia véase la tesis doctoral de M. J. GoRMAN, The Scientific Counter-Revolution: Mathematics, Natural Philosophy and Experimentalism in Jesuit Culture, 1580-c.1670, Ph. D. Thesis, Florencia: The European University Institute, 1998, en http://sts.stanford.edu/gorman/thesis.

6 «En el segundo año de los estudios de Filosofia todos los alumnos recibirán un curso de matemáticas de unos cuarenta y cinco minutos diarios, si bien a quienes muestren inclinación y facilidad para esta disciplina se les dará ocasión de estudiarla más profundamente con clases particulares una vez terminado el curso general" (Ratio studiorum, 1599, Reglas del Provincial, $\$ 20)$. 
Durante el primer tercio del siglo XVII los jesuitas se plantearon el uso de la experimentación y de instrumentos de observación esotéricos (telescopios, microscopios, barómetros, imanes, cámaras obscuras y otros dispositivos de laboratorio) como medios adecuados para alcanzar los primeros principios verdaderos e indemostrables de las ciencias matemáticas, complementando y superando de ese modo la inducción aristotélica a partir de la experiencia común de todos.

Así pues, los jesuitas desarrollaron una filosofia de la ciencia que reconocía la función primordial de las matemáticas y la experimentación, justamente los dos rasgos distintivos de la Revolución Científica de los siglos XVI y XVII, y con ello dejaron su huella en algunos de los más conspicuos revolucionarios católicos, como R. Descartes y G. Galilei. Con todo, y sin merma del mérito que tiene el haber incorporado rápidamente estos rasgos a la formación de la juventud, no fueron ellos los inventores del uso de las matemáticas y los experimentos en la investigación del mundo natural. Ambos rasgos florecieron al margen de la Companía y pueden verse en pensadores originales anteriores a la Ratio y en estudiosos protestantes y católicos ajenos a los Padres jesuitas. Pero éstos fueron sin duda perceptivos seguidores del espíritu de los tiempos y esforzados campeones de la sutura de esas nuevas tendencias con la vieja filosofía escolástica que constituía el esqueleto intelectual de la teología católica. ${ }^{7}$

${ }^{7}$ Claudio Acquaviva, quinto General de la Compañía desde 1581 hasta su muerte en 1615 , emitió el 14 de Diciembre de 1613 una Ordinatio pro soliditate et uniformitate doctrinae exigiendo a los profesores no apartarse de Aristóteles. (La expresión "solidez y uniformidad doctrinal» tuvo un enorme éxito desde que la acuñara el tercer general Francisco de Borja en 1565, cuando emitió una lista de tesis sobre las que no cabía libertad de opinión.) Acquaviva también instauró la censura de libros y de opiniones a fin de que su milicia presentara un frente cerrado de uniformidad y solidez doctrinal, y ordenó plegarse a Santo Tomás de Aquino y retractarse inmediatamente de cualquier introducción de novedades al respecto, normas que debían leerse todos los años en la apertura de curso. Así pues, cuando un jesuita escribía un libro, debía entenderse que su contenido contaba con el acuerdo de la orden, ya que debía ser aprobado por el General de la Compañía, oídos los cinco Censores Generales elegidos entre los más conservadores del gremio. Sobre estos particulares véase U. BALDINI, Legem impone subactis: Studi su filosofia e scienza dei gesuiti in Italia, 1540-1630, Roma: Bulzoni, 1992. Con todo, las cuestiones científicas y filosófocas eran demasiado variadas y complejas para que los censores pudiesen dictar doctrina en todos los campos. De ahí que se encuentren defensores de la composición del continuo a base de indivisibles, como R. de ARRIAGA en el Cursus philosopicus (1632) o de la transmutación de los metales, como F. LANA TERZI en su Prodromo (1670); pero otros muchos o bien fueron corregidos constantemente, como I. G. Pardies o, como Kircher, protegieron su hermetismo antiaristotélico y sus incoherencias con el disimulo, la amistad de papas y emperadores y otras maniobras. Sobre sus tácticas para hurtarse al control y revisión de sus obras, cf. H. SIEBERT, "Kircher and His Critics" en P. FINDLEN (ed.), Athanasius Kircher. The Last Man Who Knew Everything, Londres y Nueva York: Routledge, 2004: 79-104. 
Pero las mismas tendencias pueden observarse por doquier sin que fuesen acompañadas de la preocupación por el crecientemente obsoleto aristotelismo escolástico. Así, por ejemplo, las universidades inglesas facilitaron el estudio matemático y experimental de la naturaleza sin necesidad de pedir permiso a Aristóteles y a Santo Tomás, mientras que los requisitos aristotélicos del curriculum medieval podían obviarse discretamente. ${ }^{8}$ Por ejemplo, ya en 1661-65, Newton no terminó ninguno de los libros del syllabus aristotélico establecido en Cambridge, dedicándose en cambio a estudiar a Descartes, Gassendi, Kepler y Galileo entre otros" ${ }^{9}$, lo que no le impidió terminar los estudios brillantemente y ocupar la cátedra de matemáticas cedida por el Lucasian Professor Isaac Barrow. Desde mediados del siglo XVI los estudiantes de Cambridge y Oxford disponían de cierta libertad para obviar la escolástica aristotélica y proseguir sus inclinaciones con o sin ayuda de sus tutores que solían conocer las obras matemáticas más recientes. Sin necesidad de buscar una cobertura filosófica escolástica ni de establecer un curriculum rígido y autoritario, estas universidades permitieron el florecimiento de personas como W. Oughtred, I. Barrow, J. Wallis, I. Newton o E. Halley. Leyeron como estudiantes a sus antecesores y contemporáneos de toda Europa y fueron libres de extender el estudio matemático del mundo a través del mecanicismo cartesiano o del atomismo epicureísta que facilitaban la visión matemática de la naturaleza como un conjunto ciego de partículas en movimiento, sin necesidad de batallar con ecceidades, formas substanciales y demás tramoya escolástica inútil cuando no embarazosa incluso para la nueva teología. ${ }^{10}$ También podían desarrollar las implicaciones cosmológicas del copernicanismo que era una de las principales fuentes de inyección de matemáticas en la naturaleza, dado que una ciencia matemática como era la astronomía había revelado la verdadera estructura física del cosmos frente a la física cualitativa aristotélica. Los jesuitas, empero, encontraron cerrada esta vía por ser esencialmente anti-aristotélica no menos que por la condena explícita del heliocentrismo como herético en el mentado Decreto de 1616.

Por tanto, a pesar de la modernidad de los planes de estudios jesuiticos, las cortapisas filosóficas y dogmáticas de su adhesión al papismo les cerró el paso a

${ }^{8}$ Cf. M. FeIngold, The Mathematicians' Apprenticeship. Science, Universities and Society in England, 1560-1640, Cambridge University Press, 1984.

${ }^{9}$ R. S. Westfall, Never at Rest. A Biography of Isaac Newton, Cambridge University Press, 1980, páginas 67-70 sobre la Universidad de Cambridge y 80-89 sobre las lecturas de Newton.

${ }^{10}$ Cf. R. S. WestFall, "The Rise of Science and the Decline of Orthodox Christianity", en D. C. LINDBERG y R. L. NUMBERS (Eds.), God \& Nature: Historical Essays on the Encounter between Christianity and Science, University of California Press, 1981: 218-237. 
las innovaciones revolucionarias de la ciencia moderna. Pase que en la Ratio studiorum la primera regla del Provincial establezca que la finalidad de los estudios es conducir al "conocimiento y amor de nuestro Creador y Redentor", pues después de todo se trata de una orden religiosa y ese es un piadoso deseo común a todos los estudiosos protestantes, católicos o escépticos del siglo XVII. ${ }^{11}$ Pero la estrechez doctrinal de los jesuitas iba más lejos, como muestra el establecimiento de un Prefecto de Estudios encargado de vigilar la recta «enseñanza de Santo Tomás en teología y las reglas que prescriben la selección de tesis que deben sostenerse en filosofiam, especialmente las que habrían de imprimirse. ${ }^{12}$ Eso se aseguraba ordenando que:

No permitirá que los estudiantes de teología y filosofia tengan libros de cualquier naturaleza, sino que sólo se les autorizará aquéllos recomendados por los instructores y aprobados por el Rector. Los teólogos tendrán la Summa de Santo Tomás y los filósofos, Aristóteles y algún comentario escogido para que lo consulten en su estudio privado. ${ }^{13}$

Abundando en el tema, la segunda regla del Profesor de Filosofía prescribía que "no se aparte de Aristóteles en cuestiones importantes a menos que dé con alguna doctrina contraria a las enseñanzas comunes de las escuelas o, peor aún, contraria a la verdadera fem. De ahí parece desprenderse que no se prevé que los estudiantes puedan encontrarse con alguna doctrina aristotélica contraria a las matemáticas y los experimentos y que si ello sobreviniese, peor para las matemáticas y los experimentos. Así ocurrió con la doctrina atomista y con la copernicana, dos pilares substantivos de la Revolución Cientifica.

Sencillamente, el objetivo de los jesuitas no era aumentar el conocimiento natural, sino combatir la Reforma usando la erudición y la cultura como propaganda. ${ }^{14}$ De manera que aunque reconocieron la función de la novísima físico-

${ }^{11}$ En ese siglo no hubo ateos en el sentido actual de la palabra y lo que se tenía por tales eran deístas partidarios de una concepción más filosófica que pla de Dios, como ocurría con $\mathrm{R}$. Descartes, B. Spinoza o T. Hobbes.

12 Ratio Studiorum, cuarta regla del Prefecto de Estudios.

${ }^{13}$ Ibid., regla 30.

${ }^{14}$ Sobre las características y cortapisas de la ciencia de los jesuitas, véase W. B. ASHWORTH Jr., "Catholicism and Early Modern Science" en D. C. LINDBERG y R. L. NUMBERS (Eds.), op cit en la 
matemática, ellos mismos fueron escasamente innovadores. Sin embargo, su gusto por la emblemática y la adulación de Príncipes los llevó al estudio de fenómenos curiosos y asombrosos ${ }^{15}$, aunque sin comprometerse seriamente en la construcción de nuevas teorías que habrían de ser irremediablemente anti-escolásticas, con lo que minarían las bases de la teología católica. Su afición a las matemáticas se estrelló pronto en el campo de la astronomía con el movimiento de la Tierra, y su afición a la experimentación chocó enseguida con el atomismo y el vacío puesto de manifiesto por los experimentos de E. Torricelli y O. von Guericke. Sólo les quedaba el escepticismo teórico, la erudición inconcluyente y la experimentación como espectáculo. ${ }^{16}$ A pesar de que su red de corresponsales en todo el mundo les permitió recoger datos sobre meteorologia, historia natural o

nota 10, páginas 136-166, especialmente 153-166. Los Padres del Collegio Romano, especialmente C. Grienberger, pusieron a punto una estrategia para neutralizar las novedades teóricas antiaristotélicas y apropiarse de los descubrimientos y experimentos de Brahe o Galileo. Consistía en aceptar los datos sancionados por la Companía y adoptar una postura escéptica respecto a sus pretendidas consecuencias teóricas. Así ocurre con la censura de G. Camerota y de Grienberger a G. Biancani: se pueden presentar los hechos descubiertos por Tycho Brahe absteniéndose de usarlos para defender la fluidez de los cielos y la ausencia de esferas sólidas (U. Baldini, Legem impone subactis, citado en la nota 7, páginas 231 y sigs.). El discurso de Grienberger-Maelcote leído por éste en el Collegio Romano en Mayo de 1611 (Le opere di Galileo Galilei. Edizione Nazionale a cura di A. FAVARO, 20 Volúmenes. Florencia: G. Barbèra Editrice, 1890-1909, III-1: 293-298), más que festejar la grandeza del toscano, le arrebata sutilmente sus títulos de gloria. Es el Collegio el que sanciona de manera efectiva la realidad de los fenómenos celestes mediante su propio telescopio, a la vez que los desconecta con prudencia escéptica de las consecuencias cosmológicas voceadas por Galileo, el cual queda reducido así a un hábil menestral que se topó con admirabilia spectacula. Otro tanto hicieron Grienberger-Bardi y Biancani con los experimentos hidrostáticos de Galileo, de los que se apropiaron desconectándolos de sus implicaciones atomistas. Cf. F. P. de CEGLIA, "Additio illa non videtur edenda: Giuseppe Biancani, Reader of Galileo in an Unedited Censored Text", en M. FeINGOLD (ed.), The New Science and Jesuit Science: Seventeenth Century Perspectives, Dordrecht: Kluwer, 2003: 159-186, especialmente 168 y sig.

15 P. FINDLEN ("Jokes of Nature and Jokes of Knowledge: The Playfulness of Scientific Discourse in Early Modern Europe", en Renaissance Quarterly, 43, n. ${ }^{\circ}$ 2, 1990: 292-331, especialmente 320) ha llamado la atención sobre el gusto jesuítico por los juegos de la naturaleza y de la ciencia, de manera que una buena parte de su trabajo experimental en el siglo XVII se inspiraba en la vieja tradición de los libros de los secretos. Ello se compadecía bien con la combinación de docere y delectare por motivos pedagógicos y cortesanos, no menos que para lanzar cortinas de humo frente a los peligros de la nueva ciencia.

16 J. GRANDAMI S.J. escribió su Nova demonstratio immobilitatis Terrae petita ex virtute magnetica (La Flèche, 1654) para las personas que «fatigadas por el esfuerzo empleado en asuntos más importantes... se recrean en el gratísimo espectáculo de la admirable naturaleza». Véase M. BALDWIN, "Pious Ambition: Natural Philosophy and the Jesuit Quest for the Patronage of Printed Books in the Seventeenth Century», en M. FEINGOLD (Ed.), op. cit. en la nota 5: 285-329, especialmente el apartado The Jesuit Author and His Audience, págs. 297-301, página 300. 
culturas exóticas ${ }^{17}$ y de que su afición a los campos nuevos de la electricidad, el magnetismo o la óptica los llevó a descubrir fenómenos como la repulsión eléctrica o la difracción, la falta de libertad para articular un programa filosófico de investigación hizo que sus experimentos fuesen ciegos.

En una época en que las teorías eran aún inefectivas o inexistentes en los nuevos campos, los programas filosóficos permitieron orientar y dirigir la investigación, como ocurrió con el mecanicismo de materia y movimiento de R. Descartes y R. Boyle o con el atomismo de Gassendi, Galileo y sus discípulos. La imposibilidad de disponer de un programa director de este jaez tendió a convertir las indagaciones de los jesuitas en un centón, pues como bien decía el Señor de Verulamio, la verdad sale más fácilmente del error que de la confusión. Ellos, por tanto, hubieron de refugiarse en el circo, el enciclopedismo y la irrelevancia teórica. Así, por ejemplo, el jesuita G. Riccioli escribió un tratado anti-copernicano y anti-galileano (aunque en el proceso confirmó las leyes cinemáticas de Galileo) en el que discutía la naturaleza de las estrellas con gran erudición y variedad de hipótesis sin tomar partido por ninguna. Los fenómenos ópticos, barométricos o magnéticos estudiados por jesuitas como D. Bartolli, N. Cabeo, G. Pardies o F. Lana llevaban rápidamente a posiciones poco aristotélicas, por lo que era recomendable adoptar un tono ecléctico. Era preferible mostrar la propia cultura mediante la erudición y divulgación de las novedades ajenas, como hicieron A. Kircher y su discípulo G. Schott. También se podían entregar a refutar los aspectos más peligrosos de la ciencia, como hicieron G. Riccioli, O. Grassi o C. Scheiner con el copernicanismo de Galileo; E. Noël o G. Schott con el vacío torricelliano, o N. Cabeo o A. Kircher con la causa magnética del movimiento de la Tierra de W. Gilbert. Sin embargo difícilmente podían ofrecer explicaciones mejores.

El uso propagandístico y apologético del saber llevó a la pervivencia de la visión emblemática de la naturaleza típica de la Edad Media y el Renacimiento, según la cual «la naturaleza es un jeroglífico complejo, importante sólo como

${ }^{17}$ John Beale, miembro de la Royal Society, escribía a Henry Oldenburg el 24 de Junio de 1671 que si a principios de siglo los jesuitas tenfan cerca de trescientos colegios que rentaban anualmente dos millones de coronas, setenta ańos más tarde tendrían muchos más dispersos por todo el globo, lo que los convertía en una excelente red para estudiar fenómenos geográficamente dispersos, como la declinación magnética, así como para recoger historias naturales y maravillas del arte (A. R. Hall y M. B. HaLl, Eds., The Correspondence of Henry Oldenburg, 5 volúmenes, The University of Wisconsin Pres, 1965-68; volumen VIII: 121.) 
fuente de misterio y asombro" en la que "la separación de los fenómenos falsos de los verdaderos se torna secundaria si no irrelevante. Tal visión del mundo produjo obras de arte y literatura deliciosamente rebuscadas [como las de Kircher], pero su disolución fue un rasgo esencial de la Revolución Científica. Los jesuitas nunca consiguieron abandonar su mundo emblemáticom. ${ }^{18} \mathrm{La}$ ambigüedad entre verdad y falsedad se acrecentó entre los jesuitas al tener que combinar el fundamentalismo en Europa con el relativismo en las Indias. Las dificultades de traducir la Biblia y las doctrinas escolásticas a la lengua y cultura chinas llevaron a cierto escepticismo oportunista. Del mismo modo que el viejo cristianismo había acomodado el culto a los héroes muertos y a los lugares altos mediante la consagración de los santos y la erección de ermitas en los montes, mientras que la Trinidad y la Virgen María suplían la variedad del politeísmo pagano, así los jesuitas hubieron de permitir que los chinos conversos rezasen a Confucio, adorasen a los ancestros y llamasen Tien (cielo) a Yahvé, a la manera en que más adelante el «Padre Nuestro" habría de convertirse en el "Tío materno" trobriandés y el "Cielo» en el esquimal "Allende el horizonte de las focas».

Pero el elemento que condujo a este eclecticismo escéptico fue sin duda el copernicanismo, inaceptable en sus consecuencias cosmológicas aunque inevitable si uno quería mantenerse en la primera línea científica. Entre 1570 y su muerte en 1612, el Padre C. Clavio publicó media docena de ediciones de su In sphaeram Iohannis de Sacro Bosco commentarium que era un buen manual de astronomía ptolemaica estudiado por personas como M. Mersenne, P. Gassendi, R. Descartes o G. Galilei. Sin embargo Clavio miró para otro lado ante los descubrimientos de Tycho Brahe y Galileo que poseían importantes consecuencias cosmológicas. El primero criticó la existencia de esferas sólidas de los planetas porque las cortaban las trayectorias que había calculado para los cometas; criticó la incorruptibilidad de los cielos por la aparición y extinción de estrellas nuevas; y refutó el sistema de Ptolomeo al calcular una paralaje de Marte en la oposición que mostraba que entonces se hallaba más próximo a la Tierra que el Sol, lo que le dio pié para su conjetura cosmológica. Por su lado, Galileo refutó efectivamente el sistema ptolemaico con el descubrimiento de las fases de Venus que por tanto debía girar en torno al Sol. El descubrimiento de los satélites de Júpiter mostraba que la Luna no era una cortapisa para el sistema copernicano (pues un satélite podía girar a la vez en torno a su planeta y, junto con él, en torno al Sol),

${ }^{18}$ W. B. AsHWORTH, loc cit. en la nota 14, página 157. 
mientras que la naturaleza elemental y terrestre de los cielos estaba sugerida poderosamente por el relieve lunar o las manchas solares, y la infinitud por la ampliación del número de estrellas gracias al telescopio.

Clavio y sus discípulos del Collegio Romano confirmaron al Cardenal R. Bellarmino en 1611 la corrección de las observaciones de Galileo, y los más jóvenes empezaron a coquetear con otras cosmologías, ${ }^{19}$ alegría que cortó de raíz el Decreto anti-copernicano de $1616^{20}$. Entonces se hubieron de adoptar las posiciones ficcionalistas de Bellarmino y aceptar la ordenación cosmológica de Brahe como mal menor. Pero Brahe carecía de teóricas de los planetas y parasitaba a Copérnico. Su esquema cosmológico, aunque coincidía con el copernicano desde el punto de vista de las líneas visuales, resultaba dinámicamente absurdo y debía atribuir a los astros una ciencia infusa para saber por dónde ir. En esas condiciones, un astrónomo que no aceptase el esquema copernicano del cosmos y la función dinámica solar debía abandonar la disciplina o convertirse en un comediante. Esto es lo que hicieron los jesuitas aplicando el escepticismo instrumentalista a Copérnico y al heliocentrismo (pero no a Aristóteles y al geocentrismo) guiados por la Regla 13 ignaciana según la cual hay que creer que lo blanco es negro si así lo dice la Iglesia. Esta regla anti-empirista, unida al escepticismo ficcionalista y a las recomendaciones de la Ratio y de Acquaviva de no apartarse de Aristóteles, cada vez más difíciles de seguir, no fomentaron la capacidad científica de los Padres, pero los entrenaron a pensar una cosa y decir otra, doblez que llegó a verse como la quintaesencia del espíritu jesuítico, lo que recoge el Diccionario de la RAE al ofrecer «hipócrita, taimado» como segunda acepción de jesuita.

${ }^{19}$ Cf. el Capítulo VII del libro de J. M. LATTIS, Between Copernicus and Galileo, University of Chicago Pres, 1994.

${ }^{20}$ Según escribía N. C. F. de Peiresc a P. Gassendi el 6-7 de Septiembre de 1633, wel buen P. Athanasius [Kircher] que hemos visto pasar por aquí [Aix-en-Provence] a toda prisa, no pudo evitar confesar en presencia del P. Ferrand que el propio P. Malapert y el propio P. Clavio no desaprobaban en absoluto la opinión de Copérnico, de la que apenas discrepaban, por más que se les hubiese presionado y obligado a escribir a favor de las suposiciones comunes de Aristóteles que el mismo P. Scheiner no seguía sino a la fuerza y por obediencia, cosa que a él mismo le ocurría...n (Le opere di Galileo Galilei. Volumen XV: 254). Aunque Kircher era un tanto bocazas y lo que dice de Clavio parece forzado por el deseo de fingir ante los franceses que sus camaradas eran muy abiertos, la doblez de los jesuitas inducida por la obediencia queda bien reflejada en estas declaraciones. La idea común entonces era que los jesuitas habían promovido la condena de Galileo (cf., v.g., la carta de R. Descartes a M. Mersenne de Febrero de 1634, en Oeuvres de Descartes, C. ADAM y P. TANNERY, Eds., Parí, 1897-1913 y reediciones posteriores; I: 280-84); 
Todos estos elementos emblemáticos, apologéticos, escépticos y ficcionalistas pusieron a la ciencia de los jesuitas en un marco impracticable. Con todo, debían vestirse con los adornos científicos para impresionar a propios y extraños, lo que explica el éxito de las obras de Kircher, emblemáticas, llenas de novedades ajenas y pseudo-novedades propias, asombrosas, intrigantes, divertidas y lujosamente ornamentadas. Los jesuitas habían aprendido de Galileo a usar los descubrimientos como emblemas para adular a los Príncipes y encandilar a la República de las Letras. La gaceta sideral de Galileo, en la que dedicaba los satélites de Júpiter, los astros mediceos, a Cosme II de Medicis, era un modelo de cómo atraer a los Príncipes, conseguir su mecenazgo y llamar la atención universal de los aficionados sustituyendo el estilo pesado, dogmático y técnico de las disputationes escolásticas por el tono cortesano, brillante y mundano del descubridor de novedades. Los jesuitas intentaron imitar este género pero con un contenido anti-copernicano. Así lo hizo C. Scheiner con las manchas solares en 1612 y O. Grassi con los cometas de 1618, si bien Galileo los desenmascaró y los puso en su sitio, dando al traste con su estrategia propagandística y ganándose su enemistad canina. ${ }^{21}$

Tras la condena de Galileo, la estrella del Collegio Romano y sus matemáticos se eclipsó, pues decir que aunque una teoría (la copernicana) parezca verdadera, en realidad nunca se puede decir que lo sea porque Dios puede hacer la misma cosa de diferentes maneras que se nos escapan, lleva a paralizar la investigación. En su lugar sólo quedan los juegos y las curiosidades de la óptica, el magnetismo o la pneumática despojados de su potencial para la construcción de nuevas teoráas. Y eso precisamente en la época en que primero Galileo y después I. Newton usaban las interacciones de la luz y los cuerpos para estudiar la estructura atómica de la materia; en la época en que W. Gilbert o J. Kepler usaban el magnetismo para estudiar la interacción entre los cuerpos celestes; y en la que $E$. Torricelli, $O$. von Guericke, R. Boyle, R. Hooke y tantos otros usaban la pneumática para el estudio del vacío y del atomismo.

pero ahora sabemos, gracias al bueno de Feingold, que la condena de Copérnico y de Galileo debe imputarse al propio Galileo. Véase su contribución "The Grounds for Conflict: Grienberger, Grassi, Galileo, and Posterity” en M. FEINGOLD (Ed.), op cit. en la nota 14, páginas 121-157; especialmente las 131 y 153.

21 Véase C. Solis, "Los cometas contra Copérnico", Theoria, 41 (2001): 353-385; especialmente 368 y sig. 


\section{La recepción de la ciencia de Kircher}

La vida pública de Kircher transcurrió fundamentalmente entre 1633, cuando conoció a Peiresc y Gassendi en el Sur de Francia, y su muerte en $1680 .{ }^{22}$ Los grandes matemáticos le prestaron muy poca atención. Kepler murió en 1630 antes de que comenzase a publicar, Galileo fue condenado en 1633 pocos meses antes de que llegase a Roma, mientras que Newton, que comenzó a salir a la luz en los años setenta, cuando el jesuita se preparaba para rendir su alma, jamás se dignó mencionarlo en su correspondencia. Entremedias, los matemáticos creadores o no se ocuparon de él o lo hicieron para befarse de sus doctrinas, como fue el caso de $\mathrm{E}$. Torricelli o C. Huygens. Sin embargo, los naturalistas y experimentadores le prestaron mayor atención, si no por sus teorías, sí al menos por sus pretendidas observaciones y experimentos. Empecemos por las matemáticas de este jesuita que en 1633 iba a ir a Viena con un nombramiento como matemático de Fernando II, emperador del Sacro Imperio Romano (el matemático imperial, Kepler, había muerto tres años antes), si bien acabó en Roma sustituyendo como matemático del Collegio Romano a C. Scheiner que es el que terminó yendo a Viena.

\section{Las matemáticas puras: rectificación de curvas y cuadratura del círculo}

El libro de Kircher Ars magna lucis et umbrae (Roma, 1646) incluía algunas secciones matemáticas como preparación para los relojes de Sol y otros fenómenos ópticos. En el Libro III, Parte II, Progymnasma III, hay un primer capítulo sobre rectificación de arcos de círculo: "Del método geométrico verdadero y cierto mediante el cual, dado cualquier arco de círculo, mostraremos cómo asignarle una recta igual" (página 316 y siguientes). La Primera Proposición dice que si el cuadrante AGC (Figura 2) y el radio $A B$ se bisecan en $G$ y $E$, y se unen ambos puntos, prolongando el segmento hasta la tangente $\mathrm{HC}$, entonces DC será la recta igual al arco GC. Esta pretensión fue tomada con befa por $\mathrm{E}$. Torricelli en una carta a M. Mersenne poco después de la salida del libro que éste no había visto aún. ${ }^{23}$ Tras enunciar brevemente "la cuadratura perfectísima del matemático romano de la Sociedad de Jesús", co-

22 Sobre la vida y obra de Kircher en general, véase E. Lo SARDo (Ed.), Athanasius Kircher: il museo del mondo, Roma: de Luca, 2001. Cuando este artículo estaba ya camino de la imprenta apareció el excelente libro de P. FINDLEN (Ed.), Athanasius Kircher: The Last Man who Knew Everything, Nueva York y Londres: Routledge, 2004.

${ }^{23}$ Carta del 7 de Julio de 1646, en Correspondance du P. Marin Mersenne, religieux minime, Ed. de C. de WAARD y otros, París: Éditions du Centre National de la Recherche Scientifique, 1936 y sigs.; Vol. XIV: 363-368, especialmente 366 y sig. 
menta que «el mismo geómetra tiene además algo que tal vez resulte novedoso incluso a vuestros geómetras para quienes nada es nuevo, a saber, que el cuadrado isoperimetro del círculo es igual a dicho círculo". V. Viviani resumía esta misma carta con la "ridícula cuadratura" de Kircher que el propio Torricelli comunicaba siete días más tarde a B. Cavalieri como piedra de toque del valor de toda la obra. ${ }^{24}$

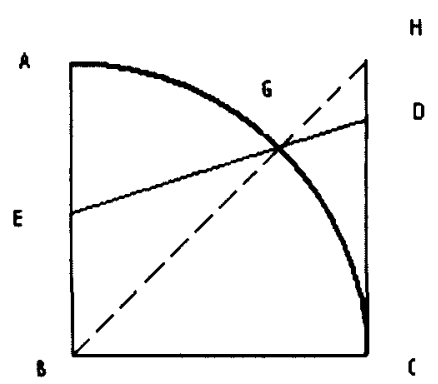

Figura 2. Rectificación del circulo de Kircher

De manera condescendiente, Mersenne le confiesa a Torricelli que a penas puede contener la risa cuando se le viene a las mientes la cuadratura del círculo de Kircher, hasta el punto de que le cuesta trabajo creer que el jesuita pudiera pensar que sean iguales los círculos y cuadrados isoperímetros, pues "consta por los sentidos que es falsom. ${ }^{25} \mathrm{El}$ recurso a los sentidos no es muy propio de un matemático y Mersenne no lo es, por lo que no entiende bien por qué está equivocado el teorema de Kircher y no parece convenir en que por esa "uña» se pueda juzgar todo el león, lo que conllevaría desestimar el resto del Ars magna, que supera las ochocientas páginas in folio. Así, por más que le diga a Torricelli que Kircher merece calabazas si afirma tales cosas, se dedica a preguntar a todo el mundo qué opina de la cuadratura en cuestión. Le escribe al propio Kircher sin recibir respuesta alguna. ${ }^{26}$ Tras consultar con diferentes corresponsales, recibió finalmente una explicación simple y numérica de Mathurin Nauré. ${ }^{27} \mathrm{Si}$ Arquímedes no yerra, si el diámetro es 7 , la circunferencia no llega a 22 . O bien, dado un radio de 140 , el octavo de la circunferencia, GC, será casi 110 [109,95], lo que es menos que CD. En efecto CD = HC-HD; siendo HC conocido (el radio), basta calcular

${ }^{24}$ Carta del 14 de Julio de 1646, Ibid., XIV: 385-386: "Mando a V.P. à un poco di saggio del libro del Padre Athanasio Kircher. Mando una sola proposizione, ma tale che da questa sola ugna ella potrà argomentare quanto sia tutto quel lione».

${ }^{25}$ Carta del 15 de Septiembre de 1646, Ibid., XIV: 454-61, especialmente página 458. Como es obvio, un cuadrado de lado unidad tiene un perímetro como 4 y un área como 1 , mientras que el círculo isoperímetro habría de tener un área mayor, como 1,27.

${ }^{26}$ Carta del 22 de Septiembre de 1646; Ibid., XIV:472-476. Kircher le escribió año y medio más tarde, el 10 de Marzo de 1648 (Ibid., XVI: 160-165), medio año antes de la muerte de Mersenne, diciendo que pasaba mucha horas en el museo tratando ora de matemáticas ora de cosas más recónditas y lamentando que aún no hubiese recibido un ejemplar del Ars magna; sin embargo no dice nada sobre su cuadratura.

${ }^{27}$ Del 9 de Octubre de 1646; Ibid., XIV: 512-515. 
HD. Como los triángulos EBG y HGD son semejantes, BG/GE : GH/GD; pero como $\mathrm{BG}=2 \mathrm{~EB}$, entonces $\mathrm{HD}=1 / 2 \mathrm{GH}$. Pero $\mathrm{GH}$ es la hipotenusa menos el radio (HB-GB); por el teorema de Pitágoras HB es algo menos de 198 [197,98], con lo que GH será algo menos de 58 [57,98] y HD, casi $29[28,99]$. De ahí que DC sea $140-28,99=111,005$ ó un poco más de 111 mientras que, según Arquímedes, GC era algo menos de 110.

Si Kircher pretendiese refutar a Arquímedes, termina Neuré, las cosas le saldrían aún peor de lo que le salió la refutación de la filosofía magnética de Gilbert (que defendía el movimiento diurno de la Tierra). Con todo, el fraile mínimo seguía sin convencerse de que el conjunto de la obra fuese un desastre y continuó mencionándola junto con los Comentarios a los Meteoros de Aristóteles del también jesuita N. Cabeo, para el que tenía grandes elogios. ${ }^{28}$ Sin embargo, por las mismas fechas el descrédito del libro se estaba generalizando, pues Ch. Cavendish escribía desde París a John Pell, futuro miembro de la Royal Society, que se encontraba en Amsterdam, ${ }^{29}$ señalando que el único valor del Ars magna estaba en sus grabados y que P. Gassendi no lo recomendaba, razón por la cual no se sentía alentado a comprarlo ni a leerlo.

\section{Las matemáticas mixtas: astros, ángeles y emblemas}

Kircher poseía una competencia astronómica peculiar. ${ }^{30} \mathrm{Su}$ obra sobre el particular fue el Itinerarium extaticum (Roma, 1656) ${ }^{31}$ que se le ocurrió tras quedarse dormido en un concierto. Se inspiraba en el Somnium Sciopionis de Cicerón y en el Somnium de Kepler (publicado póstumamente en 1634, aunque una prime-

${ }^{28}$ Cf., v. g., la carta a A. Rivet del 11 de Octubre de 1646; Ibid., XIV: 521-526. También le pregunta a I. Boulliau sobre las cuadraturas, Ibid. XIV: 559-562.

29 Carta del 12 de Octubre de 1646; Ibid., XIV: 533-534.

30 Kircher hizo algunas observaciones de eclipses y cometas, aunque su contribución más importante a la astronomía estriba en haber servido de buzón para recibir y comunicar datos sobre el particular. Véase J. FLETCHER, "Astronomy in the Life and Correspondence of Athanasius Kircher", Isis, 61 (1970): 52-67.

${ }^{31}$ No se debe confundir esta obra con otra del mismo título, Itinerario del extasis, Madrid: Siruela, 1986, editada por I. GOMEZ DE LIAÑo, que no es una edición del Itinerarium extaticum, sino una colección de grabados de diferentes obras de Kircher (entre las que sólo se incluye el frontis del Iter extaticum de 1660) con introducciones y pies poco cualificados. Tampoco debe confundirse con el catálogo de una exposición, editado con el mismo título (The Ecstatic Journey, University of Chicago Library, 2000) por I. D. Row/LAND, con un excelente ensayo introductorio y comentarios pertinentes. 
ra versión manuscrita circuló con éxito desde 1609), quien a su vez inspiró junto con Galileo, Bruno y otros el célebre The Discovery of a World in the Moone seguido del Discourse (Londres, 1638 y 1640) del que sería obispo y fundador de la Royal Society, J. Wilkins. Tanto Kepler como Wilkins y más tarde C. Huygens ${ }^{32}$ se dedicaron a usar los conocimientos astronómicos matemáticos y telescópicos para explicar desde una perspectiva copernicana qué aspecto tendrían las cosas desde los planetas y cómo serían estos. Así Kepler explica que en la Luna los días duran quince de los nuestros y conjetura las enormes diferencias de temperatura que ello entraña, las características del relieve mucho más alto que el nuestro, el aspecto del cielo en los dos hemisferios, en uno de los cuales reina siempre una Tierra de un tamaño quince veces superior al de la Luna para nosotros, y los complejos movimientos del Sol y los planetas al proyectar sobre ellos el triple movimiento lunar. Por su lado Huygens se dedica especular en el Libro I sobre la posibilidad de las faunas y floras planetarias, bajo la idea de que son para nosotros mundos nuevos como las Américas, con nuevas formas vivientes aunque sometidas a las mismas leyes, mientras que en el Libro II aplica la astronomía matemática a estudiar el aspecto que ofrecen los cielos desde cada planeta, a la manera que Kepler había hecho con la Luna. Por ejemplo, desde Mercurio el Sol tiene un diámetro aparente tres veces mayor que desde aquí, por lo que su luz y calor sería insoportable para las criaturas terrestres (y si allí hubiera otras, se les antojaría nuestro planeta demasiado frío). Los planetas sólo se ven en oposición, con Venus brillando mucho más que para nosotros, pues aparecería diez veces mayor y la verían llena. Por el contrario, desde Júpiter no se ve más planeta que Saturno, pues los demás están siempre en conjunción (con una elongación máxima para Marte de $8^{\circ}$ ) y un Sol con un diámetro un quinto menor que el nuestro, por lo que daría $1 / 25$ veces la luz y calor que aquí da. Su día dura 5 horas y no presenta variaciones estacionales por tener el eje normal al plano de la Eclíptica. A cambio, sus cuatro satélites alegran su cielo, etc. Es decir, tanto Kepler y Wilkins como Huygens aplican sus sólidos conocimientos astronómicos a otros planetas. Pero no era eso lo que proyectaba Kircher.

Lo que Kircher veía en los cielos era el universo infinito y cambiante de Bruno, completado con los descubrimientos telescópicos de Galileo, traducido todo ello sin excesivo celo al geocentrismo de Tycho Brahe. El hermetismo de Kircher, reforzado por sus estudios de las antigüedades orientales, lo animaron a

${ }^{32}$ Kosmotheoros, La Haya, 1698, Oeuvres completes, Vol. XXI: 677-842. 
pensar que las grandes verdades no son para el público, sino para los escogidos, y de ahí la escritura jeroglífica, los símbolos y acertijos de los Pitagóricos o la idea rabínica de que las Sagradas Escrituras son un símbolo de verdades ocultas al vulgo y abiertas sólo a los sabios. Dado que Kircher se creía tal, hay motivos para sospechar que podía sentirse alentado a no expresar abiertamente lo que pensaba. Al menos eso es lo que recomendó a Quirin Kuhlmann, un fanático y sectario que acabó en la hoguera en Moscú (1686) por orden del Pedro el Grande. Kircher le había recomendado prudencia y disimulo en la expresión de sus ideas frente a la vigilancia de la Inquisición «usando de la necesaria precaución antes de dar a la luz asuntos secretos». ${ }^{33}$ Con estas pistas hay motivos para desconfiar del valor nominal de las palabras de Kircher. En efecto, dos censores jesuitas del Iter extaticum lo acusaron de crímenes muy similares a los de Galileo. ${ }^{34} \mathrm{La}$ primera crítica es que al negar que las estrellas estén todas en la superficie de una esfera, las coloca a distintas distancias de la Tierra tornándolas innumerables (lo que, aunque se atribuya genéricamente a "Copérnico y sus sucesores", recuerda especialmente los infinitos mundos de Bruno). La segunda es que niega el copernicanismo de boquilla y no de corazón, pues a lo largo del libro expone con mimo los argumentos copernicanos a favor del movimiento de la Tierra y con

${ }^{33}$ La correspondencia fue publicada por Q. KuHLMANN, Epistolae duae, prior de arte magna sciendi (Leiden, 1674), véase la página 43; citada por I. D. RowLAND, op cit. en la nota 31, página 83. La inspiración bruniana de Kircher fue señalada explicitamente por $G$. SCHOTT en la segunda edición de Iter... praelusionibus et scholiis illustratum, schematibusque exornatum d̀ Gasp. Schotto Societatis Jesu (Wurzburgo, 1660). Véase I. RowLAND, "Kircher Trimegisto", en E. Lo SARDO, citado en la nota 22, páginas 113-123, y "Athanasius Kircher, Giordano Bruno, and the Panspermia of the Infinite Universe", Capítulo 8 de P. FindLEN (Ed.), op. cit. en la nota 22.

${ }^{34}$ ROWLAND, op. cit en la nota 31 , página 100 , cita la censura conservada en la Biblioteca Nazionale Centrale, Roma, Fondo Gesuitico 1331, fasc. 15, páginas 207v-210v y 222v-223r; J. FleTCHER, op. cit. en la nota 30, página 59 y nota 56; C. ZILler CAMENIETZKI, "L'Extase interplanetaire d'Athanase Kircher: Philosophie, cosmologie et discipline dans la Compagnie de Jésus au XVIIe sièclen, Nuncius, X-1 (1995): 3-32. Los Padres censores del libro criticaron su tibio anti-copernicanismo, por lo que la segunda edición preparada por G. SCHOTT (Iter extaticum, Wurzburgo 1660) aporta explícitamente en apoyo la autoridad de Bruno entre otros. Como en casi todo, Kircher se muestra aquí fiel a la doctrina eclesiástica, aunque se mueve por aguas turbias, algo detectado por Huygens al señalar (Kosmotheoros, página 770) que su obra sería mejor si expresara libremente sus ideas, pero si no ha tenido el valor de hacerlo, no se explica por qué no ha preferido abstenerse. Tanto él como G. Riccioli se oponen al copernicanismo "entachés d'une crédulité soumise a l'autorité humaine" (el Papa), mientras que otros (como Cassini o Römer) lo hacen por "une intelligence tardive" (Ibid., página 694). 
desgana los contrarios (algo de lo que fue acusado Galileo). ${ }^{35}$ En tercer lugar, como ocurrió también con Galileo según descubrió P. Redondi, ${ }^{36}$ se le acusaba de sostener que las cualidades secundarias (subjetivas, como el olor, color, etc.) no están accidentalmente en la substancia, sino que derivan necesariamente de las cualidades primarias objetivas, lo que va en contra de la doctrina de la transubstanciación en la Eucaristía. En efecto, según la teoría oficial, en ese proceso se mantienen las mismas cualidades mientras se cambia la materia subyacente (el pan por carne); pero si los accidentes derivan necesariamente del material, si algo huele y sabe a pan, entonces es pan y no costilla.

En cualquier caso, por más que tal vez fuese un copernicano al modo de Bruno y lo mantuviese oculto con la típica doblez jesuítica, el Itinerarium no ve en los planetas lo que dice la astronomía matemática, ${ }^{37}$ sino sus influjos emblemáticos. Por ejemplo, en Mercurio ve cosas serenas que inducen inteligencia en los que reciben su influjo en el nacimiento, en Venus ve cosas bellas, en Saturno cosas tristes y tenebrosas, etc. Consideraciones «sin sentido y poco razonables", comenta Huygens, que constituyen "inepcias de astrólogos tiempo ha rechazadas». En lugar de plantear problemas astronómicos serios, se pregunta cosas tales como si un judío en Venus podría bautizarse con agua local.

Así pues Kircher parece no disponer de conocimientos astronómicos que le permitan hablar razonablemente de los planetas, ni tampoco de una teoría física que explique sus movimientos. En efecto, como Bruno, supone que cada una de las infinitas estrellas fijas es un Sol rodeado de su sistema planetario; pero con Brahe supone que todas ellas giran diariamente en torno a una Tierra que no rota. "Ignoro - señala Huygens- si se ha dado cuenta de que eso entraña" que

${ }^{35}$ En Iter extaticum (1669), pág. 38 señala que Copérnico apoyó su sistema "con muchos argumentos e hipótesis ingeniosas" por lo que lo aceptan todos los matemáticos protestantes "y algunos católicos cuyos talentos y plumas, como no es de extrañar, sienten el prurito de ofrecer novedades"; ROWLAND, loc. cit., página 67.

${ }^{36}$ Galileo eretico,Turín: Einaudi, 1983; traducción española de A. Beltrán, Galileo herético, Madrid: Alianza, 1990. Descartes se enfrentó en las «Respuestas a las cosas que pueden llamar la atención a los teólogos" al mismo problema que le había planteado Arnauld en las Cuartas objeciones a sus Meditaciones metafisicas (1641).

${ }^{37}$ Kircher creía que los ejes de todos los astros son paralelos al de la Tierra, lo que resulta llamativo dado el argumento de Galileo en el Dialogo según el cual el no paralelismo de los ejes terrestre y solar le permitió "descubrir el máximo secreto de la naturaleza", lo que produjo en $\mathrm{C}$. Scheiner una «rabia canina". El paralelismo de los ejes se reitera y se ilustra con un dibujo en Mundus subterraneus (1665), Tomo I: 104-105. 
los infinitos sistemas copernicanos giran a una velocidad inimaginable con una centrifugación destructiva, ambas infinitas. A cambio suponía que los cielos son líquidos (siguiendo a Tycho Brahe y R. Bellarmino S.J.) y como los planetas no están sujetos a ninguna estructura sólida, debía atribuir a cada astro un equipo de ángeles. ${ }^{38}$

Mersenne pudo ver disminuida su apreciación de los conocimientos astronómicos y gnomónicos (sobre relojes de Sol) exhibidos diez ańos antes por Kircher en el Ars magna lucis et umbrae (Roma 1646) tras recibir una carta de Constantijn Huygens, ${ }^{39}$ el padre del famoso Christiaan Huygens que contaba a la sazón con diecisiete años. En la carta alababa las buenas prendas del zagal para quien es palmario lo que a otros se les antoja obscuro, amén de reírse de buen grado de quienes, como los jesuitas, con pocas nueces hacen mucho ruido, tal como ocurre con las proyecciones mágicas del padre Kircher en Ars magna, donde compara la luz del proyector con la luz divina. Como se sabe, señala, los jesuitas ponen mucho empeño en tales fruslerías ("quanto conatu magnas saepe inanias prodant", para decirlo con Plauto). Prueba de ello es el libro de Kircher, lleno de errores triviales como que nada arde bajo el agua, cuando nuestros expertos en fuegos artificiales lo logran sin problemas. En cualquier caso, cuanto había de aprovechable sobre gnomónica en el libro de Kircher podía leerse en los cuatro folios redactados por Christiaan en $1646 .{ }^{40}$ (Una vez crecido, Christiaan no prestará mayor atención a Kircher hasta el Kosmotheoros.)

Constantijn termina contándole a Mersenne una anécdota para que Kircher la incluya en la segunda edición del Ars magna. Durate la guerra «personas serias de edad y condición" dicen haber conocido en Anveres a un prisionero con la facultad de ver a través de los vestidos con tal de que no fuesen rojos. En una ocasión en que «la mujer del carcelero acudió a consolarlo de su calamidad en compañía de otras mujeres, se vieron sorprendidas al verlo reír, y al insistir en que dijese cuál era la causa, respondió fríamente: porque una de ustedes no lleva ropa interion. Y termina: «Razonad sobre ello y haced que Kircher no lo olvide en su segunda edición, pues eso sí que se puede considerar Ars magna por excelencia». Esta anécdota no es sólo una gracia, pues entraña

\footnotetext{
${ }^{38}$ Iter extaticum (1660), pág. 52.

${ }^{39}$ Del 26 de Noviembre de 1646; Ibid., XIV: 635-638.

${ }^{40}$ C. HuYgens, Oeuvres completes, Vol. XI: 64-67.
} 
el rudo problema de la credibilidad de los informes ajenos de personas serias, como veremos inmediatamente.

\section{Credibilidad vs. credulidad: informes sobre hechos naturales}

El comentario de Torricelli sobre Kircher que desencadenó aquella agitación en la República de las Letras fue, si no injusto, sí un tanto malévolo por cuanto que se agarraba a este error del matemático del Collegio Romano para desacreditar toda su producción. Torricelli había asistido a Galileo junto con V. Viviani en sus últimos meses de vida y, tras la muerte del maestro el día de Reyes de 1642, lo sustituyó como matemático y filósofo del Gran Duque Fernando II de Toscana. Todos conocían alli el papel desempeñado por los jesuitas en la condena de Galileo, entre los que destacara C. Scheiner. Por eso no es de extrañar que los sabios florentinos no tuviesen en mucho aprecio a los padres romanos. ${ }^{41}$ Esa predisposición a veces desmedida contra los matemáticos jesuitas puede apreciarse en la carta que le escribía a Torricelli su discípulo M. Ricci criticando el Ars magna porque en la página 233 exponía la propiedad trivial pero básica de la parábola según la cual los cuadrados de las semiordenadas que cortan perpendicularmente al eje, son como los segmentos del eje desde el corte hasta el vértice. ${ }^{42}$

Veinticinco años más tarde (en 1671) se produjo un ataque a las doctrinas médicas de Kircher por parte de Francesco Redi, médico y superintendente de la farmacia y la fundición de los Medici. Redi tenía siete años cuando se produjo la condena de Galileo en 1633, pero entró al servicio del Gran Duque media docena de ańos después de la muerte del maestro y trabajó con los galileanos experimentalistas de la Accademia del Cimento, activa entre 1657 y 1667. Por consiguiente pertenecía al círculo de sabios florentinos que tenían cuentas pendientes con los jesuitas romanos.

La polémica se desarrolló con ocasión de las piedras de serpiente que en la segunda mitad del siglo llegaron a Roma traídas por misioneros jesuitas y a Flo-

${ }^{41}$ Sobre esta animadversión véase M. BALDWIN, "The Snakestone Experiments", Isis, 86 (1995): 394-418; página 407, donde cita a E. CoCHRANE, Florence in the Forgotten Centuries, 1527-1800, University of Chicago Press, 1973, especialmente las páginas 211-12, 253, 386.

${ }_{42}$ P. Galluzzi y M. Torrini (Eds.), Le Opere dei discepoli di Galileo Galikei, Carteggio, 2 Vols., Florencia: G. Barbèra, 1975 y sigs; Vol I: 273-274. Anadía Ricci k`Y que? habrá otras quizá más simples que callo para no ofender a V. S. con el recuerdo de tales inepciasm. 
rencia traídas por dominicos y franciscanos (Figura 3). Estas piedras eran substancias porosas e hidrófilas, de color verdoso o rojizo, que puestas sobre la picadura de un animal ponzoñoso, sorbían el veneno. Depositadas luego en un vaso de leche, descargaban el veneno dejando la leche verdosa. Se obtenían de la cabeza de cobras de la lejana India o la China, o bien eran facticias; pero en cualquier caso, caras. ${ }^{43}$

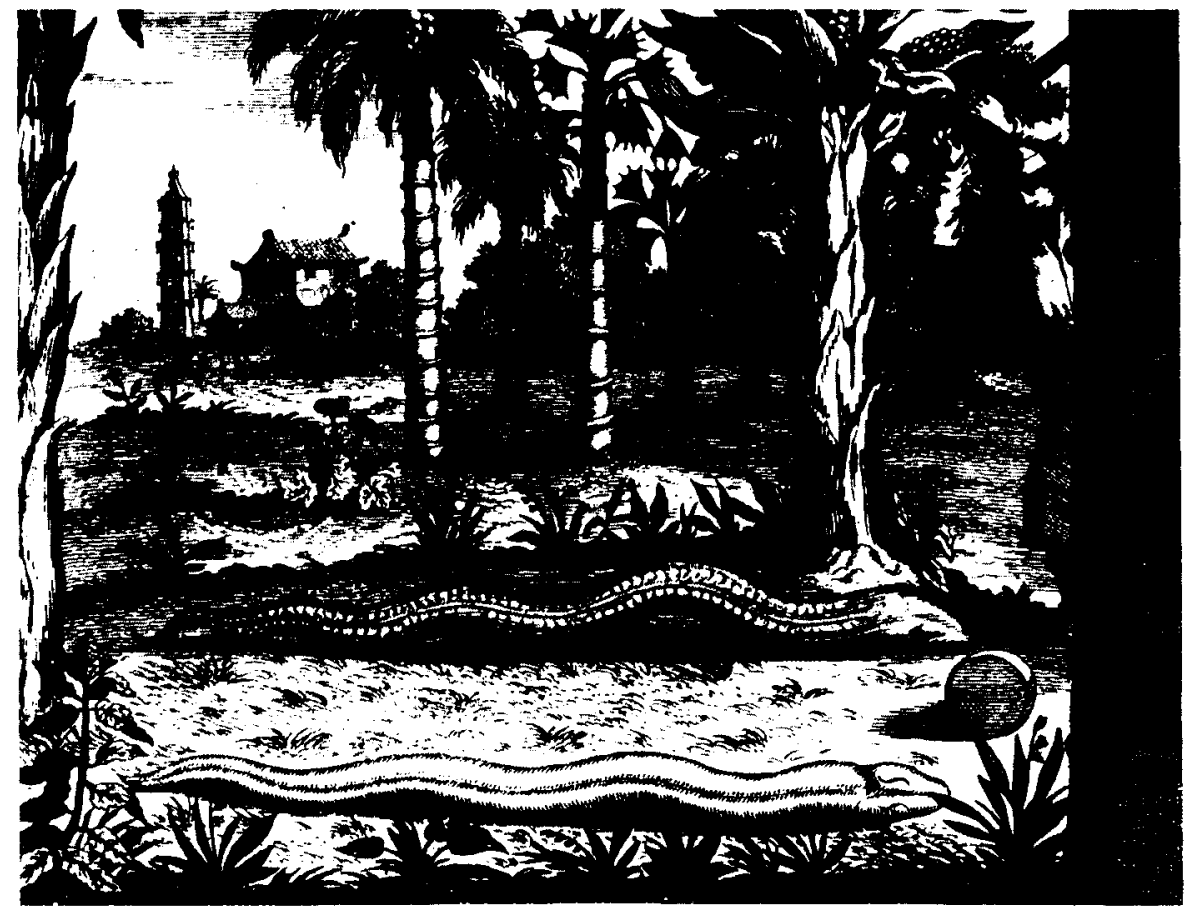

Figura 3: Un brahmán furtivo acecha a las serpientes peludas o cobras de cabelo de los portugueses para sacarles la piedra, una de las cuales se representa entre los reptiles. Kircher, China illustrata (Amsterdam, 1667), página 81

Kircher recibió con buena disposición la noticia de este fármaco que encajaba bien con su visión hermética de la medicina derivada de van Helmont, que era un médico paracelsiano. Aunque era católico, van Helmont fue perseguido por los jesuitas que acompañaban a los ejércitos espańoles en Bélgica, especial-

${ }^{43}$ Kircher, China monumentis qua sacris qua profanis... illustrata (Amsterdam, 1667), páginas 80-85. Para la discusión de esta polémica véase M. BALDWIN, cit. en la nota 41 . 
mente por el jesuita J. Roberti quien hizo posiblemente publicar su escrito sobre el ungüento armario, De magnetica vulnerum... curatione (Paris, 1621), para poder perseguirlo luego. ${ }^{44} \mathrm{La}$ visión de la medicina de Kircher era igualmente hermética y paracelsiana, estimando que lo semejante curaba lo semejante por la existencia de conexiones ocultas de carácter magnético entre las partes del cosmos. ${ }^{45}$ El modo de operar de la simpatía es ecléctico, variado y poco preciso, entrañando movimientos ocultos, emanaciones invisibles, antiperistasis y cualesquiera otros procedimientos. ${ }^{46} \mathrm{La}$ simpatía entre las partes del cosmos fue la clave del naturalismo neoplatónico renacentista al que Kircher se adhería bajo el manto del magnetismo ${ }^{47}$ que es el paradigma de las fuerzas ocultas e invisibles mediante las que interactúan las partes del cosmos. Consiguientemente, el centro del Museo de Kircher estaba ocupado por un imán. En 1639, Kircher escribía a P. Gassendi dándole cuenta del contenido de su próxima obra (Magnes, sive de arte magnetica, 1641), en cuyo libro tercero «muestro la llamada cadena magnética mediante la cual pruebo que todo el mundo y cada una de sus partes magnetizan». ${ }^{48}$ Poco después, M. Mersenne daba noticia a T. Haak de la existencia de "un jesuita llamado Antonio [sic] Kircher... el cual imprime todo un volumen sobre el imán... y que el Padre Benedeto [Castelli], matemático del papa, traba-

${ }^{44}$ El ungüento armario se aplicaba al arma y no a la herida, actuando por algún tipo de simpatía que podía interpretarse ora de modo espiritualista ora de modo mecanicista, como hacía $\mathrm{K}$. Digby con el polvo simpático; cf. C. Solis, "Alicuius in verba. Tenerife y la Royal Society", en Los orígenes de la ciencia moderna, La Orotava: Fundación Canaria de Historia de la Ciencia, 2004: 575-602.

45 Sin embargo Kircher rechazaba el ungüento armario más por motivos gremiales que teóricos, pues su filosofía magnética era perfectamente afín al medicamento simpático. Pero fiel a sus correligionarios señalaba en Magnes, sive de arte magnetica (Roma, 1641, páginas 715, 777 784) que el ungüento armario, al asentarse en acciones a distancia, no era magia natural, sino negra: "Concluimus ergo hanc curationem fallacem, suspectam, \& minime naturalem, à nigro illo vectore spiritu omnis mendacij patre profectum" y "Quod ut luculenter deducam, dico hunc effectum dupliciter fieri posse, vel ex pactu cum Daemone initio, ut pleraque eius generis..." etc. (páginas 782 y sig.).

${ }^{46}$ Magnes, sive de arte magnetica, pág. 533 y sig. Contrasta con la explicación corpuscularista y mecanicista de la simpatía ofrecida por K. DigBY en el Discours... touchant la guérison des playes par la poudre de sympathie (Paris, 1658). Según Digby ese Discours era una conferencia pronunciada el af́o antes en Montpellier ante un par de docenas de médicos, matemáticos, teólogos y curiosos.

${ }_{47}$ Al que dedicó varias de sus obras como Ars magnesia (Wurzburgo, 1631), Magnes, sive de arte magnetica (Roma, 1641 y reediciones en 1643, 1654) y Magneticum naturae regnum (Amsterdam 1667).

48 Carta de A. Kircher a P. Gassendi del 2 de Junio de 1639, en Correspondance du P. Marin Mersenne, citada en nota 23, Vol. VIII: 427 y sig. 
ja sobre el mismo tema, y pretenden hacernos cambiar de filosofía en favor de la especulación del alma universal que reside en esta piedra". ${ }^{49}$

Esta filosofía permitía la posibilidad del magnetismus antidotorum mediante el que unos sapos secos u otro material ponzoñoso podría atraer por simpatía el veneno del enfermo librándolo del mal. Según cuenta Kircher en Magnes, él mismo visitó en Diciembre de 1640 la famosa espelunca de las serpientes donde se producen curaciones simpáticas, si bien no siendo entonces época de ofidios, no pudo observar su acción, aunque el Cardenal Barberini le contó algunos casos (y no vamos a dudar del sobrino del Papa). Ahora bien, el veneno es antídoto natural del veneno si hay algún contacto, pues de lo contrario estaríamos ante un caso de acción a distancia y por ende, de cacomagia debida al diablo. Ese contacto es usualmente oculto, pero innegable, como la virtud plástica que es una afección o potestad impresa por la imaginación en los cuerpos, al modo de aquella que, impresa en la sangre del asesinado, hace que ésta fluya en presencia del asesino. ${ }^{50}$

Así pues, cuado a mediados del siglo aparecieron las piedras de serpiente, Kircher estaba teóricamente armado para explicarlas. Expuso su acción curativa en 1667, tanto en China illustrata como en Magneticum naturae regnum, basándose en informes de jesuitas y en un solo ensayo realizado por él en 1663. La descripción del mismo es sumaria y sin esos detalles que muestran al experimentalista preocupado por el éxito de la experiencia y la comunicación precisa de cómo se realizó. Dice haber provocado que una víbora mordiese a un perro y, tras aplicar la piedra a la herida, el animal estuvo fastidiado hasta su recuperación al día siguiente. Esto se vio reforzado por una sucesión de noticias de terratenientes, nobles y príncipes en las que se cuentan casos en los que sus animales, campesinos o criados, mordidos por víboras o inespecificados animales ponzonosos, curaron tras la aplicación de la piedra. Y es aquí donde viene a cuento la befa de Constantijn Huygens en el sentido de que debería incluir en la segunda edición del Ars

${ }^{49}$ Carta del 31 de Diciembre de 1639, Correspondance du P. Marin Mersenne, Vol. VIII: 722. CASTElli compuso un inédito Discorso sopra la calamita del que se ocupó A. FAVARo en el Bulletino di Bibliografia e di Storia delle Scienza mathematiche e fisiche, XVI (1883): 545-564.

50 Ibidem., págs. 800-828; 904 y sigs. Un lustro más tarde, en Ars magna lucis et umbrae (Roma 1646) defiende la separación de la magia natural y la diabólica (págs. 769 y sig.) e ilustra cómo la primera, basada en los arcanos naturales de las cosas, puede imprimir en las piedras vistas de ciudades, alfabetos, emblemas o cristos (páginas 805-807). 
magna la anécdota del prisionero, certificada por «personas serias de edad y condición", pues para Kircher la seriedad institucional de sus compañeros de orden o de los príncipes de la Iglesia, como los misioneros jesuitas o el Cardenal Barberini, es apoyo más que suficiente para aceptar los informes más estrambóticos.

Con todo, la proliferación renacentista de historias maravillosas, atestiguadas por personas de alta condición, llevó a mediados del siglo XVII a desconfiar, si no de la virtud moral, sí de la solidez epistemológica de esos informantes sobre acontecimientos casuales y aislados. De ahí que los más avisados, como Huygens y Descartes, desconfiaran de tanta maravilla narrada por viajeros y curiosos. Por ejemplo, ya en 1637 Descartes denunciaba ${ }^{51}$ el escaso valor de las observaciones y experimentos ajenos debido a que, al ser voluntarios y no pagados, sus autores buscan la diversión y el halago; tienden a comunicarlos inadecuadamente por mor del secretismo; y tienden a falsearlos para que ejemplifiquen sus dogmas predilectos. De ahí que desde mediados del siglo apareciesen algunas sociedades cientificas y experimentales que tenían como principalísima misión contrastar, comparar y reproducir a placer los efectos pretendidos de los colegas, y corroborar los informes de viajeros y navegantes a tierras exóticas. La Accademia del Cimento tenía como lema Provando e riprovando, mientras que la Royal Society de Londres tenía el de Nullius in verba. ${ }^{52}$ La primera publicó unos Saggi di naturali esperienze fatte nell'Accademia del Cimento (Florencia, 1667), en cuyo Prefacio se señala la necesidad de combatir las falsedades derivadas de un «inmoderado deseo de saber" mediante los experimentos que no hay que tomar tampoco sin crítica, especialmente los ajenos. El objetivo básico de la Accademia era pues realizar repetidamente los experimentos para asegurarse de los resultados "pues desgraciadamente vemos que hay errores establecidos mediante lo que se tiene por experimentos", basados muchas veces en la autoridad o la reverencia a las personas. De ahí su interés en hacer experimentos exactos y comunicarlos con precisión «a fin de animar a otros a repetir los mismos experimentos con el máximo rigor». De este modo no será necesario fiarse de las palabras de nadie, sino que todos podremos ser

51 Discurso del método (1637), Sexta Parte; Oeuvres de Descartes, vol. VI:71-3.

52 Provando e riprovando procede de La divina comedia, Paradiso, III, 1-3 y alude a hacer una prueba una y otra vez; cf. W. E. K. MIDDLETON, The Experimenters: A Study of the Accadenia del Cimento, Baltimore: The Johns Hopkins Press, 1971, páginas 52 y siguiente; P. GaluzZI, "L'Accademia del Cimento: 'Gusti' de principe, filosofia e ideologia dell'esperimento", Quaderni Storici, XVI (1981): 788-844. El lema de la Royal Society procede de Horacio, Eptstolas, I: 14: "Nullius addictus iurare in verba magistri», en el sentido de que no se fiaban de las palabras de nadie, sino de las obras mismas de la naturaleza. 
jueces de lo que hace la naturaleza, cosa que se lograría con la libre y desapasionada correspondencia entre las sociedades europeas. Finalmente, se debe abandonar toda especulación y anticipación de la naturaleza, toda afirmación dogmática de doctrinas y opiniones, pues «la única misión de la Academia es realizar experimentos y tratar de ellos". ${ }^{53}$ Se pueden hacer consideraciones similares sobre los fines de la Royal Society, cuyas Reglas proponen como objetivo uestablecer registros fidedignos de las obras de la naturaleza», «separando el conocimiento de la naturaleza de los colores de la retórica y de los artificios del capricho o del delicioso engaño de las fábulass, para lo cual sus miembros prescinden de sectarismos y doctrinas generales y se fían en cambio del constante trabajo colectivo, consiguiendo sus objetivos «no por la gloriosa pompa de las palabras, sino por los callados, efectivos e irreprochables argumentos de las producciones reales". ${ }^{54}$

Redi pertenecía al círculo de la Accademia del Cimento y estaba familiarizado con la facilidad con la que podemos engañarnos acerca de los hechos de la naturaleza y por ende con la necesidad de realizar ensayos experimentales cuidadosos, controlados y repetidos. Como miembro del grupo experimental más refinado instrumental y metodológicamente del momento, sabía de la escasa fiabilidad que ofrecía el modo crédulo, amante de lo sorprendente y ameno con el que procedía el jesuita. Pero precisamente por lo avanzado y novedoso de su posición en los años sesenta, su método no fue general e instantáneamente percibido como superior al procedimiento basado en correveidiles. ${ }^{55}$ En realidad, los experimentos de Redi, más que como refutación de las tesis de Kircher, son notables por

${ }^{53}$ Cf. W.E.K. MidDleton, op. cit. en la nota anterior, páginas 90-92.

54 T. SPRAT, History of the Royal Society, Londres, 1667, pág. 61 y sig. Esta obra ha sido reeditada por J. I. COPE y H. W. JONES en Londres: Routledge and Kegan Paul, 1959. Los esfuerzos de la Sociedad londinense para contrastar las noticias exóticas mediante cuestionarios a viajeros, gobernadores, comerciantes y navegantes fiables fueron constantes desde su fundación, y en ellos desempeńó un papel fundamental R. Boyle, tal vez la persona más preocupara en la época por las cuestiones de credibilidad y comunicación de resultados objetivos. Para algunos ejemplos de este esfuerzo, véase C. Solts, "Alicuius in verba", citado en la nota 44.

${ }^{5}$ REDI realizó experimentos en los años sesenta con piedras que unos franciscanos llevaron a Florencia en 1662, y publicó sus resultados en Esperienze intorno a diverse cose naturali... scritte en una lettera al Reverendisimo Padre Atanasio Chircher de la Compagnia di Giesú, Florencia, 1671. Sobre la oposición entre Kircher y Redi y la orientación farmocológica experimental de éste, véase P. BASILE, Linvenzione del vero. Studi sulla letteratura scientifica da Galilei a Algarotti. Roma: Salerno, 1987, páginas 49-124; véase también la "Introduzione» de W. BERNARDI a su edición de F. Redi, Esperienze intorno alla generatione degl'insetti. Florencia: Giunti, 1996, págnas 5-65, así como W. BERNARDI y L. GUERRINI (Eds.), Francesco Redi: un protagonista della scienza moderna: documenti, esperimenti, immagini, Florencia: Olschki, 1999. 
formar parte de la invención del método experimental, un método que no es obvio y que debió refinarse en sus procedimientos de laboratorio y en las técnicas de comunicación a los colegas en un largo proceso que se inició justamente a mediados del siglo XVII. En el campo médico y farmacéutico estas técnicas hoy básicas se tardarían aún en inventar, como por ejemplo las de ensayo aleatorio y doble ciego, en el que ni los experimentadores ni los pacientes saben quién recibe un tratamiento y quién un placebo ${ }^{56}$. Así pues, Redi, cuya información sobre los experimentos es mucho más exacta y detallada que la de Kircher, entendió la necesidad de recurrir a series de ensayos y no a un caso particular que ejemplifique lo que uno desea defender. Asimismo controló en la medida de lo posible la estandarización de los procedimientos. En lugar de limitarse a mordeduras de diferentes víboras u otros animales ponzoñosos mal especificados, usaba un preparado de nicotina elaborado en la farmacia de los Médicis y lo aplicaba no ora a un criado, ora a un perro, sino a series de animales de prueba (por ejemplo, pollos). Así, con las excepciones y anomalías que son de esperar en los experimentos biológicos, cuya complejidad impide controlar todas las circunstancias, Redi mostró que los animales semejantes envenenados por él en condiciones similares con venenos y dosis iguales, tendían a morir inexorablemente por más que se les aplicase la piedra de marras.

Martha Baldwin, ${ }^{57}$ con la intención de evitar un juicio sobre la polémica dictado desde lo que hoy sabemos, señala que los experimentos de Redi no eran convincentes y probatorios porque no lograron el consenso ni zanjaron la discusión, algo que tampoco ocurrió con sus experimentos en contra de la generación espontánea de metazoos. La idea es que los experimentos nunca son del todo probatorios y siempre están abiertos a dudas escépticas. Sin embargo, en este caso la continuación de la polémica tiene que ver más bien con el hecho de que Redi estaba haciendo dos cosas en vez de una sola. No sólo demostraba la ineficacia de la medicina, sino que introducía para ello un método revolucionario. Esto es, establecía un procedimiento experimental riguroso, subrayando el crite-

${ }^{56}$ Las actuales técnicas de ensayos clínicos aleatorios con placebo y doble ciego se fueron desarrollando durante la primera mitad del siglo pasado, aunque siempre haya antecedentes curiosos, como los de James Lind sobre el escorbuto a bordo del Salisbury (1747). Hizo seis grupos de enfermos a los que dió raciones diarias de sidra, cítricos, vinagre, ajo, etc. Los que recibieron cítricos mejoraron muchos, los de sidra muy poco y el resto nada. De este modo demostró clínicamente la bondad ya conocida de los cítricos.

${ }^{57}$ Artículo citado en la nota 41 . 
rio de que la replicabilidad de los resultados es más importante que la credibilidad o nobleza de los testigos ${ }^{58}$. Y en ese momento los Saggi, recién publicados, no se habian difundido lo bastante como para imponer los nuevos estándares, mientras que la Royal Society aún se debatía intentando que sus sesiones no degeneraran por falta de experimentos.

Baldwin señala también que entre las motivaciones de Redi para atacar a Kircher pudieron entrar la animadversión de los galileanos florentinos hacia los jesuitas romanos; la oposición a los fármacos exóticos que rivalizasen con las teriacas de la farmacia de los Médicis supervisada por Redi; el galenismo de Redi, opuesto a la iatroquímica paracelsiana; o a la oposición de este médico tradicional al intrusismo de los jesuitas, obligados por sus largas estancias en tierras de infieles a ejercer ellos mismos la medicina como buenamente podían y a explorar y explotar las farmacopeas locales, como el polvo de los jesuitas (obtenido de corteza de Cinchona sp. que contiene quinina), o el colmillo de hipopótamo, útil como hemostático y antiafrodisíaco. Bien pudiera ser así; pero ello no empaña el hecho de que Redi estaba desarrollando un método de ensayo experimental revolucionario y superior a las anécdotas de viajeros o misioneros y a los chismorreos de nobles o prelados.

\section{Credulidad vs. credibilidad: informes sobre maravillas}

Aunque la filosofia magnética y oculta de Kircher no satisficiese a los espíritus geométricos más inclinados hacia la filosofía mecánica, con todo algunos de sus hechos despertaron inicialmente cierto interés. Por ejemplo, R. Descartes escribía a Constantijn Huygens en 1642 que, tras haber leído «el tratado del imán" " en él más que una sola experiencia que sea nueva", como es que un imán esférico con el eje perpendicular al horizonte, tiene un punto de su ecuador que siempre mira al Polo Norte sin declinar. Y añadía: «lo que me cuesta mucho trabajo

58 REDI insistió en la repetibilidad de los resultados en Esperienze intorno alla generazione degli insetti (Florencia 1668), mientras que Boyle hacía hincapié en la credibilidad del autor y en los detalles que convirtiesen al lector en "experimentador virtual", porque escribía más bien para aficionados (virtuosos) sin instalaciones que para profesionales capaces de reproducir experimentos en sus propios laboratorios.

${ }^{59}$ Carta del 31 de Enero de 1642, en Oeuvres de Descartes, Vol. III: 520-4. Alude a un manuscrito del jesuita J. Grandami, véase la nota 119 y el texto a que corresponde. Kircher recogió el experimento en la tercera edición de Magnes (Roma 1654). 
creer", señalando que "si supiese dónde hallar imanes esféricos, trataría de desvelar la verdad». Huygens le escribía al año siguiente sobre Magnes, sive de arte magnetica (Roma 1641) de Kircher diciendo que, aunque los jesuitas son romos, como están ociosos hacen informes útiles. ${ }^{60}$

Pero por más que las observaciones de Kircher fuesen más creibles que sus teorías, a medida que pasaba el tiempo iba cogiendo confianza y contaba cosas cada vez más increíbles. Ya le habían acarreado cierto descrédito, como veremos, sus excesos en el Oedipus Aegyptiacus (Roma 1652-55), donde aceptaba todavía que el Corpus hermeticum era antiquísimo, a pesar de que I. Casaubon hubiera probado ya en De rebus Sacris et Ecclesiasticis (Londres, 1614) que los textos atribuidos a Hermes ni eran egipcios (sino griegos) ni eran arcaicos (sino del siglo II de nuestra Era), merced al análisis del uso de términos platónicos y cristianos como demiourgos y homoiousine. ${ }^{61}$ Pero las cosas no le fueron mejor en cuestiones naturales, especialmente tras la publicación en 1665 del Mundus subterraneus, obra donde Kircher, tras haber observado en 1638 unas erupciones y terremotos en el área de Nápoles y Calabria, creyó atisbar los secretos no ya de la corteza terrestre, sino del manto y aún del núcleo. ${ }^{62}$ En el libro puede verse representado el interior de la Tierra con sus hidrofilacios (depósitos de agua) para las fuentes y sus pirofilacios para los volcanes, con sus laboratorios y canales subterráneos que conectan los Polos Norte y Sur, no menos que el Maelstrom con el Golfo de Botnia.

${ }^{60}$ Carta del 7 de Enero de 1643, Oeuvres de Descartes, III: 801-3: «He aquí por otra parte el Imán de Kircherus, donde hallareis más arrugas que buen pafio como ocurre normalmente con los jesuitas. Estos escritorzuelos, no obstante, os pueden servir en cuestiones de hecho pero no en cuestiones teóricas [quae facti sunt, non juris]. Están más ociosos que usted para proveerse de experiencias y, si fuese necesario, uno puede servirse de sus informes". Descartes siguió el consejo, no repitió el experimento y lo incluyó en los Principia philosophiae de 1644, Parte IV, \$170 (Oeuvres, VIII: 301302), donde confiesa que eso es lo que "afirman algunos" y que no ha realizado la experiencia.

${ }^{61}$ Hallándose Sir Robert Southwell, de viaje por Francia, se encontró con W. Paget que venía de Roma, quien le contó que la fama de Kircher estaba un tanto de capa caída por sus estudios de los jeroglíficos antiguos. Carta a H. Oldenburg del 28 de Octubre de 1659; Correspondence of Henry Oldenburg, I: 323-25.

62 Kircher visitó Sicilia y Malta como acompanante del Landgrave de Hesse, F. d'Assia, que se había convertido al catolicismo el año anterior. En el Sur de Italia se enfrentó durante una quincena a las corrientes del estrecho de Mesina (Caribdis), al terremoto de Calabria y a las erupciones del Etna, Estrómboli y Vesuvio. En Malta conoció al Inquisidor General Fabio Chigi (sobrino nieto del Papa Pablo V) con quien estableció una firme amistad y que se convertiría primero en el nuncio de Inocencio X en la Paz de Westfalia (1648) y luego en Papa con el nombre de Alejando VII (1655). 
Lynn Thorndike señalaba ${ }^{63}$ que este gusto por lo maravilloso era corriente entre los jesuitas del siglo XVII, lo que hace suponer que pudiera deberse a un plan preconcebido de la orden para agradar al público culto y a los cortesanos. El fin era entretener sin entrar en discusiones teóricas desagradables ni en temas espinosos como el movimiento de la Tierra, la existencia de átomos y vacío o la transmutación de los metales bajos en oro. La erudición escasamente crítica aunque divertida, las anécdotas intrigantes, los fenómenos curiosos o los aparatos de magia natural generaban en el público una cierta suspensión embobada del juicio que ocupaba el lugar de la investigación de la verdad acerca de la naturaleza. De este modo, aunque en el prólogo al Mundus subtrerraneus Kircher nos diga que no incluye en el libro nada que no haya comprobado personalmente o le hayan comunicado personas dignas de toda confianza, ${ }^{64}$ ambos filtros fracasaron estrepitosamente como enseguida comprenderían los lectores en principio más favorables.

La lista de hechos fantásticos que Kircher da por buenos sería interminable, pues equivaldría a reexponer toda la obra. Los miembros naturalistas de la Royal Society estaban entre los lectores más interesados por las historias naturales contenidas en el libro, aunque su objetivo no era el mero asombro y pasatiempo, sino que estaban obsesionados por hacer registros fidedignos de las Obras de la Naturaleza con olvido de las teorías que consideraban dogmáticas anticipationes naturae. De ahí que inicialmente H. Oldenburg y R. Boyle (al igual que Descartes y Huygens padre) tuviesen fe en el valor de las obras jesuíticas como bases de datos. En las actas del primer cuarto de siglo de la Sociedad se menciona a Kircher a cuento de la transmisión del sonido (susurros) en edificios; la presencia de gusanos en la sangre de los enfermos de peste, causada por puestas invisibles de huevos; el agua no evaporable; la historia de las armas de fuego y la pólvora, o la causa de los extraordinarios Fata Morgana (espejismos) de ejércitos y ciudades observables en Regio de Calabria. ${ }^{65}$ Con todo, los Fellows de orientación mate-

${ }^{63}$ Cf. A History of Magic and Experimental Science, 8 Vols., Nueva York: Columbia University Press, 1923-58; Vol. VII, Capítulo 20, centrado sore el Mundus de Kircher.

${ }^{64}$ Como señala con inmodestia en las páginas 2-3 (no numeradas) del Praefatio II: «Ego vero, cum ita à natura constitutus sim, ut iis quae ab Authoribus, circa rerum naturalium virtutes \& prodigia tradita sunt, facile fidem non habeam, nisi me vel relationes à viris fide dignissimis indubia attestatione communicatae; vel propria experientia, \& sensata rerum inspectio certissimum redderent".

${ }^{65}$ Las actas de sesiones están recogidas en T. BIRCH, The History of the Royal Society of London, 4 Vols., Londres: A. Millar, 1756-1757. Véanse las sesiones del 5-XI-1662 en que H. Powle habla de los sonidos; del 6-VIII-1664, 21-III-1666 y 31-X-1683 donde Sir John Hoskins, W. Charleton 
mática tenían mayor aprecio por las teorías generales que consideraban demostrables y una menor adoración por los hechos mismos y los efectos asombrosos. El ejemplo más eximio fue el de I. Newton, ${ }^{66}$ pero antes de que éste irrumpiese con su física matemática desbordante en una asombrada Royal Society, ya Sir Christopher Wren había expresado la misma actitud. Al año siguiente de que el rey Carlos II otorgase a la Sociedad una carta patente y una maza ceremonial, los miembros andaban agitados por cómo entretener y ganarse al Rey en su inminente visita. La Micrografia de R. Hooke, por ejemplo, tuvo su origen en el encargo de preparar unas láminas microscópicas para esa ocasión. Pues bien, a finales de Julio de 1663, C. Wren escribía desde Oxford al Presidente de la Sociedad sobre la preparación de algunas experiencias para su realización durante la visita, señalando que los experimentos del vacío de Torricelli, aunque muy importantes y novedosos para la física (la "filosofia»), podían resultar algo sosos, pero que ello no debiera llevar al extremo contrario e incurrir en bufonadas, pues "presentar sólo trucos y cosas para despertar el asombro, algo a lo que son muy dados Kircher, Schott e incluso los ilusionistas, difícilmente habría de convenir a la gravedad de la ocasión". ${ }^{67}$

La tendencia de Kircher a prestar atención a cualquier historia con tal de que fuese asombrosa era conocida por los Fellows antes incluso de la publicación del Mundus subterraneus. Así por ejemplo, ya en 1661 Robert Southwell escribía a Robert Boyle desde Roma ${ }^{68}$ diciéndole que frecuentaba a Kircher con quien había visitado repetidamente el Museo. Lo tenía por persona culta, industriosa y llana, si bien "por otro lado tiene reputación de muy crédulo y proclive a poner

y W. Aglionby hablan sobre los gusanos de la peste; del 20-VI-1678 donde R. Hooke menciona la evaporación; del 17-IV1679 donde Hoskins trata de las armas de fuego y la pólvora, y del 15VII-1685 donde Ch. Willougby menciona la explicación de Kircher de los Fata Morgana.

${ }^{66}$ Véase el Discurso de las Observaciones, donde reprocha a los naturalistas que con sus procedimientos jamás llegarían a darse cuenta de que los colores se someten a leyes matemáticas y puede hacerse de ellos una ciencia exacta. Cf. I. B. COHEN (Ed.), Newton's Papers and Letters on Natural Philosophy, Harvard University Press, 1958, página 225.

${ }^{67}$ T. BiRCH, loc. cit. en la nota 65, Vol. I: 288. Gaspar Schott (1608-1666) era un jesuita que había sido alumno de Kircher desde los viejos tiempos de Herbípolis (Wurzburgo) de donde huyeron ambos a Avifín en 1631 ante el avance de las tropas protestantes. Colaboraron de nuevo en Roma de 1652 a 1655, y desde entonces Schott editó obras de Kircher y cerca de una docena de compendios de experimentos e instrumentos ajenos magníficamente ilustrados, con la erudición acrítica, el eclecticismo y el gusto por lo fantástico propios del maestro.

${ }^{68}$ Carta del 30 de Marzo de 1661, en T. BIRCH, The Works of the Honourable Robert Boyle, 6 Vols., Londres, 1772, Vol. VI: 298-300. 
en letra impresa cualquier historia extraña que llegue a su conocimiento si resulta plausible». También criticaba que tuviese explicación para cualquier cosa que se le preguntase, lo que frecuentemente le hacía sonreír. Como ejemplo de ello mencionó el caso del ganso Solan de Escocia ${ }^{69}$ que, según pretende Kircher, nace de los árboles. Su explicación del asunto es que, como han visto unos marineros holandeses que andaban por Novaya Zemlya, los gansos depositan en la banquisa una cantidad ingente de huevos que bastaría para alimentar a toda Europa. Mas con el deshielo, caen al mar y las olas los baten y proyectan sobre las costas de Escocia e islas adyacentes donde embadurnan los árboles con semejante ponche. En ellos se engendran los gansos, por mor de la "virtud específica" de la pasta y de la "vegetación natural» del árbol, impregnados ambos por el «influjo omnipotente del Soln. ${ }^{70}$ Southwell muestra su escepticismo sobre la explicación de Kircher ("no se qué dirá usted de esta genealogía") y piensa que sus ideas extrañas sobre la generación lo llevan a contar cuentos. ${ }^{71}$ En efecto, en una ocasión le contó la historia de una fregona que se quejaba de dolores de espalda y sentía

${ }^{69}$ Hoy se conoce con ese nombre al alcatraz común (Sula bassana L), pero el extraño ganso de esta historia parece corresponder más bien a un ganso genuino, la barnacla carinegra (Branta bernicla $\mathrm{L}$ ) o tal vez a la canadiense que hiberna en Irlanda.

${ }^{70}$ Se trata de una vieja leyenda posiblemente inspirada por la semejanza de los percebes de arribazón con los cuellos y picos de las barnaclas de cuello obscuro. Aparece recogida por Giraldus Cambrensis en su Topographia Hibernia de la segunda mitad del siglo XII (traducida como The History and Topography of Ireland, Penguin, 1982). Los obispos y clérigos veleidosos se agarraban a esta historia para comer ganso en Cuaresma so pretexto de que era en realidad pescado. Aunque Alberto Magno observó a los gansos en cuestión y los vio copular y empollar, la historieta fue proseguida por Thomasius Cantipratensis quien, como ahora KIRCHER (Mundus subterraneus, Amsterdam, 1665, Tomo II: 337, 346), los hacía crecer no en maderos flotantes, sino en árboles costeros. Esta versión acabó a mediados del siglo XVI en la Historia natural de C. GESSNER, de donde probablemente deriva la versión de Kircher. Pueden leerse algunos detalles de esta historia en el ya viejo pero siempre ameno libro de WILLY LEY, El pez pulmonado, el dodó y el unicornio. Una excursión por la zoologta fantástica, Madrid: Espasa-Calpe, 1963 (el original es de 1941). KIRCHER había contado esta historia en Magnes, sive de arte magnetica (1641), página 711 , junto con otros casos de animales criados en árboles. Por ejemplo, en Chile hay un árbol que desarrolla vermes en las hojas que luego caen a tierra como serpientes. La razón es que el suelo está lleno de serpientes y su semilla se absorbe por las raíces y genera alimañas por la virtud solar.

${ }^{71}$ Kircher tenía una concepción hermética de la generación y "vegetación" aplicable a toda la materia, según la cual se podían engendrar metales en las entrañas de la Tierra, orquídeas a partir de semen caído al suelo o invertebrados a partir de estiércol de mamíferos. Todo dependía de la presencia de una virtud espermática o seminal capaz de engendrar seres vivos a partir de materia muerta, frecuentemente con ayuda de las emanaciones del Sol. De este modo no eran terminantes las fronteras entre lo vivo y lo no vivo, entre lo orgánico y lo inorgánico, entre unas especies y otras, mientras que por su parte los astros eran seres vivientes en continua actividad panspérmica, visión un tanto bruniana. 
que algo le reptaba por dentro. Sajada por un cirujano, salió una rana. De acuerdo con sus ideas neoplatónicas sobre los principios plásticos que organizan la materia, Kircher explicaba el asunto suponiendo que la chica había puesto a secar su camisón en un lugar al que acudían las ranas a copular, con lo que cayó sobre la prenda algo de esperma. Más tarde, con el calor de la espalda ("puesto que las chicas son calientes", pretende el fraile) el esperma se vio atraído y se alimentó de ella hasta que el cirujano hizo de comadrona de ranas.

En el Mundus subterraneus abundan hasta tal punto las historias de este tipo que despertó un educado escepticismo de continentales y británicos. La obra fue resumida por $\mathrm{H}$. Oldenburg en las Philosophical Tansactions, que funcionaban como órgano de la Royal Society, y por un comentarista anónimo en Le Journal des Sçavans, que salía los lunes en París con sumarios de libros. ${ }^{72}$ La recensión de Oldenburg tiene una primera parte exclusivamente descriptiva de las divisiones y temas abordados en el libro sin criterios evaluativos ni juicio crítico alguno, mientras que en la segunda subraya aquellos aspectos más sobresalientes y asombrosos que pudieran despertar el interés de los lectores y que sólo en unas pocas ocasiones se presentan con algún distanciamiento (: "he imagines...", "this Author fancies..."). Por su parte, el comentarista del Journal se entrega desde el principio a subrayar los aspectos más pintorescos de cada uno de los doce libros, recurriendo con más frecuencia a cláusulas distanciadoras (: "le Pere dit...», «il pretend...», «il pretend aussi...», «il pretend mesme...», «il rapporte l'histoire estrange..."). De entre las múltiples maravillas que se reseñan, ambos coinciden en las más sobresalientes, como las siguientes del Tomo I (libros I-VIII): las cadenas montañosas de la Tierra se disponen siguiendo los círculos paralelos y meridianos (página 68 y sig.); existen en su interior venas análogas a las de la sangre que conectan grandes depósitos de agua y fuego (hydrophylacia y pyrophylacia, páginas 70 y sigs., 175 y sigs., 181, etc); las aguas del océano se sumen por el Polo Norte y surgen por el Polo Sur (página 158); existen asimismo conexiones subterráneas entre el Mar Caspio, el Negro y el Golfo Pérsico, entre el Mar Rojo y el Mediterráneo, entre el Maelstrom noruego y el golfo de Botnia o entre el mar de Fernando Poo y los lagos del continente africano (páginas 85, 146 y sigs.). En el Tomo II (libros IX-XII) destacan la existencia de símbolos plasmados

72 H. Oldenburg, "Of the Mundus Subterraneus of Athanasius Kircher", citado en la nota 2; Le journal des Şavans, n. 26 (28 de Junio de 1666): 299-305 y no 30 (26 de Julio de 1666): 347-352. 
naturalmente en piedras (página 23); la de una aldea de África que está petrificada en su totalidad con sus habitantes y ganados (página 50); la de una fauna subterránea como los dragones o las golondrinas, que en realidad no migran, sino que se meten durante el invierno debajo de la tierra o del mar, donde las pescan los polacos en grandes racimos y, puestas a calentar, reviven; la de hombres abisales de color verde, dos de los cuales aparecieron en Inglaterra y uno de ellos, tras aprender el idioma, dijo que en su país no había sol (páginas 97 y sigs.); la de gusanos venenosos y casi invisibles en la sangre que causan enfermedades y que se reproducen vertiginosamente, pues se quintuplican mientras se reza un Miserere; la de la generación espontánea de invertebrados, etc., etc ${ }^{73}$.

La noticia de este tipo de maravillas kircherianas, llegó al Colegio Invisible del que saldría la Royal Society antes de que ésta se fundase y de que se publicase el libro, pues R. Boyle le pidió a Oldenburg en 1658 que comprobase unas cuantas en su viaje al continente. Desgraciadamente, respondió éste, no irá a Italia sino a Alemania, por lo que no podrá traerle noticias del «industrioso Kircher" sobre la espelunca de las serpientes, sobre el crecimiento de conchas pulverizadas, plantadas y regadas con agua de mar, sobre el fénix vegetal, sobre el experimento del flujo y reflujo el mar mediante un anillo de mercurio afectado por la Luna o sobre la refutación de los movimientos magnéticos de los planetas en torno al Sol según Kepler y de la rotación terrestre según Gilbert. ${ }^{74}$ Cuando finalmente llegó el libro a la librería de Thompion al precio de 50 chelines cada volumen, ${ }^{75}$ Oldenburg tuvo ocasión de ojearlo y le escribió a Boyle: «mucho me temo que lo único que nos ofrece, como acostumbra, son colecciones de lo ya existente y conocido sin descubrimientos de consideración". Sin embargo encontraba tentadores los títulos de las diferentes partes y pensaba que el contenido podía justificar el elevado precio, pues trataba de todo, "aguas, metales, piedras (sin olvidar la filosofal), fuegos, tierras, insectos, hombres subterráneos, los propios demonios, etc.» ${ }^{76}$.

${ }^{73}$ Los gusanos estaban presentes en todas las substancias, aunque eran tan pequefios que ni su microscopio podía separarlos. A pesar de todo les atribuyó la responsabilidad de la peste de 1655 en su libro Scrutinium physico-medicum contagiose luis, quae pestis dicitur (Roma, 1658).

${ }^{74}$ Carta de Oldenburg a Boyle del 19 de Marzo de 1658, The Correspondence of Henry Oldenburg, I: 155 y sig.

75 Carta del 18 de Septiembre de 1665; Ibid., II: 512. El precio del libro era elevado y Oldenburg trató de rebajarlo a 45 chelines y de cambiarlo por varios libros suyos. Es bien sabido que $\mathrm{Ch}$. Wren ofreció como premio un libro de 40 chelines a quien derivara dinámicamente las leyes de Kepler.

${ }^{76}$ Carta del 28 de Septiembre de 1665; Ibid., II: 532. 
B. Spinoza tuvo ocasión de ojear el libro en casa de Huygens el cual «aplaude su piedad más bien que su capacidad». ${ }^{77}$ Con todo Boyle necesitaba creer en la verdad de lo atestiguado por Kircher y su red de misioneros dispersos por todo el globo, porque él mismo estaba tratando de crear un estilo de comunicación de experiencias basado en la credibilidad más que en la repetición efectiva de las experiencias que usualmente estaban fuera del alcance geográfico o instrumental del público lector. Como en el siglo XVII ese público no estaba compuesto por un grupo de colegas profesionales alojados en instituciones de investigación dotadas de laboratorios, la replicabilidad efectiva no era un buen criterio. ${ }^{78}$

Con todo, incluso la moralidad de Kircher empezó a empañarse con sospechas de plagio no formuladas expresamente. En efecto, tras exponer las ideas de Kircher sobre péndulos y cuerdas armónicas, así como la dependencia de los tonos del grosor, longitud y tensión de las cuerdas, Oldenburg pasó a interesarse sin ninguna explicación por la primera parte del segundo tomo de las Mathematical Collections de T. Salusbury (Londres, 1665), donde se traducen los Discorsi de Galileo en los que se explican por vez primera los intervalos consonantes por la proporcionalidad de las vibraciones. ${ }^{79}$ Sin embargo, Oldenburg se muestra discreto en su respuesta a Spinoza defendiendo el valor de Kircher como recopilador de hechos: "por más que sus razonamientos y teorias no avalen su ingenio, con todo las observaciones $y$ experimentos que nos ofrece

${ }_{77}$ Carta de Septiembre u Octubre de 1665, Ibid., Il: 540 y sig.

${ }^{78}$ S. SHAPIN y S. SCHAFFER, Leviathan and the Air Pump: Hobbes, Boyle and the experimental Life, Princeton, 1985, abordan en el Capítulo 2 el problema de cómo compaginar la creencia de que el conocimiento se basa en los experimentos con el hecho de que muy pocos dispusiesen de laboratorios. Para ello Boyle desarrolló un estilo de comunicación que convertía a los lectores en experimentadores virtuales: "The technology of virtual witnessing involves the production in a reader's mind of such an image of an experimental scene as obviates the necessity for either direct witness or replication. Through virtual witnessing the multiplication of witnesses could be, in principle, unlimited. It was therefore the most powerful technology for constituting matters of fact. The validation of experiments, and the crediting of their outcomes as matters of fact, necessarily entailed their realization in the laboratory of the mind and the mind's eye. What was required was a technology of trust and assurance that the things had been done and done in the way claimed."

79 Carta de Oldenburg a Boyle del 10 de Octubre de 1665, Correspondence of Henry Oldenburg, II: 555. La teoria musical de Galileo se expone al final de la Jornada I de los Discorsi, Vol. VII, páginas 138-150, de Le Opere di Galileo Galilei. Huygens (Oeuvres complètes de Christiaan Huygens, XX: 124) criticará la incapacidad de Kircher (Musurgia universalis, Libro VI, Capítulo I, Teorema 9, págs. 428-30) de establecer como Mersenne (Harmonie universelle, Libro VIII) que, en las cuerdas vibrantes, las frecuencias de las vibraciones son subduplas de las tensiones. 
hablan de la diligencia del autor y de su voluntad de hacer méritos ante la República Filosófica. Así pues, como ve, le atribuyo un poquito más que la piedad.... ${ }^{80}$ También R. Moray escribía a Oldenburg en el mismo sentido, señalando frente a los continentales que, aunque no sea muy listo, se esfuerza y ofrece datos de interés: "Digan lo que digan el Sr. Huygens y otros de Kercher [sic], le aseguro que yo soy de aquéllos que consideran que la República del Saber está pendiente de él, pues aunque no carezca de paja... con todo se puede hallar trigo en casi todas partes. $Y$ aunque no trate la mayoría de las cosas de modo completo y preciso, ofrece materiales para que lo hagan otros. Estimo que es una cantera filosófica útil.... ${ }^{81}$ Sin embargo Moray no había leído aún el Mundus subterraneus en el que Kircher utilizaba con libertad una carta suya sobre las mareas anómalas en las Hébridas, al Oeste de Escocia. Pero como los datos de Moray no casaban bien con sus especulaciones, los consideraba imperfectos, maniobra que como es natural amostazó a Sir Robert Moray, quien se disgustó al ver el mal uso que hacía Kircher de sus datos. ${ }^{82}$

Después de este incidente y de la imposibilidad de reproducir algunas experiencias de Kircher que veremos en el siguiente apartado, Oldenburg comenzó a enviar mensajes a otros miembros de la República de las Letras para controlar las informaciones de Kircher. A comienzos del año siguiente (1666) mandó a J. Hevelius que vivía en Dantzig (Gdansk) una lista de preguntas sobre curiosidades de Polonia, Suecia, Bielorrusia o Moscú, la séptima de las cuales se interesaba por la presunta comunicación kircheriana entre el Maelstrom y el golfo de Botnia. ${ }^{83}$ También escribió a R. F. de Sluse en Lieja preguntándole por una receta para combatir las plagas de las vides de la que hablaba Kircher ${ }^{84}$ Consistía en polvo de carbón de Lieja mezclado con aceite. Sluse le informó de que nadie allí sabía nada de semejante emplasto, por lo que el jesuita hablaba de memoria y ésta le fallaba. No obstante prometió hacer la prueba la siguiente primavera, si bien advierte que allı se usa la ceniza de carbón en los cultivos pero como fertilizante, no como insecticida. También escribió en 1668 a E. Browne en Viena

${ }^{80}$ Carta del 12 de Octubre de 1665; Ibid., II: 565; las cursivas son mías.

${ }^{81}$ Carta del 19 de Octubre de 1665; Ibid., II: 574 y sig.

${ }^{82}$ Cf. Mundus subterraneus, página 143 y sig., así como la correspondencia de Moray y Oldenburg en Septiembre sobre el asunto de las Hébridas, Corespondence of Henry Oldenburg, II: 590 y 592.

${ }^{83}$ Carta del 30 de Marzo de 1666, Ibid., III: 74. La lista completa se publicó en las Philosophical Transactions, no 19 (19-XI-1666): 344-46.

${ }^{84}$ Cf. la carta del 26 de Enero de 1669 y la respuesta del 12 de Febrero de mismo año; Ibid., V: 358 y 417. La receta aparece en el Capítulo 6 del libro 8 del Mundus subterraneus. 
planteándole cuestiones de química y minería, entre ellas si, como dice Kircher, las venas metálicas corren en las minas en dirección Norte-Sur. La respuesta pone en duda las descripciones de Kircher y sus informes mineros. ${ }^{85}$

Aunque las cosas iban mal en Inglaterra para la reputación de Kircher como recolector de Obras de la naturaleza, la existencia en aquella isla de una tradición neoplatónica resistente a los esfuerzos mecanicistas del «ateon Hobbes llevó a Boyle, el "mecanicista irresoluto" ${ }^{86}$, a tomar en consideración algunas posibilidades defendidas por el Padre Kircher y a tender a dar crédito a sus informes. Veamos el caso de los afectados por la picadura de la tarántula que ejemplifica bien la concepción simpática o «magnética» del cosmos de Kircher, amén de su amor por el espectáculo y su laxitud epistemológica en la aceptación de informes y experiencias.

El "tarantismo» es (aún se describen casos) una de esas manifestaciones menádicas de histeria social frecuentes en la Europa medieval que se exacerbaron en el siglo XIV y alcanzaron su acmé en el siglo XVII. Como los afectados del baile de San Vito o la danza de la Muerte, los taranti del Sur de Italia (de Apulia y la zona de Taranto, nuestro Tarento) se veían compelidos a bailar en los meses de Julio y Agosto, manía que retornaba todos los años con los calores (Figura 4). El mal se iniciaba presuntamente por la picadura de una tarántula ${ }^{87}$. El paciente se despertaba un mal día sintiendo un pinchazo y se lanzaba a la calle vestido más o menos vistosamente para unirse a otros afectados y bailar de modo extravagante y aun lascivo. Paraban para la siesta y al atardecer reiniciaban la "marcha" hasta que la hiperventilación, la taquicardia, el poco comer y mal dormir terminaban en síncope. Se suponía que bailar distribuía el veneno por el cuerpo y facilitaba su expulsión con el sudor, de modo que los músicos italianos desarrollaron una danza rápida de 6/8 llamada «tarantela" que sobrevivió al mal y fue practicada incluso por Chopin y Listz. Los magistrados contrataban músicos por el verano para atender a los pobres afectados.

${ }^{85}$ Correspondence of Henry Oldenburg, V: 262, VI: 11 y 587.

${ }^{86} \mathrm{La}$ expresión procede del título del apartado 2 del Capítulo VI (Robert Boyle, the irresolute mechanist) de J. HeNRY, Matter in Motion, Ph. D. Thesis, Open University, Marzo de 1983; véanse las páginas 248-267.

${ }^{87}$ Algún espécimen de la familia Licosida. En el siglo XVII la sistemática de arácnidos y artrópodos en general era muy deficiente. 


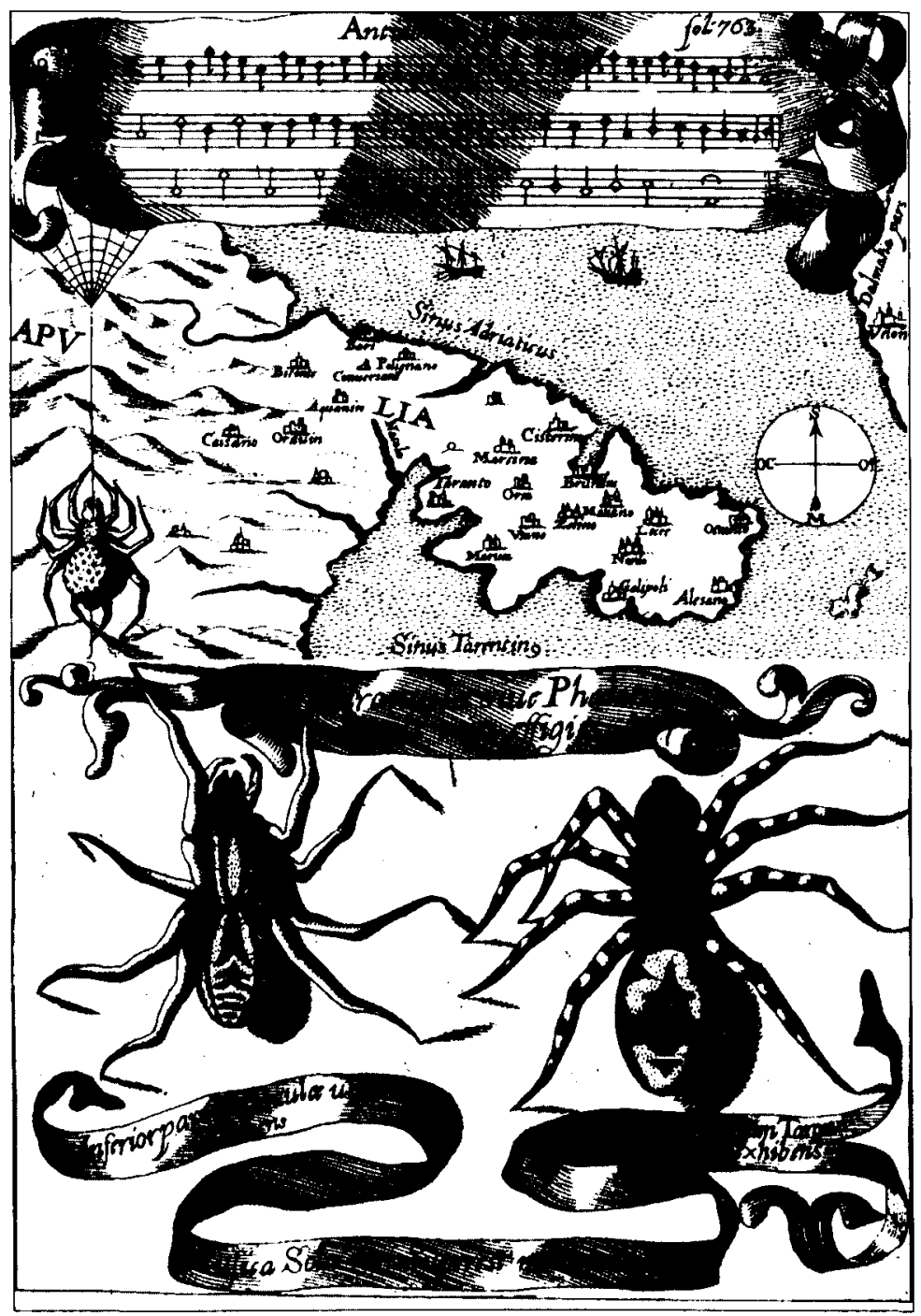

Figura 4. De la partitura de una tarantela se descuelga sobre el mapa de Apulia una tarántula como un centollo. Abajo se representa el aspecto ventral y dorsal de una tarántula o phalangium. Kircher, Magnes, sive de arte magnetica (Roma, 1641, página 874). Imagen tomada de la segunda edición de Colonia, 1643, folio 763

Kircher se ocupó de la enfermedad magnética en Magnes (1641) y en $\mathrm{Mu}$ surgia (1650), ofreciendo partituras de tarantelas y la explicación de cómo actúa la música sobre la enfermedad. Sus doctrinas fueron conocidas en Inglaterra gra- 
cias a W. Charleton, un médico erudito no muy alejado de Kircher, que comenzó como seguidor de van Helmont y se convirtió luego al atomismo, ofreciendo un centón del saber contemporáneo en su muy leída obra Physiologia EpicuroGassendo-Charletoniana (Londres, 1654). Expone que, según Kircher, existe una simpatía entre las vibraciones musicales, la tarántula y el veneno de ésta que es como su sangre. La música que hace bailar al taranto hace asimismo bailar a la araña, como se comprobó en el refectorio de los jesuitas de Roma cuando una Duquesa se interesó por el tema. Los padres pusieron a la peligrosa alimaña en una barquilla que flotaba en una palangana de agua para que no huyera; mientras tanto un arpista ensayaba varios sones hasta dar con uno que, teniendo proporción con el veneno, hacía bailar a la araña, pues el veneno que le sirve de sangre es viscoso y recibe bien las impresiones sonoras. Por eso la música adecuada cosquillea al bicho y al taranto que no pueden dejar de bailar. El sudor hace que éste pierda el veneno y mitigue su mal, no existiendo otro remedio. Por ejemplo, los superiores de un capuchino de Tarento afectado por el mal consideraron indigno del uniforme esa danza desenfrenada y le prohibieron el remedio, lo que lo impulsó a mitigar los picores bañándose de noche en la mar, do pereció ahogado, lamentándose los superiores de su superstición al haberle negado la danza.

Los músicos contratados por las autoridades civiles procedían como sigue. Interrogaban al taranto sobre el aspecto de la araña y el lugar donde había sido picado. Acudían allí, cazaban un ejemplar del mismo tipo y le tocaban varios aires hasta dar con el que simpatizaba con su veneno y lo hacía bailar, con lo que sabían qué tocarle al enfermo. Como era de esperar, el virtuoso Boyle quedó impresionado con este caso de simpatía vibratoria, pues su escepticismo ante las doctrinas generales y su amor a las obras de la naturaleza lo dejaban desarmado, ya que carecía de criterios teóricos para negar informes ajenos y los únicos de que disponía lo inclinaban a creer a las personas de calidad como los jesuitas del Collegio Romano. ${ }^{88}$

En la segunda Parte de The usefulness of Natural Philosophy, Boyle se hace eco del tarantismo y de la explicación mecánico-simpática de su cura musical por pro-

${ }^{88} \mathrm{La}$ fe de Boyle en la veracidad e inteligencia del jesuita es notable hasta los ańos sesenta. Así, habiendo leído en PLINIO (Historia natural, IX, 74, 159) que las ranas se disuelven en barro en Otońo para renacer la Primavera siguiente, señala que «le habría dado poco crédito si no fuera porque la relación de Kircher parece apoyarlon; véase la versión original del libro de Boyle The Usefulness of Natural Philosophy (1663), en.M. HuNTER y E. B. DAVIS (Eds,), Works of Robert Boyle, Londres: Pickering \& Chatto, 1999, Vol. XIII: 315. 
ducción de movimientos en los espíritus y humores que afectan a los nervios y los músculos, produciendo el baile y el sudor reparadores. Pero el mecanicismo no es plenamente resolutivo, pues sudar no basta y no sirve sudar paleando brea. Es preciso bailar por la agitación de los humores, como señalan entre otros P. A. Mattioli y el «inquisitivo jesuita» ${ }^{89}$ Estas opiniones no difieren mucho de los pensamientos un tanto ocultos del corpuscularista Boyle. En efecto, en Of the Grat Effects of Even Languid Motion señala: «los hombres no creen usualmente lo que la modificación del movimiento invisible de los fluidos pueda provocar en los cuerpos dispuestos de los animales». ${ }^{90}$ Tras tildar a Kircher de persona de reputación y erudición, menciona los informes sobre las serpientes con patas de El Cairo que saltan al oír música y al gran pez del estrecho de Mesina que se ve afectado por una cierta melodía, ruda al oído humano, con la que los marineros hacen que siga al barco. Boyle acepta la relación de Kircher «que supongo verdadera, aunque el ensayo no tuvo exito conmigo", porque quizá no haya tenido en cuenta las condiciones adecuadas. A pesar de la adoración de las obras y el despego de las doctrinas, la de los movimientos invisibles le hace desconfiar de sus propios experimentos.

Sin embargo, las reiteradas inexactitudes, reales o no, del industrioso Kircher no dejaron de sorprender a Boyle, como ocurrió con la descripción del palo de los riñones o lignum nephriticum que hacía Kircher en Ars magna lucis et umbrae (Roma, 1646) basándose en una copa hecha de esa madera que le había enviado un jesuita desde México. Al no coincidir en absoluto con la de sus propias muestras, señalaba que "o su memoria le engaña" o no hablamos de lo mismo. ${ }^{91} \mathrm{El}$ fracaso de los intentos de repetir sus experimentos, como veremos a continuación,

${ }^{89}$ Cf. especialmente Musurgia universalis, sive Ars magna consoni of dissoni, Roma 1650 , Libro IX, Parte 2, Capítulo 4, donde tarantos y aranias se mueven con la misma tensión que tienen las cuerdas pulsadas.

${ }^{90}$ Capitulo VI, Observación V; cb T. BIRCH, The Works of the Honourable Robert Boyle, citado en la nota 68, V: 119. La producción de grandes efectos con causas insignificantes es la marca de la magia. Al comienzo de An Essay of the Great Effects of Languid and Unheeded Motion to which is annex'd an Experimental Discourse of Some Unheeded Causes of the Salubrity and Insalubrity of the Air and its Effects (Londres, 1685, aunque redactado dos decadas antes), Ibid., V: 2 , sefiala que los efectos usualmente atribuidos a cualidades ocultas son en realidad producidos por umovimientos locales débiles o imperceptibles de los cuerpos entre sí, a menudo a distanciau, otra característica de las acciones mágicas. Véase el Experimental Discourse... V: 62, donde trata de la aparición de cruces en paños, incluso en los guardados en alacenas, descrita por KIRCHER en Diatribe de prodigiosis crucibus (1661).

${ }^{91}$ Experiments touching Colours (1664) en M. HUNTER y E. B. DAVIs (Eds,), Works of Robert Boyle, citado en la nota 88, Vol. IV: 109 y sig. Hay dos palos de los rifones, el arbusto mexicano Eysenhardtia polystacha y el árbol filipino Pterocarpus indica. 
debilitaron asimismo la tendencia a recurrir a las informaciones del jesuita, de manera que si bien en el primer lustro de los años sesenta era muy citado por Boyle, a partir del Mundus subterraneus las citas comienzan a ralear, se tornaron marginales y desaparecieron prácticamente de los escritos de los quince años que median entre 1675 y su muerte en 1691. En aquel año encontramos la última referencia de consideración a una observación de Kircher sobre la resurrección de una planta, que no aceptaba porque no estaba de acuerdo con las condiciones del experimento ni con las inferencias de fraile. ${ }^{92}$ Sin embargo aceptó otros experimentos similares realizados por "personas veraces" en el jardín de una de ellas consistentes en quemar una planta de amapola roja y sembrar sus cenizas, de donde surgieron antes de lo esperado "ciertas plantas mayores y más claras que la del tipo que se han visto en aquellos lugares». De ahí concluía la existencia de una fuerza plástica capaz de reorganizar la materia a partir de las cenizas. No parece haber pues ninguna discrepancia teórica para rechazar la experiencia de Kircher; tan sólo hay una pérdida de confianza en su capacidad o en su credibilidad.

No debería terminar este apartado sin señalar la existencia de estudios más sobrios sobre la etología de las tarántulas. El médico napolitano Tommaso Cornelio (1614-1684), seguidor de Galileo y amigo de M. Malpighi, publicó una colección de investigaciones propias en Progymnasmata physica (1663). En una carta a John Dodigton ${ }^{33}$ explica que las tarántulas son arañas grandes y jaspeadas que cavan en tierra nidos profundos cuya entrada es del tamaño de una nuez. En verano se las puede hacer salir y capturar silbando. Promete enviarle algunos ejemplares vivos, ya que ha comprobado que pueden vivir semanas sin comer, o en su defecto, secas o conservadas en alcohol. Sobre el tarantismo tiene una opinión distinta de la vulgar basada en "muchas observaciones y conjeturas", según la cual en los países aridísimos que provocan el jadeo y se pasa mucha sed, la afección no depende de la picadura. Lo que ocurre es que cuando alguien es picado teme que le sobrevenga el mal y cuando con la llegada de los calores nota los síntomas del fenómeno, los atribuye a la picadura. $Y$ termina prometiendo escribir una relación pormenorizada cuando llegue la Primavera y mejore su salud. Un mes más tarde Oldenburg envió a M. Lister una larga cita de esta carta y terminaba comentando: "Si no hay aqui error se trata del descubrimiento de una monstruosa ficción que nos han impuesto merced a una tradición general, particularmente

92 Véase más abajo el apartado sobre el Fénix vegetal, páginas 301 y sigs.

${ }^{93}$ Del 9 de Enero de 1672, The Correspondence of Henry Oldenburg, VIII: 494 y sig. 
gracias a Epiphanio Ferdinandi, Kircher, Wolferd Senguerd, etc. ${ }^{94}$ El método clínico de Redi, las ideas epidemiológicas de Cornelio y la replicación efectiva de las pretensiones ajenas resultaba así más fiable que las anécdotas de "personas de calidad». Con ello, para los años setenta el crédito de Kircher estaba de capa caída incluso en una institución propicia como la Royal Society.

\section{Arcanos, jeroglíficos e imaginación}

El gusto de Kircher por la prisca sapientia y su codificación en emblemas secretos lo alentaron a estudiar la escritura jeroglífica. Cuando en 1633 entró en contacto con Nicolas Claude Fabri de Peiresc, este quedó impresionado por sus conocimientos de idiomas y puso en sus manos un léxico y algunos otros manuscritos traídos a Roma en 1626 por Pietro della Valle, así como otros traídos por T. Minuti y los estudios de T. Obicini para que editara el léxico y gramática coptos. Con todo ello Kircher compuso una gramática, el Prodromus coptus (Roma, 1636), completada más tarde en Lingua aegyptiaca restituta (Roma, 1644). La idea que motivaba a estos estudiosos era la creencia de que el copto o una forma antecedente era la lengua natural que codificaba la escritura jeroglífica. (El copto convivió con el demótico desde el $700 \mathrm{a}$. C., siendo la quinta fase de la lengua de los egipcios hasta que para el siglo XIV el dominio árabe de la zona la puso al borde de la desaparición.) Con todo, Kircher prefería considerar que un poco de inspiración podría suplir el pesado trabajo filológico de descodificar una escritura. En realidad, pensaba Kircher, los jeroglificos eran una escritura universal que codificaba directamente el pensamiento sin pasar por una lengua natural, de modo que lo mejor que se podía hacer era escrutar la propia cabeza. Tanto más cuanto que la escritura jeroglifica no se usaba para hablar de reyes y tributos, sino para recoger una revelación y un saber prístino expuesto mediante emblemas universales.

La proclividad de Kircher a sustituir el trabajo por la imaginación fue motivo de serias preocupaciones por parte de Peiresc, como se manifiesta en su correspondencia de comienzos de los años treinta hasta la aparición del Prodromus. La imaginación de Kircher rozaba la impostura al inventar orígenes exóticos y novelescos para sus informaciones. ${ }^{95}$ De este modo, a la vez que Peiresc lo reco-

94 Oldenburg a M. Lister, 10 de Febrero de 1672, Ibid., VIII: 534.

${ }^{95}$ La literatura ocultista está llena de tales recursos. Por ejemplo, Sir K. Digby recibió la receta del polvo simpático de un misterioso carmelita retornado del Oriente profundo, un recurso muy 
mendaba a Cassiano dal Pozo, ponía de manifiesto ciertas reticencias ante su imprudencia y secretismo. ${ }^{96}$ En efecto, Kircher le mostró con reticencias un libro árabe sobre Egipto sin dejarle más que ojearlo sin tomar notas. El autor sería un rabino ficticio, tal vez de su invención, el Raby Barachias Nephi de Babilonia, ${ }^{97}$ de donde sacaría sus claves para traducir los jeroglíficos. Peiresc se malicia que se trata de una traducción de algo ya conocido y le hace notar a Kircher que algunos pasajes muestran que el autor no sabe muy bien lo que dice. Eso incomodó al fraile que interpretaba con su ayuda el obelisco de San Juan de Letrán.

Todavía en 1634 Peiresc seguía sin conseguir examinar detenidamente el Barachias mientras que Kircher progresaba en sus «especulaciones jeroglificas" sin terminar de una vez el diccionario y gramática del copto que della Valle había traído de Oriente, por lo que era de temer que éste se impacientase y desconfiase "no sin razón" al temer que tan valiosos materiales fuesen usados para especulaciones que hacen "violenza all'authorità degli antichi, per fondar le sue congieture». ${ }^{98}$

Los temores de Peiresc y della Valle no eran infundados dada la traducción que hizo Kircher de unas antiguas inscripciones halladas en el monte Oreb (el Sinai), según el cual rezaban: Deus Virginem concipere faciet et ipsa pariet filium. Peiresc expresaba cierta aprensión acerca udel buen Padre Kircsero [sic] que tan estupendas cosas ha hallado en aquella inscripción bárbara suya", 99 en cuya interpretación, decía a G. Naudé, «no encuentro un fundamento que apoye su conjetura, y le insistiré en que no la incluya en el Prodromus a fin de no correr el riesgo de echar a perder el resto». ${ }^{100}$ En la correspondencia con los hermanos Dupuy se muestra más mordaz «el pobre Padre Athanase Kircher se ha imagina-

usado por Kircher, pues como veremos, un árabe encontrado por casualidad en Marsella le pasó una rara materia heliotrópica y un monje de San Salvador de Mesina le enseńó la antigua música de la Oda de Píndaro; véanse las notas de C. Huygens sobre la Musurgia universalis (Roma, 1650), en Oeuvres complites de Christiaan Huygens, XX: 111 y sigs., 550 y sigs.

96 Véase la correspondencia de Septiembre de 1633 en J. F. LHOTE y D. JOYAL (Eds.), Nicolas-Claude Fabri de Peiresc lettres à Cassiano dal Pozo (1626-1637), Clermont Ferrand: Adosa, 1989; especialmente la página 133. Véase también la correspondencia con los Dupuy de Abril y Mayo del mismo afio en P. T. LAROQUE (Ed.), Lettres de Peiresc aux Frères Dupuy, París: Imprimerie Nationale, 1890, Vol. II.

${ }^{97}$ Kircher identificará Babilonia con la antigua Menfis o Heliópolis, sobre el Nilo, al Norte del Cairo; cf. Oedipus I, 8-9 o Sphynx mystagoga, 42-3.

${ }_{98}$ Cartas del 29 de Junio y del 29 de Diciembre de 1634 a C. dal Pozzo; loc. cit. en la nota 96

99 Ibidem, 29 de Abril de 1636.

${ }^{100}$ Carta del 5 de Junio de 1636; Ibidem, página 237. 
do que ciertos caracteres de los que se dice que están grabados en el monte Sinaí significan lo que a él se le ha ocurridom. ${ }^{101}$ Un mes más tarde anunciaba el envío de la traducción de Kircher "con el ruego de que no la enseñe para no dañar demasiado la reputación que este buen hombre había adquirido, el cual se muestra sin duda un poco excesivamente crédulo en las cosas sobre las que resulta muy difícil tratarn. ${ }^{102}$

La exquisita cortesía de Peiresc con el fraile no le impidió percatarse perfectamente del tipo de sujeto de que se trataba, pues aquel joven prometedor se había convertido en un par de años en objeto de desconfianza y risión privada. Pero la pública orgía de interpretaciones arbitrarias publicadas en el Oedipus aegyptiacus (Roma, 1652-54) aceleró su descrédito público tal como comunicaba R. Southwell a H. Oldenburg.

Todavía en los años setenta el joven G. W. Leibniz mencionaba con mucha frecuencia a Kircher a quien citaba entre los más grandes del siglo por sus trabajos sobre magnetismo, combinatoria, diseño de lenguajes artificiales y estudio del origen común de los naturales. ${ }^{103}$ Sin embargo, tras la lectura de Polygraphia nova (Roma, 1663) y de Turris Babel (Roma 1679), se dio cuenta de que Kircher no hacía más que tomar préstamos ajenos sin ofrecer nada propio de interés. Como señalaba a H. J. Friedrich: «La poligrafía del P. Kircher que Vd. ha visto es tan poca cosa y se halla tan lejos de mis propósitos que no existe la menor posibilidad de que me haya aprovechado de ella. Asimismo, la mayoría de las invenciones de este padre no son sino jueguecillos de ingenio más lindos que útiles [...] El Ars magna de Lulio tiene mayor relación con lo que propongom. ${ }^{104}$ Leibniz perdió todo interés por Kircher y en los veinte años siguientes las referencias

${ }^{101}$ Carta del 22 de Abril de 1636, Lettres de Peiresc aux Frères Dupuy, op. cit, en la nota 96, página 33.

102 Ibidem, carta del 13 de Mayo de 1636; véase también la del 3 de Junio siguiente.

${ }^{103}$ En la Correspondencia General, politica e histórica, así como en la Correspondencia filosófica, entre los años 1668 y 1678 (Berlín: Akademie Verlag, 1986 y sigs.), se alude a Kircher cerca de treinta veces a cuento sobre todo de Magnes (1641), la unidad de las lenguas y el arte combinatoria, mientras se espera con interés la publicación del Arca Noë (1672) y la Turris Babel (1679). Véase, a modo de ejemplo, la carta a H. Coring del 8 de Febrero de 1671 sobre la armonfa de las lenguas naturales que Kircher pensaba tratar en parte en Turris Babel. Sobre las relaciones entre ambos, véase P. FRIEDLÄNDER, "Athanasius Kircher und Leibniz, ein Beitrag zur Geschichte der Polyhistorie im XVII Jahrhundert", en Atti della Pontificia Accademia Romana di Archeologia, $3^{2}$ serie, Rendiconti, 13 (1937): 229-247.

104 Carta de Abril de 1679, página 559 de las Philosophischer Briefwechsel, 1663-1685. 
a él en la correspondencia cayeron a poco más de una docena. Casi siempre usa el nombre de Kircher como carta de presentación ante otros jesuitas para obtener información sobre la China, mientras que las opiniones sobre sus trabajos son claramente denigratorias. G. Meier le dice que cuando se acuerda de Kircher, a quien tantas veces vio en Roma, no deja de asombrarse de que fuese tan famoso en vida siendo tan torpe ${ }^{105}$ y Leibniz comenta a W. E. Tentzel que, aunque docto y de ingenio fértil, era menos estricto de lo que ahora se estila por lo que atañe a los jeroglíficos y asuntos egipcios, sobre los que no dijo nada de valor según estiman los entendidos. ${ }^{106}$

\section{Instrumentos, relojes y trampas saduceas}

La afición de Kircher a las máquinas e instrumentos asombrosos lo llevó a copiar liberalmente y a modificar las máquinas de los antiguos, como los órganos de Herón y los diversos tipos de relojes tradicionales o las modernas cámaras obscuras y linternas mágicas. Hubo tres casos entre muchos otros que despertaron la especial curiosidad de los contemporáneos al estar conectados con el aún misterioso y mal comprendido magnetismo, lo que en el caso de Kircher se agrandaba al concebirlo como las cadenas que mantenían la unidad, simpatía y correspondencia entre las diversas partes del cosmos. Los dos primeros instrumentos de que nos ocuparemos fueron sendos relojes magnéticos, uno construido por el jesuita inglés Franciscus Linus, afincado en Lieja, y otro diseñado por el propio Kircher. El tercero era una brújula que no declinaba inventada por el jesuita J. Grandami y divulgada por Kircher.

El primer reloj, construido por Linus (Figura 5), estaba destinado a engañar y asombrar, tal vez para revelar el poder y dominio jesuítico de la magia natural y también quizá para tender una trampa a quienes defendían la rotación magnética de la Tierra siguiendo a W. Gilbert. El reloj «magnético» se basaba posiblemente en una idea anterior de Galileo, como se verá. Consistía en una esfera de cera o de cobre, situada en el centro de un globo de vidrio lleno de agua, que daba una vuelta con los cielos cada 24 horas, mostrando la hora contra un pece-

${ }^{105}$ Carta del 10 de Octubre de 1691, loc. cir., Allgemeiner... Briefwechseh 1691-92, página 390.

106 Carta del 3 de Enero de 1695, Allgemeiner... Briefwechsel 1695, página 125; véase también la carta a A. Acoluthus del 10 de Octubre del mismo año, ibid., página 727. 


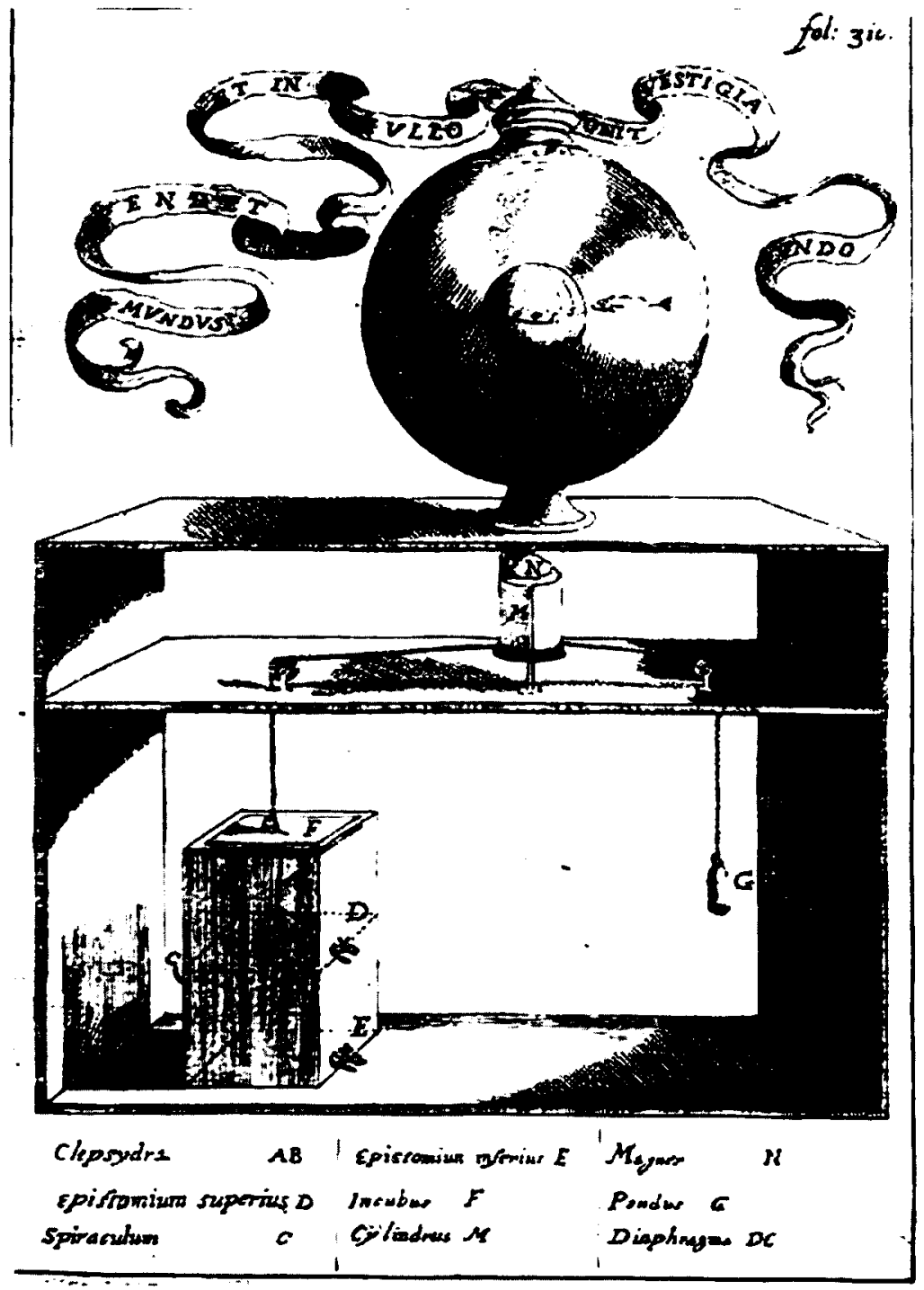

Figura 5. Dibujo de de Kircher (Magnes, sive de arte magnetica, Roma, 1641; lámina entre las páginas 310 y 311 ) del reloj magnético de Franciscus Linus. En el pedestal se esconde una clepsidra o reloj de agua. El flotador $\mathrm{F}$ desciende con el nivel de agua y hace rotar el tambor M que lleva encima un imán N. Éste hace girar un hierro escondido en la esfera de bronce que flota a media altura en el agua del recipiente de vidrio superior, de manera que los números horarios de su ecuador muestran la hora cuando pasan ante el pez. Esta clepsidra no parece capaz de funcionar mucho tiempo sin intervención de un operador, como se supone que ocurría con el de Linus que tuvo varios días en su casa el nuncio de Colonia Pierluigi Caraffa 
cillo asimismo flotante entre las aguas. ${ }^{107} \mathrm{El}$ reloj exhibía varios misterios, como crear un movimiento perpetuo, equilibrar una esfera metálica en medio de las aguas y mostrar la correspondencia entre el macrocosmos y el microcosmos con un aparato que seguía la marcha diaria de las estrellas (pues, como decía el también jesuita $\mathrm{O}$. Grassi, entre los católicos la Tierra no se mueve). ${ }^{108}$

Aunque el reloj era una añagaza, las noticias llegaron a los centros de información científica europea, esto es, a Peiresc y Mersenne, ya en el verano de 1633, antes de la publicación del libro de Pietrasancta. También se mencionó entonces un reloj fabricado por Kircher con unas curiosas semillas «magnéticas" del que hablaremos enseguida. ${ }^{109}$ Por lo que respecta al reloj de Linus, Peiresc concibió la esperanza de tener una prueba directa del movimiento terrestre poco después de la condena de Galileo. Así, tras la publicación del libro

$107 \mathrm{El}$ aparato fue admirado por diversos príncipes de la Iglesia, como el nuncio Monseñor Caraffa, cuyo confesor, el jesuita S. PIETRASANCTA, lo describió en De symbolis heroicis, Amberes, 1634. La obra llevaba un frontis de P. P. Rubens que estaba intrigado por su funcionamiento y que en una carta (18-XII-1634) se ofreció a Peiresc para ir a verlo y averiguar algo.

Sobre máquinas e instrumentos de experimentación, véase $M$. J. GORMAN "Athanasius Kircher e la cultura barrocca delle macchine" y F. CAMEROTA, "Riconstruire il seicento: macchine ed esperimenti», en E. Lo SARDO, cit en la nota 22, páginas 217-256.

${ }^{108}$ En De magnete (Londres, 1600), Libro VI, Capítulo III, W. GILBERT consideraba que la Tierra era un gran imán que rotaba diariamente debido a ello: "una calamita esférica situada en un recipiente sobre el agua, se mueve circularmente sobre su centro (como es manifiesto) en el plano del horizonte en conformidad con la Tierra", y por lo mismo ésta "se halla suficientemente dotada de fuerzas peculiares para el movimiento circulatorion, con lo que el Primum mobile o la esfera de las fijas, es ficticio. La idea procede de PEDRo el PEREGRINo en la Epistola de magnete (1269), Capítulo X, donde pretende que la calamita recibe el influjo de los cielos, de modo que si una esférica se sujeta con pivotes por los polos y se orienta en el meridiano, se moverá con los cielos. El carácter ficticio de este efecto fue usado por los jesuitas para atacar el movimiento diurno, como veremos que hará J. Grandami, a pesar de que GALILEO habia indicado que no era créble en el Didlogo, páginas 439-40, que recogen las investigaciones que hizo sobre el asunto a mediados de 1626. No se puede descartar la posibilidad de que el reloj cósmico fuese una trampa para poner en ridículo a los copernicanos que, como Peiresc, según veremos enseguida, confiaban en que se pudiese probar con él el movimiento terrestre. Cf. M. BALDWIN, "Magnetism and the anti-Copernican Polemic" Journal for the History of Astronomy, XVI (1985): 155-174.

${ }^{109}$ Carta del 21 de Mayo de 1633, en Lettres de Peiresc aux Frères Dupuy, Vol. II. Peiresc cuenta que Kircher estuvo en Aix con noticias y "secretos de la naturaleza", como un reloj consistente en un canal practicado en un corcho y relleno de semillas que van con el Sol aunque esté nublado y que, aunque él no tuvo ocasión de examinarlo, lo vio el Elector de Maguncia. 


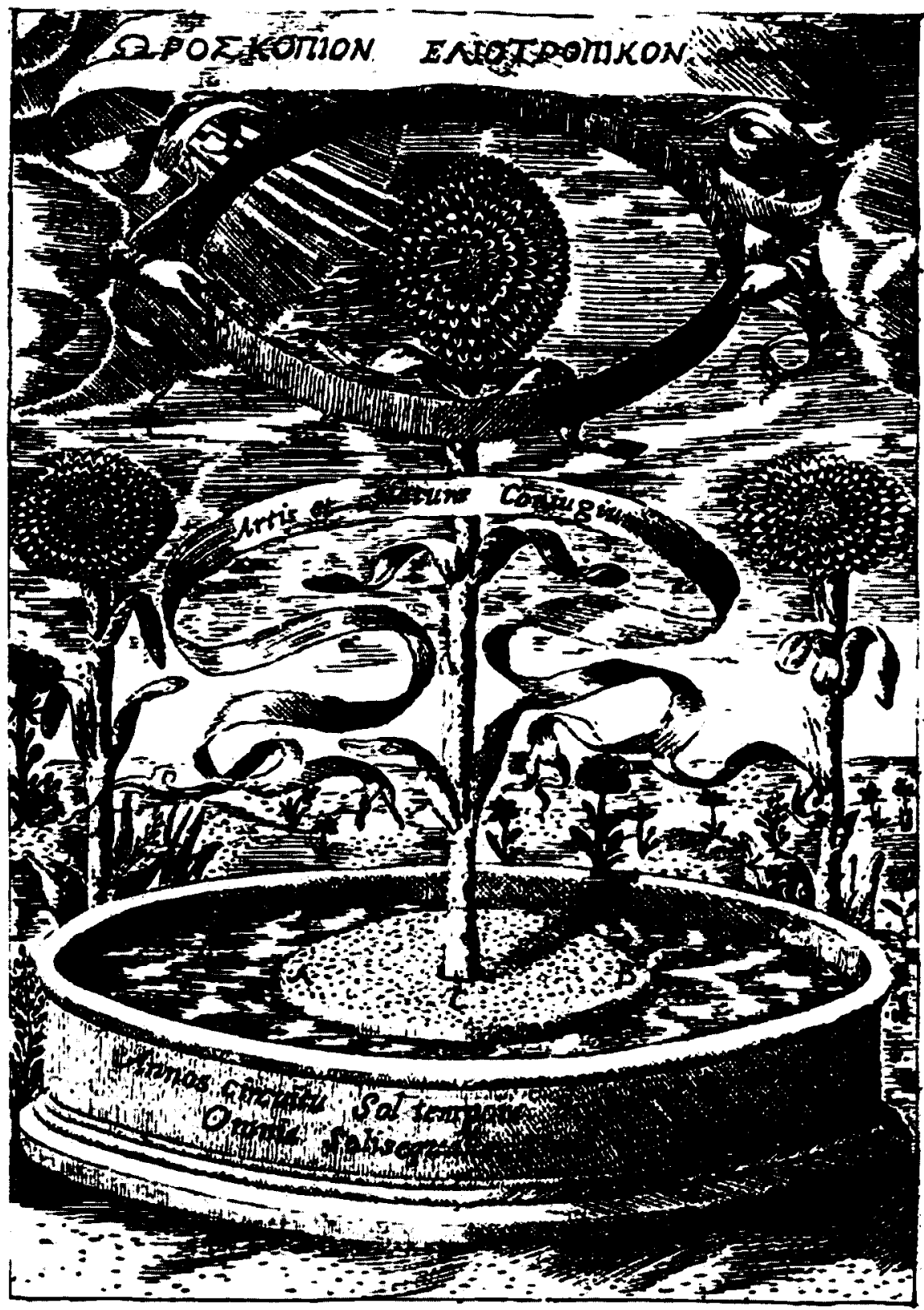

Figura 6. El reloj de girasol debía ponerse en hora todos los días al amanecer. Kircher, Magnes, sive de arte magnetica (Roma, 1641), página 736 
de Pietrasancta, informó a Galileo de la existencia del reloj, confesando ignorar su fundamento, ${ }^{110}$ y quince días más tarde le sugería que así como una gota imita la forma esférica del océano, tal vez una piedra (sobre todo si es preciosa) se mueva en el agua como la Tierra en el éter. ${ }^{111}$ Pero Galileo conocía los trucos para hacer que un cuerpo sólido quedase flotando en medio del agua sin ascender ni descender, tal como expondría en la llamada "digresión hidráulica" de las páginas 113-116 de los Discorsi (1638), así como el modo de jugar con los imanes. En su respuesta del 12 de Mayo de 1635 desde el arresto domiciliario de Arcetri ${ }^{112}$ le dice a un Peiresc excesivamente dispuesto a rendirse al magnetismo cósmico que sería gran maravilla que el globo girase por una fuerza oculta, si bien el carácter "oculton de la fuerza puede ser más trivial, ya que él mismo había fabricado algo semejante años atrás mediante una esfera de cobre con un hierro dentro, de la misma densidad que el agua para equilibrarse en ella sin flotar ni hundirse. Todo el milagro consistiría en esconder un reloj mecánico corriente en el pedestal, gracias al cual se movería un imán que haría a su vez rotar a la esfera. Si el reloj de Linus no se basase en este truco ingeniado por él, comenta, será algo realmente "celeste y divino». En efecto, seis años más tarde Kircher desveló en la página 310 de Magnes, sive de arte magnetica (Roma, 1641) la trampa de Linus que ya Galileo había insinuado a Peiresc. De ese modo se daba al traste con las posibles especulaciones copernicanas al estilo de Gilbert y Kepler, que no se habían disparado gracias en parte a las explicaciones de Galileo a Peiresc.

Pero Kircher tenía otro as en la manga para mostrar esta vez el magnetismo o simpatía universal: el reloj vegetariano. Se trata de aquel reloj mencionado ya por Peiresc en Mayo de 1633, que según pretendía Kircher funcionaba gracias

110 Carta del 1 de Abril de 1635, Opere di G. Galilei, XVI: 245 y sig.

111 Carta del 14 de Abril de 1635, Ibidem, XVI: 259 y sig.

112 La carta no está en las Opere, pues se perdió hasta que dio con ella STILLMAN DRAKE, "A long-lost Letter from Galileo to Peiresc on a Magnetic Clock», en B. DIBNER y S. DraKE, $A$ Letter from Galileo, Norwalk, Conn.: Burndy Library, 1967: 14-36. Se puede encontrar también en http://www.Stanford.edu/— mgorman/Kircher/Galileopeiresc.html. A. Beltrán me ha hecho ver que Galileo llevaba casi veinte años sospechando de la ciencia de los jesuitas; por ejemplo, en una carta a Marsili del 21 de Abril de 1629 (Opere, XIV: 36), desconfiando de los ataques a Gilbert de N. CABEO en la Philosophia magnetica (Ferrara, 1629), apunta: «si el jesuita escribe contra Gilbert, creo que no veremos mayores sutilezas de las acostumbradas en estos reverendos, los cuales, a mi parecer, son bastante triviales en cuestiones filosóficas." También en este juicio, como en tantos otros, Galileo se adelantó a sus contemporáneos. 
a una raíz ${ }^{113}$ (Figura 7). La noticia le llegó a Galileo a través de J. Bouchard y R. Magiotti. ${ }^{114}$ Según el primero, el reloj funciona con una raíz que sigue al Sol flotando en agua y que le fue entregada por cierto árabe. El segundo atribuye a Kircher una falsa estancia en Oriente y describe el reloj como un flotador de corcho con una aguja que señala las horas y que gira merced a una raíz que sigue al Sol. El propio Kircher relataría más tarde que la misteriosa «substancia” heliotrópica procedía de un mercader árabe con el que pegó la hebra casualmente en Marsella. Tras una larga charla, como Kircher calculase la hora con un anillo horario, el árabe le confió que en su país un médico famoso tenía un artificio el cual, "mediante cierta materia, se giraba siempre hacia el Sol y daba las horas de día y de noche». El árabe dice no saber de qué substancia se trata. Pero, mira por dónde, llevaba un poco de dicha materia en la faltriquera que le propuso cambiar por su anillo horario. "Dicho y hecho", señaló Kircher. Poco después usó la materia en cuestión para confeccionar un reloj que mostró en Roma a "eminentísimos varones", algunos de la Compañía, a quienes explicó que el efecto no procedía de las cualidades primarias (las cuatro elementales y manifiestas) de la substancia, sino de "cierta virtud específica" u oculta. ${ }^{115}$ Desgraciadamente (o tal vez por suerte), la substancia árabe se pudrió con la humedad y para mantener el espectáculo recurrió al ingenio del Padre Linus ya mencionado.

Las primeras noticias de 1633 sobre un reloj vegetal (entonces de semillas) llegó también a oídos de R. Descartes quien escribió a Mersenne pidiéndole in-

113 P. Gassendi, De vita Peireskii, 1651, en Pietri Gassendi... Opera omnia in sex tomos divisa, París, 1658, Tomo V: 239-362, página 321. Este reloj no debe confundirse con el de la Figura 6, donde un girasol que flota sobre agua indica las horas mientras brilla el Sol, publicado en Magnes, sive de arte magnetica (Roma, 1641), página 736 y sigs. (Roma, 1654, página 644).

114 Sendas cartas desde Roma, el 18 de Marzo de 1634, en Opere di Galileo, XVI: 63 y sig, 65 y sig. Todavía tres años más tarde Magiotti se quejaba a Galileo (carta del 16 de Mayo de 1637, Opere di Galileo, XVII: 80) de que Kircher se había ido a Malta con el Landgrave de Hesse sin darle la raíz magnética prometida.

115 Magnes, sive de arte magnetica (Roma, 1641), páginas 373-9. Ahora ya no se trata de una raiz o semilla como ocho ańos antes, sino una inespecífica substancia. Tras la marcha de Kircher a Roma en el Otoño de 1633, el 7 de Enero de 1634, le escribla desde Avińón Antoine François Payen preguntándole qué debía hacer con el saco de pipas que se había dejado, ya que "no conservan mucho tiempo la propiedad de girar como la planta" (Correspondencia de Kircher, Pontificia Università Gregoriana, Roma, Volumen 568, folio 255). 
formación del reloj "sans Soleil" que se le antoja un tanto difícil de fabricar. ${ }^{116}$ También Peiresc y Mersenne desconfiaban del artilugio, especialmente por las dificultades para hacerse con una muestra de la substancia maravillosa, por lo que escribía el primero: "Et pour l'horloge du solanum, il n'a pas tenu à escripre et à toutes instances humainement possibles; mais nous ne l'avons sçeu obtenir et je suis de votre avis et n'en crois non plus que vous». ${ }^{117}$

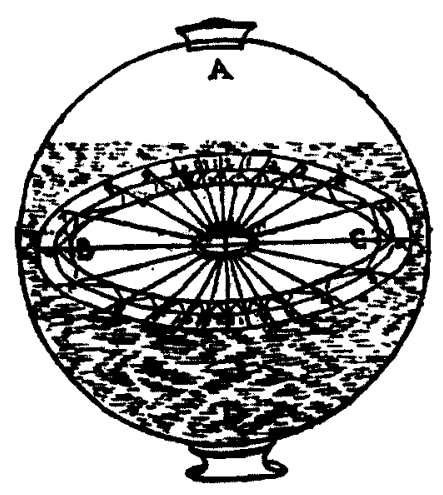

Figura 7. Reloj magnético-vegetal de Kircher que sigue los movimientos del Sol día y noche.

Magnes, sive de arte magnetica (Roma, 1641), página 738.

116 Carta del 22 de Julio de 1633, Oeuvres de Descartes, I: 266-269. Anteriormente G. Wendelin había escrito a Mersenne el 15 de Junio de ese mismo año (Correspondance du P. Marin Mersenne, III: 430 y sig.), describiendo el heliotropo magnético del jesuita ingles (Francis Hall, alias Franciscus Linus) en el que una esfera de cera giraba horizontalmente siguiendo al Sol, pues pretende que "en este mundo todos los cuerpos son magnéticos». Antes aún, el 21 de Mayo, cuando Kircher era huésped de Peiresc, éste informaba a los Dupuy del reloj magnético. Finalmente el propio Kircher harfa una demostración en el Colegio jesuítico de Aix el 3 de Septiembre en presencia de Peiresc. La demostración del reloj magnético resultó frustrante, pues en realidad se trataba de una vulgar brújula (usaba una trozo de calamita) que, en cualquier caso, no marcaba las horas. C. de WAARD en Correspondance du P. Marin Mersenne, III: 427, señala la existencia de un informe de Peiresc (Carpentras Bibl. d'Inguimbert, ms. 1864, fol. 215 sigs.) que transcriben y comentan HANKINS y SILVERMAN, op. cit. en la nota 1, páginas 23-27. Estos autores tratan a Kircher con caridad (ibidem, págs. 32 y sig.): no es que fuese un falsario, sino que para él los aparatos y experimentos no servirían para descubrir cómo opera la naturaleza, sino para ejemplificar cómo se pueden imitar sus efectos maravillosos debidos a causas por siempre ocultas (como el mecanismo de relojería oculto en la peana). Sea.

117 Peiresc a Mersenne, 13-15 de Octubre de 1633, Correspondance du P. Marin Mersenne, III: 504. Esto se escribe poco después de las primeras dudas de la Primavera y Verano de 1633 sobre Kircher y su misterioso Barachias, lo que corroboró las tendencias inventivas del jesuita. 
Descartes leyó y tomó algunas anotaciones del Magnes (1641) de Kircher que copiaría Leibniz, e intercambió opiniones con Constantijn Huygens en Enero de 1643. Descartes comentaba: «el jesuita escribe muchas fanfarronadas [farfanteries], es más charlatán que sabio. Entre otras cosas habla de una substancia que había obtenido de un mercader árabe que se vuelve hacia el Sol por el día y por la noche, pero no explica en absoluto de qué materia se trata. El Padre Mersenne me escribió antaño, hace unos ocho años [en el verano de 1633], que

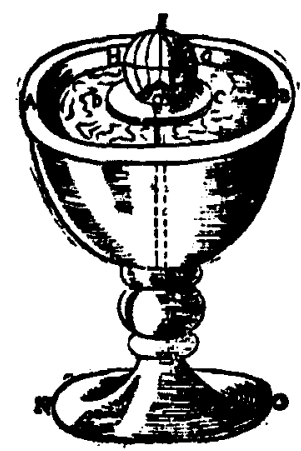

Figura 8. Según J. Grandami S.J., la terrella o calamita esférica, libre de girar sobre el agua con el eje normal al horizonte, sefiala el Norte y no declina. Dibujo reproducido en S. J. Kestler, Physiologia Kircheriana experimentalis (Amsterdam, 1680), página 156 era simiente de heliotropo, cosa que no creo, a menos que esa grana tenga más fuerza en Arabia que en nuestro país, pues tuve la ociosidad de realizar la experiencia pero no resultó en absolutom. ${ }^{118}$

Las farfanteries magnéticas no acabaron ahí. En 1642 circuló por la República de las Letras un tratado sobre el imán debido con toda probabilidad al jesuita J. Grandami, rector del Colegio de Rouen, en el que se exponía un instrumento notable que señalaba el Norte sin declinar. Grandami publicó el dispositivo tres años más tarde y fue reexpuesto en 1654 por Kircher en la tercera edición de Magnes. ${ }^{119}$ Kircher dice que la experiencia fue hecha por Grandami en presencia del también jesuita N. Zucchi y él mismo. Consistía en colocar en una copa de agua un corcho que podía girar libremente sobre un pivote (Figura 8). Sobre el corcho se ponía un imán esférico con el eje perpendicular al horizonte. Habrá entonces un punto del ecuador del imán que se situará siempre en el meridiano local.

118 Carta a C. Huygens del 14 de Enero de 1643, Oeuvres de Descartes, III: 803-4; véase también la carta anterior de Huygens del día 7 del mismo mes, loc cit., III: 801-3. El 5 de Septiembre (loc. cit, IV: 717-8) escribirá a Clovius reiterando la misma opinión: «hace tiempo que he recorrido a Kircherus [Magnes], opero no he hallado en él nada sólido. Sólo se encuentran baladronadas [farfanteries] a la italiana, por más que sea alemán de nacionalidad".

119 J. GRANDAMI, Nova demonstratio immobilitate Terrae petita ex virtute magnetica, La Flèche, 1634, página 45 y siguiente. Se pretende refutar a Galileo señalando que, del mismo modo que un imán suspendido no rota (cosa que ya sabía Galileo), la Tierra suspendida en el aire, tampoco, pues tanto uno como otra se orientan respecto al cosmos y se mantienen en reposo. Véase también la tercera edición de Magnes, sive ars magnetica, Roma, 1654, donde aparece una nueva Proposición VI: «Magneticum globum preparare qui portatus, constanti lege, meridianam lineam toto orbe demonstret" (páginas 310-12). 
Grandami atribuía el efecto a la "correspondencia» entre los meridianos de la Tierra y del imán. Ni que decir tiene, como señalará Kircher, que tal aparato posee una gran utilidad para la navegación al hurtarse a las desviaciones a Este y Oeste de las agujas de las brújulas ordinarias.

En Enero de 1642, Constantijn Huygens le escribió a Descartes diciendo haber visto un tratado del imán difícil de leer por el mal papel, la abundancia de faltas y la obscuridad del contenido que no obstante contiene alguna experiencia nueva que no conocía. Descartes le respondió pocos días después tras haber leído el manuscrito diciendo que «como vos, no me arrepiento de haber leído el Traité de l'aymant por más que ninguna de sus razones valga", ya que contiene una experiencia nueva. ${ }^{120}$ Esta experiencia es la de Grandami y dejó tal huella en Descartes que la dio por buena sin realizar el experimento por no disponer de imanes esféricos. En Mayo de 1643, Descartes contó a Huygens y a Mersenne cómo se podría explicar esa curioso fenómeno, explicación que publicará el siguiente año en sus Principia Philosophiae ${ }^{121}$. Su idea es que la atracción se debe a la virtud magnética que corre entre los Polos y el Ecuador por la superficie de la Tierra, así como radialmente entre el centro y la superficie. (En los Principia dicha virtud no es sino un chorro de partículas en forma de rosca que encajan en los poros asimismo con rosca de los cuerpos magnéticos y los orientan en la dirección de la corriente.) La declinación magnética se debe a que la corriente superficial se desvía aquí y allá por las irregularidades de la corteza; pero el aparato de Grandami, al tener el eje (y por ende los poros) perpendicular a la superficie, recibe principalmente la corriente radial que no se halla tan afectada por las irregularidades como la horizontal. Añade que sería muy fácil comprobar experimentalmente si su conjetura es correcta, pero no lo hizo.

Quien hizo los experimentos ya en Octubre de 1641 fue Pierre Petit, físico, astrónomo, comisario de artillería de Richelieu y más tarde intendente general de fortificaciones. Era también un miembro destacado de la academia de Montmor y formó parte del círculo de Mersenne, donde frente a los cartesia-

${ }^{120}$ Cartas del 20 y del 31 de Enero de 1642, Correspondance du P. Marin Mersenne, XI: 23 y sig., y 28 y sig.

${ }_{121}$ Véanse las cartas del 24 y 30 de Mayo de 1643, Correspondance du P. Marin Mersenne, XII: 172 y 196. La explicación del efecto aparece en Principia (1644), Parte IV, \$170, Oeuvres, VIII: 301-2, donde, siguiendo su manía de no citar a nadie, sefiala que el efecto se produce según "algunos». 
nos, dados a confiar en la bondad del esquema general mecánico de su maestro, se hacía hincapié en el interés de la experimentación para la construcción de las teorías. Petit escribió Une observation sur l'aimant controlée et refutée 122 en la que examinaba la pretensión de Grandami y descubría su falsedad. Con pulcritud, riqueza de detalles y determinación a aprender de la experiencia, repitió varias veces el experimento con dos imanes y descubrió que el meridiano marcado en ellos se alineaba con el meridiano local con un error de entre $5^{\circ}$ y $13^{\circ}$. Al invertir los imanes, se intercambiaba la posición de los hemisferios Este y Oeste, algo que había pasado desapercibido a Grandami y que contradecía su afirmación de que conservaban la posición relativa a las estrellas. Mediante ulteriores experimentos descubrió que inclinando el eje, se vuelve al Norte uno u otro de los hemisferios del imán, por lo que "el eje tiende siempre en línea recta al Polo de la Tierra" y trata de alinearse hacia el Polo como en los imanes usuales. Conjeturaba que si el eje no tuviese inclinación alguna, no mostraría ningún movimiento de orientación, cosa que trató de comprobar suspendiendo los imanes de una red de seda sin resultados claros, por lo que dejó su dilucidación para más adelante.

\section{Animadversión contra el vacio}

La publicación del aparato de Grandami por parte de Kircher trece años más tarde no contribuyó a mejorar su imagen de persona informada y fiable. ${ }^{123}$ Por más que los cartesianos se dejasen llevar por sus intuiciones mecánicas sin prestar la suficiente atención a los experimentos, su dogmatismo era más flexible que el de los padres, por lo que estudiaron con seriedad el problema del vacío cuya imposibilidad era un asunto central de la filosofia de Descartes. Para los jesuitas, la negación de la existencia del vacío resultaba excelente para atacar el epicureismo, cuya física se basaba en los principios de los átomos y el vacío que interactuaban al azar en contra de la Providencia. Ya hemos mencionado que se oponían especialmente al mecanicismo epicureísta que se enfrentaba directamente a la explicación católica de la transubstanciación. Así pues, Kircher atacó la posibilidad de

122 Con fecha 1 de Octubre de 1641; Correspondance du P. Marin Mersenne, X: 845-53. Los editores indican que Mersenne le envió este escrito a Huygens quien normalmente se lo comunicaria a Descartes, pero no hay constancia de ello en la correspondencia.

${ }^{123}$ El experimento de Grandami siguió figurando en la antología de Kircher seleccionada por su discípulo J. S. KESTLER, Physiologia kircheriana experimentalis, Amsterdam, 1680, páginas 156 $y$ siguiente. 
producir un vacío, ${ }^{124}$ basándose en que el sonido se transmite por los espacios supuestamente vacíos, siendo así que se trata de una alteración local en un medio continuo como el aire. En un ladillo señalaba el origen de su oposición al vacío: "sententia de vacuo periculosa in fide». El experimento al que alude se basaba en una afirmación de Galileo en los Discorsi (página 65), según la cual la resistencia a la fractura de una columna de agua es igual al peso de una columna de dieciocho codos $(10,5 \mathrm{~m})$, razón por la cual las bombas de succión fracasan por encima de esa altura. Entre 1641 y 1643 G. Berti hizo en Roma un experimento muy vistoso inspirado en los Discorsi (y que inspirarfa a su vez a $\mathrm{E}$. Torricelli) consistente en erigir sobre un recipiente de agua un tubo de dieciocho codos terminado en un globo de vidrio. Se llenaba el conjunto de agua y se observaba hasta dónde descendía y qué quedaba en el recipiente de vidrio. ${ }^{125}$ Kircher cuenta que sugirió introducir una campanilla en el recipiente de vidrio y accionarla desde fuera con un imán para comprobar si se oía. Como era así, quedaba demostrado que el recipiente no estaba vacío y que había en él un medio vibrante que transmitía el sonido. Aunque E. Maignan indicó que el sonido podía transmitirse a través del soporte que unía la campana al aparato, Kircher prefirió no enterarse. Tampoco quiso enterarse de que, en 1644, E. Torricelli supuso que el peso de la columna de agua estaba equilibrada por el peso del aire atmosférico ( $y$ no por la resistencia a la fractura debida al vacío), con lo que bastarían $75 \mathrm{~cm}$. de mercurio (catorce veces más denso que el agua) para hacer la experiencia del vacío. Consiguientemente resulta un tanto patética su petulante afirmación en la Musurgia de 1650 de que no se sabe qué sostiene a los líquidos a una altura fija. Sobre todo teniendo en cuenta que entretanto hablan tenido lugar los espectaculares experimentos públicos de B. Pascal, el ascenso de su cuñado al Puy de Dôme y su polémica con el jesuita E. Noël sobre el vacío. Tampoco pareció rectificar en su vida a pesar de los experimentos desarrollados luego por la Accademia del Cimento y por R. Boyle quien publicó la Ley de Boyle. ${ }^{126}$

${ }^{124}$ Musurgia universalis (Roma, 1650), páginas 11-13. Sobre la oposición de los jesuitas al vacío por sus consecuencias peligrosas para Aristóteles y la eucaristía, véase el Capítulo VI de la tesis de M. J. Gorman citada en la nota 5. 1648.

${ }^{125}$ El experimento fue descrito por R. Magiotti a Mersenne en una carta del 12 de Marzo de

${ }^{126}$ Kircher reiteró su posición de 1650 siete años más tarde en su aportación al libro de su discípulo G. SCHOTT, Mechanica hydraulico-pneumatica, Wurzburgo, 1657. En este momento los investigadores de la Accademia del Cimento iniciaron los experimentos que publicaron en los Saggi di naturale esperienze fatte nell'Accademia del Cimento, Florencia, 1667, extraordinarios por la riqueza instrumental y la precisión. Véanse las páginas 96-100 donde exponen los experimentos de 
Hasta más avanzado el siglo no se consiguió un dispositivo experimental y un vacío lo bastante perfectos para mostrar la no transmisión del sonido en el vacío. Sin embargo ya en los años cuarenta era dudoso el experimento en que se basaba Kircher y por tanto era precipitada su conclusión en defensa de la fe. Por ejemplo, Mersenne ${ }^{127}$ señala sus dudas sobre el experimento de G. Berti dado que, como indicará también Kircher en Musurgia, el agua alcanzó tan sólo una altura de tres metros (lo que podría explicarse porque el aparato no era estanco y había sobre el agua aire a una presión de 0,7 atmósferas, equivalentes a 7,5 metros de agua). Además se observó que el agua del tubo «hervía», suministrando otra fuente posible de aire al recipiente de vidrio. Más adelante Boyle realizó experimentos del vacío en el vacío donde medía el nivel de evacuación de la campana de una máquina pneumática mediante un tubo de Torricelli en su interior. ${ }^{128}$ De este modo comprobaba la dificultad de asegurar una estanqueidad total y de desalojar completamente el aire, a la vez que mostraba que era la presión del aire la causante del fenómeno.

Así pues, para los años setenta ya no se podía dudar razonablemente de los experimentos del vacío, de la posibilidad de evacuar el aire de determinados lugares y de la consiguiente desaparición en ellos de la presión, así como de que la presión ordinaria del aire se debía al peso de la atmósfera, por más que se pudiese discutir por qué el aire (pero no el agua) era elástico o si acaso permanecería en la campana un éter sutil que pudiera transmitir las vibraciones de la luz, pero no las del sonido o la presión que se debían al aire. Pues bien, incluso el jesuita G. Pardies desconfiaba del experimento de Kircher y criticaba el experimento de la Accademia del Cimento por su resultado, pues para entonces la audición del sonido era ya un indicio de que el vacío no era perfecto. ${ }^{129}$ Pardies era un jesuita inteligente que tuvo problemas con sus superiores por su libertas philosophandi, si bien, jesuita al cabo, hubo de condescender lo que nos priva de saber qué pensaba exactamente. Dado que para entonces Boyle había conseguido apagar el

transmisión del sonido en el supuesto vacío, sin que fuesen capaces de evitar completamente el contacto de la campana y la transmisión por sólidos ni de asegurar la ausencia de vapores de mercurio en el vacio torricelliano. La actitud de no ir más allá de lo que los experimentos autorizan contrasta con la confianza de Kircher en un solo experimento mal controlado.

127 Carta a los galileanos italianos del 1 de Julio de 1643, Correspondance, XII: 20-227.

${ }^{128}$ Experimento XVII de New Experiments, Londres 1660, en T. BIRCH (Ed.), The Works of the Honourable R. B., I: 33-39.

129 Carta a Oldenburg del 3 de Marzo de 1672; The Correspondence of Henry Oldenburg, VIII: 452. 
ruido de un despertador evacuando el aire del recipiente, Pardies confiesa fiarse infinitamente más de Boyle por su precisión única que de su correligionario. Hacia las mismas fechas, en 1671, Christiaan Huygens comentó la Musurgia de Kircher seńalando ${ }^{130}$ que sus experimentos sobre el vacío estaban mal hechos precisamente porque se oía la campana. Es decir, para comienzos de la década de los setenta, la idea de Torricelli estaba tan bien confirmada por una gran variedad y riqueza de experimentos que podía utilizarse para calibrar con ella si los experimentos estaban bien o mal hechos: si se oía el sonido, o había aire o había transmisión de vibraciones por el soporte sólido. El propio Huygens diagnosticaba que en la parte superior de tubo de Berti había aire, dado que el propio Kircher señala que la columna de agua era de diez pies (menos de un tercio de lo necesario para equilibrar sola el peso del aire atmosférico). Más tarde, el 19 de Diciembre de 1674, Huygens repitió el experimento y no oyó el despertador. ${ }^{131}$ Pero Kircher no volvió sobre su dictamen acerca del vacío de 1650 , que ya entonces era sospechoso tras los experimentos y polémicas de Pascal en 1647-48.

\section{El Fénix vegetal}

Aunque los matemáticos (uno de cuyos dominios era la pneumática) desconfiasen pronto del jesuita, los naturalistas baconianos estaban muy interesados por la supuesta riqueza de sus informes y experiencias. Pero incluso Boyle y los experimentalistas de la Royal Society que adoraban los hechos terminaron desconfiando de Kircher. Un par de ejemplos bastarán para mostrar esa desconfianza en campos en los que estaba excluido un tratamiento exacto y un juicio tajante. Pues, en efecto, el anti-dogmatismo de Boyle y adláteres hacía muy difícil juzgar la calidad de los informes de observaciones y experimentos por su contenido (a la manera en que un astrónomo puede despreciar una observación de la Luna llena a mediodía o un pneumático, el vacío en el que se oye una campanilla). Por consiguiente, lo único que les quedaba era hacer mucho hincapié en que las observaciones procediesen de personas de calidad, dignas de crédito. De esta manera Boyle no podía menos de prestar oídos al "diligente" Kircher que trabajaba en la universidad matriz de los jesuitas, publicaba obras lujosísimas con el patrocinio de Papas y Emperadores, y se hallaba conectado con una amplia red de misioneros bien formados y dispersos por las Indias.

130 Oeuvres, XX: 111 y sigs.; especialmente 123-28.

${ }^{131}$ Ibid., XIX: 239. 
Con todo, aunque Boyle y la Royal Society no pudiesen competir con dicha red mediante sus cartas esporádicas a navegantes, comerciantes y diplomáticos, resultaba que las obras de Kircher estaban llenas de "instrumentos" y "experiencias" de laboratorio que resultaban relativamente más fáciles de controlar que la generación del ganso escocés o los desagües submarinos del Polo Norte. Y aunque algunos fallos de replicación podín tener sus disculpas, tanto va el cántaro a la fuente que al fin se rompe.

Como ya vimos, en 1658 Oldenburg respondía a una carta de Boyle diciéndole que en su viaje por Europa no pasaría por Italia, por lo que no podría traerle noticias del "Mundo subterráneo del industrioso Kirchern. ${ }^{132}$ Boyle estaba especialmente preocupado por dos experimentos, uno en el que se demostraba el influjo de la Luna sobre las aguas marinas para producir las mareas y otro sobre la resurrección de animales y plantas tras su destrucción. Nos ocuparemos ahora de este último y dejaremos el primero para el apartado siguiente.

El experimento de Kircher consistía en cerrar herméticamente en un recipiente de vidrio las cenizas de una planta que se resucitaba luego mediante un suave calor, al modo indicado por el médico paracelsista J. Duchesne (Quercetanus, c. 1544-1609). Kircher estaba muy satisfecho de esta ocurrencia que enseñaba en el Collegio Romano a los visitantes distinguidos, como a una tal Alexandra (llamada así por el Papa Alejandro VII) que había sido reina de Suecia con el nombre de Cristina y que se había convertido al catolicismo después de matar a Descartes a madrugones. La conversa Alexandra, aficionada a la alquimia y a la intriga, fue muy adulada en Roma con honores y celebraciones emblemáticas. El 31 de Enero Kircher la entretuvo en el museo del Collegio Romano con el Fénix vegetal, símbolo de su regeneración y conversión, antes de que esa misma tarde asistiese en el Palacio Barberini a una ópera compuesta para ella. ${ }^{133}$ También le dedicó su Itinerarium extaticum (Roma, 1656).

132 Carta del 19 de Marzo de 1658; The Correspondence of Henry Oldenburg, I: 155-56. El año anterior KIRCHER había publicado en Roma el Iter extaticum II, qui mundus subterraneus prodromus dicitur, mientras que el Mundus subterráneus salió en 1665.

${ }^{133}$ La vita humana ovvero il Trionfo della Pietà (1656) de Marco Marazzoli, músico asociado a la casa Barberini y luego al Papa Alejandro VII, con un libreto engorroso de G. Rospiglioso lleno de personajes alegóricos: la Inocencia, la Vida, el Placer, el Entendimiento, etc. Marazzoli gozó de prestigio en su día pero hoy se interpreta poco. Una excepción es Il Trionfo de Glasgow del 9 de Agosto de 1990. Pueden ofrse tres cantatas grabadas recientemente con melodias y vocalizaciones seductoras y sinuosas interpretadas por Arianna Savall y el Ricercar Consort (MIR 9931, 2003). 
Kircher practicaba también la resurrección de invertebrados. Según cuenta B. de Monconys en su Tercer viaje a Italia, ${ }^{134}$ en 1664 Kircher le informó de que si se moja con agua de lluvia polvo de moscas secas expuesto al sol, en una hora surgen moscas vivas. Y según se desprende de la mencionada carta de Oldenburg a Boyle, Kircher hacía crecer de nuevo a los moluscos a partir de sus conchas pulverizadas, sembradas e irrigadas con agua marina. La idea detrás de todo esto es que la reproducción depende de una virtud plástica que no es fácil de destruir y que permanece en las cenizas o el polvo. ${ }^{135}$

Boyle estaba interesado en la síntesis orgánica y deseaba tener más detalles sobre los materiales y procedimientos de las experiencias de resurrección de Kircher. Aunque Oldenburg no iba a Italia, no olvidó el encargo de Boyle y lo pasó a otros. Como ya mencionamos, R. Southwell le escribió al año siguiente desde Francia diciéndole que se había encontrado con W. Paget procedente de Roma quien le recomendaba visitar a Kircher si deseaba conocer los detalles de la resucitación del Fénix vegetal. «Me dijo - - scribe Southwell— que estuvo con él y recuerda haber visto en un frasco una planta de la longitud de un dedo con una suerte de cenizas en el fondo, pero me di cuenta de que no había sido cuidadoso en su observación»" ${ }^{136}$ Southwell acabó dejándose caer por Roma a principios de 1661 e intimó con Kircher a quien encontró erudito, industrioso y de trato llano, aunque demasiado crédulo y dado a improvisar. ${ }^{137}$ Le contaba a Boyle que si bien no presenció el experimento del Fénix vegetal, le dieron una flor nacida de las cenizas de una planta así como la receta que es larga e intrincada y que le llevaría a su vuelta. Ignoro qué fue de la receta, pero no debió de convencer a un Boyle cada vez más escéptico a pesar de su disposición favorable, como buen cristiano, hacia la resurrección. En efecto, como vimos más arriba, en 1675 mencionaba el Fénix vegetal de Kircher y, aunque compartía con él la posible explicación del fenómeno, decidió no utilizarlo, aunque le venía bien, dado que llevarlo a cabo exigía tiempo y no

${ }^{134}$ BalthaSAR DE MONCONYs, Journal des voyages de M. de Monconys, Lyon, 1665.

${ }^{135}$ Y que puede organizar la materia. De ahí las imágenes de animales en las rocas (nuestros fósiles) que son el resultado de la infiltración de semillas de peces y crustáceos. Sólo cuando la virtud plástica cae en una matriz de la misma especie produce descendientes idénticos a los padres, pero en otras matrices, produce quimeras como ocurre con las fieras dadas a copular con todo lo que se pone por delante. En el cieno o la suciedad, produce invertebrados, reptiles y aún ratones sin necesidad de progenitores vivos, razón por la cual Noé pudo prescindir de incluirlos en el Arca.

${ }^{136}$ Carta del 28 de Octubre de 1659, The Correspondence of $H$. Oldenburg, I: 323-25.

137 Southwell a Boyle, 30 de Marzo de 1661 (T. BIRCH, The Works of the Honourable Robert Boyle, VI: 298-300), donde expone la historia kircheriana del ganso escocés y los percebes. 
estaba "totalmente de acuerdo con todas las circunstancias e inferencias que parecen corresponderle». ${ }^{138} \mathrm{La}$ diferencia entre Boyle y Kircher no estriba tanto en las doctrinas consideradas cuanto en las estrecheces experimentales a que estaban dispuestos a someterlas. Por ello cabe pensar que el minucioso Boyle no sacó nada en limpio de la receta que Kircher le dio a Southwell y no quiso utilizar un experimento sospechoso que le hubiera venido de perlas. En efecto, como bien dice San Pablo en 1 Corintios, XV:35-38 (cosa que recuerda Boyle en su ensayo sobre la resurrección), no resucitaremos exactamente con los mismos cuerpos que teníamos, pues podrían estar para entonces corrompidos, agusanados o tornados en cenizas, sino que recuperaremos el cuerpo a partir de una semilla con la que se forma el organismo completo. El Apóstol expresa a las mil maravillas la doctrina de la «virtud plástica» de los herméticos que permanece indeleble en medio de las cenizas para sintetizar en condiciones adecuadas la carne u órganos del original.

Como veíamos más arriba, en lugar del experimento de Kircher, Boyle mencionó otro hecho con amapolas por "dos personas eminentes conocidas mías" que son "personas de gran veracidad y juicio", dando a entender por oposición que, al menos en este caso, Kircher no le merece tal consideración. ${ }^{139}$ A pesar de

138 Some Physico-Theological Considerations about the Possibility of the Resurrection, Londres, 1675, en HUNTER-DAVI, The Works, VIII: 295-313, página 302. En el no publicado Essay of the Holy Scriptures (c. 1649-54), Ibid., XIII: 173-223, página 204, Boyle alude al cabalista francés J. GAFFAREL, Curiosités inouyez sur la sculpture talismanique des persans, horoscope des patriarques et lecture des estoiles (1629-30), Parte I, Capítulo 5, donde parece dar a entender que Étienne de Clave se ocupó del Fénix vegetal. También alude a Quercetanus Redivivus, seu ars medico-hermetica, ex Quercetani scriptis digesta opera (1648), Capítulo 23, donde se atribuye el experimento a un médico polaco. Boyle toma la coincidencia de tantos autores no como indicio del carácter libresco y recopilador de estos químicos, sino como indicios de la credibilidad del fenómeno, y apunta la explicación hermética usual: "la esencia seminal de una planta quemada se puede conservar en sus partes incombustibles, como prueba el hecho de que en el hielo de las cenizas disueltas en agua de algunas de ellas se represente la forma o imagen de la planta prístina». Véanse al respecto sus New Experiments and Observations touching Cold, or an Experimental History of Cold, Londres, 1665, The Works, IV: 202-458, página 448, donde vuelve a mencionar que cuando se congela el agua en que se han disuelto las partes salinas de una planta, el hielo presenta la imagen de la planta en cuestión, como cuenta J. Gaffarel que hacía diariamente É. de Clave.

${ }^{139}$ Possibility of the Resurrection, loc. cit., VIII: 303. En la sección 35 de los Physico-Chemical Essays (Londres, 1661), The Works, II: 93-113; 109-110, Boyle se muestra escéptico sobre la posibilidad de recomponer organismos a partir de cenizas o restos como propone Kircher en Ars magna, Parte V, Capítulo 3, con conchas regadas con agua marina. Si fuese cierto, sería, más que una síntesis de lo disgregado, una suerte de reproducción debida a algunas partículas "imperceptiblemente escondidas en alguna parte del cuerpo destruido", cosa que es posible con los moluscos de Kircher que, siendo viscosos, mantendrían las partes prolificas sin dispersarse del todo. 
que ambos entretuviesen ideas semejantes, Boyle las consideraba con escepticismo y las usaba para sugerir y dirigir experimentos pulcramente realizados, mientras que Kircher, lejos de ponerlas nunca en entredicho, las usaba para suplir los experimentos o para sugerir cómo inventarlos.

\section{Hervores selenitas}

Con todo, la experiencia más efectiva a la hora de desacreditar la ciencia de Kircher entre los experimentadores ingleses fue la de la atracción del agua marina por parte de la Luna. Kircher atribuía las mareas a la acción lunar ${ }^{140}$, cosa obvia para todos excepto para Galileo quien usaba una explicación mecánica de las mareas que exigía el doble movimiento de la Tierra. ${ }^{141}$ Lo nuevo de Kircher es la eexplicación" de la acción lunar. Pretende que se trata de una atracción que ejerce la Luna, no se sabe mediante qué (pues no es partidario de las acciones a distancia), sobre la sal y el nitro contenidos en el agua marina. Si esa acción se produce también con el Sol, ello se debe a que en la conjunción (en la Luna nueva) los rayos de aquél pasaron a través de la Luna y se impregnaron de su virtud. A quien esto le parezca increrble no tiene más que poner un tubo con flores atravesando la pared para comprobar cómo los rayos solares entran en la estancia cargados de olor. Pues igual les pasa con la virtud lunar (Figuras 9 y 10). Salvado este escollo, se ofrece un experimento en favor de la acción lunar sobre las mareas. Al lector actual (y cada vez a más al lector de la segunda mitad del siglo XVII) habría de parecerle extraño llamar experimento a eso, pues no se parece nada a los que hacían Galileo, C. Huygens y los matemáticos, ni a los que hacian R. Boyle, P. Petit y otros experimentalistas en las Sociedades cientificas. No es una medición con un dispositivo experimental capaz de arrojar valores numéricos con los que apoyar o contradecir una teoría articulada matemáticamente, ni es un experimento cuidadosamente controlado, realizado, expuesto y repetible para poner de relieve un efecto natural hasta entonces desconocido. Kircher llama experimento a un historieta llamativa para la imaginación que ayuda pedagógicamente a fijar en la mente una afirmación teórica que en realidad no prueba, ya que mantiene con ella un nexo lógico laxo cuando no peregrino.

${ }^{140}$ En Mundus subterraneus (Amsterdam, 1665), página 130 y siguientes. Repite lo mismo quince años más tarde en la antología preparada por su discípulo S. J. KETLER, Physiologia kircheriana experimentalis (Amsterdam 1680), página 19 y siguientes.

141 Didlogo, Jornada Cuarta; véase Opere VII: 445-446 (páginas 362-363 de la excelente edición espafiola de A. Beltrán, Madrid: Alianza, 1995), donde critica la función lunar porque también hay una pleamar cuando la Luna está bajo el horizonte, mientras que en el medio del Mediterráneo no hay mareas por más que la Luna esté en el meridiano. 


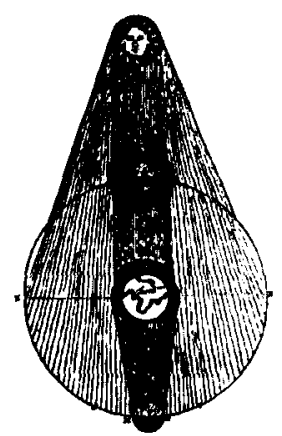

Figura 9. Los rayos solares se impregnan de virtud lunar. Kitcher, Mundus subterranus Amsterdam 1665), I: 135.

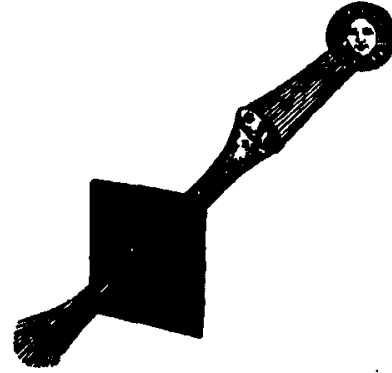

Figura 10. Los rayos solares se impregnan de aromas florales. Kircher, Mundus subterranus

(Amsterdam 1665), I: 134

El experimento (Figura 11) consiste en llenar con mercurio un tercio de un anillo de vidrio de forma oval: « $\mathrm{Si}$ acercas entones una vela desde la zona del punto $\mathrm{C}$, el mercurio al sentir el calor se dilatará y se retirará al

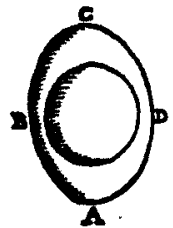

Figura 11 espacio $\mathrm{BD}$ a pesar de las angosturas que lo oprimen, a la vez que retirándose en ondas, dejará casi vacías las partes $\mathrm{C}$ y $\mathrm{A}$, éstas por la fuga del calor, aquéllas por la compresión y condensación del frío. Asi es sin duda como dichas ondas seguirán indefinidamente el curso de la vela, no de modo distinto a como las del mar siguen a la Luna" (Magnes, Roma, 1641, páginas 680-81).

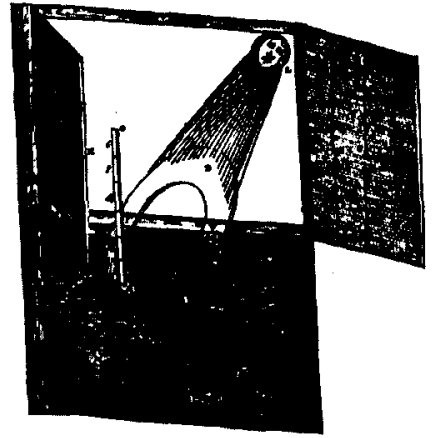

Figura 12. Experimentum $I I$ acerca del influjo lunar sobre el agua salada. Kircher, Mundus subterranus (Amsterdam, 1665), Tomo I, página 130 y siguiente

Tal cosa, de ocurrir, apoyaría muy débilmente la tesis de Kircher pues el efecto térmico de una vela sobre el mercurio no parece tener gran cosa que ver con la acción de la svirtud magnética» de la Luna sobre la sal marina. En Mundus (páginas 130-31) el Experimentum II (Figura 12) mejora mucho en vistosidad. El anillo se llena con mercurio y agua marina, y se añade un tubo vertical graduado por el que asciende el mercurio cuando la mitad del anillo se expone a los rayos lunares durante la Luna llena. Y para acabarlo de arreglar añade que "se puede experimentar esto mismo con agua extraída de bismuto y chupones de olivo cortados en el plenilunion. 
Los detalles del experimento no están claros, por lo que el lector bien dispuesto no sabría bien qué debería controlar para repetirlo, lo que no alentaba a los curiosos a gastar tiempo y dinero en sopladores de vidrio, mercurio, bismuto y otros materiales. Para paliarlo estaba el menos vistoso pero no menos interesante Experimentum I, más fácil de repetir. En él basta exponer a los rayos lunares en un lugar abierto una palangana de agua con nitro y sal común. Al hacerlo, promete Kircher, «verás con admiración cómo el agua comienza enseguida a hervir y a presentar burbujas, tanto más vehementemente cuanto más próximas estén las luminarias sea a la conjunción o a la oposición [i.e., Luna nueva o llena]».

Mundus subterraneus fue muy esperado en Inglaterra y cuando llegó a manos de Oldenburg, éste le escribió a R. Moray informándole de varios experimentos allí contenidos que ponían de manifiesto que la Luna es la única causa de las mareas, merced a la capacidad dilatante que ejerce sobre las aguas nitrosas. Y termina pidiéndole: "Por favor experimente, si no lo ha hecho ya alguno de nuestros amigos oxonienses, si el agua nitrosa mezclada con sal expuesta en una palangana en un lugar al aire libre hierve y burbujea tanto más vehementemente cuanto más próximas se hallen ambas luminarias a los lugares de su oposición o conjunción, como dice nuestro Autor que hará para nuestra admiración». ${ }^{142}$

Cuatro días más tarde Boyle le escribió a Oldenburg agradeciéndole el envío de algunos experimentos sobre la acción de ácidos sobre piedra que ignora si son del Mundus, aunque en cualquier caso «si bien aún no he tenido tiempo de ocuparme de ello, con todo a primera vista estoy tentado a dudar del resultado". Sobre el experimento de las mareas dice que ha recibido la visita de Murry (Moray) para ver si sale el experimento de Kerker (Kircher), sobre el que pronto recibirá un informe. ${ }^{143}$

La respuesta de Moray llegó al día siguiente señalando que si Kircher «no apoya su hipótesis de las mareas mejor que con el experimento que nos mandaste ensayar, no es previsible que consiga aquí seguidores", y pasa a relatar cómo perdió media hora por la noche (al día siguiente era el plenilunio) contemplando una jofaina con litro y medio de agua en la que había disuelto unos veintiocho gramos de nitro y otro tanto de sal marina. A pesar de todo, no vio aquella

142 Carta del 7 de Noviembre de 1665, The Correspondence of Henry Oldenburg, II: 592. Como se ve, Oldenburg escribía a Moray con el libro de Kircher delante.

${ }^{143}$ Carta del 11 de Noviembre de 1665, Ibidem, página 603 y siguiente. 
famosa agitación ni nada que se le pareciese, exceptuando algunas burbujitas usuales debidas a que las sales no estaban del todo disueltas. Dijo que iba a repetir el experimento la noche siguiente con el ayudante de Boyle mirando más tiempo. Se quejó, no obstante, de la falta de precisión en la descripción del experimento, pues sólo se mencionan los ingredientes y no las proporciones precisas. A falta de ello, usaron la proporción que se encuentra en el agua del mar. Pero teme que el experimento sea un caso perdido aunque «tendremos la satisfacción de comprobarlom. ${ }^{144}$

Cuatro días más tarde informó cumplidamente de que "Thom [el ayudante de Boyle] en sus dos noches de observación no vio en el experimento lo que promete Kircherm. ${ }^{145}$ Dos días después le escribió Boyle suponiéndolo enterado por Moray de que el experimento "no salió como promete Kircher, sino como yo preví. Y aludiendo al Experimentum II, añade: "por lo que respecta al experimento del mismo Autor con mercurio y agua salada encerrados en un anillo, si bien la falta de vidrios adecuados me impedirán ensayarlo [...], con todo aparte de que es casi el mismo aunque no tan favorable como aquél que publicó. en su Ars Magnetica [Magnes, sive de arte magnetica,] hace veinte o treinta años, no puedo menos de pensar que resulta improbable que salga, al menos en nuestro clima donde al condensar los rayos de la Luna con una lupa grande, no logré producir ninguna alteración sensible en los cuerpos que parecen muy fácilmente afectables por ellos [...]».

Como se ve, el bueno de Boyle, incluso cuando duda con toda razón de la posibilidad de reproducir los experimentos ajenos, no deja de buscar caritativamente posibles causas del fallo, como el frío clima oxoniense, antes que tachar a una persona notable de impostora o necia. El siempre correcto y diplomático Oldenburg se mostró en privado más desencantado con el jesuita: «es un mal presagio, creo yo, que falle precisamente el primer experimento que hemos seleccionado de los de Kircher, siendo probable que pase lo mismo con el siguientem. ${ }^{146}$ A partir de 1665 los experimentalistas del Reino Unido desconfiaron seriamente de la competencia técnica cuando no de la integridad de Kircher, algo que ocurría también con los franceses e italianos.

${ }^{144}$ Ibidem, páginas 605-607.

145 Carta del 16 de Noviembre de 1665, Ibidem, página 610.

${ }^{146}$ Oldenburg a Boyle, 21 de Noviembre de 1665, Ibidem, página 615. 
En la segunda mitad del siglo XVII no estaba estandarizado el modo de realizar experimentos físico-químicos ni ensayos clínicos, por lo que el frecuente recurso a la experimentación como fuente del conocimiento científico era en gran medida retórico cuando no vacío. Muchas veces los experimentos servían sólo para ilustrar tesis generadas y probadas filosóficamente. Pero incluso algunos de los grandes y buenos experimentadores, como Galileo, no sabían muy bien cómo articular los experimentos con la teoría, dado que aún conservaba un esquema epistemológico de corte aristotélico en el que la ciencia era demostrativa al modo euclídeo, razón por la cual una experiencia particular no tenía un encaje fácil. ${ }^{147}$ Los discípulos de Galileo, especialmente en la Accademia del Cimento, hicieron mucho por refinar y poner a punto las técnicas de demostración experimental, mientras que Boyle se esforzó por elevar el nivel epistemológico de la experimentación considerándola una piedra angular en el aumento del conocimiento. Sin embargo el método estaba seriamente amenazado por la dificultad de controlar y repetir las innumerables pretensiones de haber hallado algo, sea por ineptitud de los autores, sea por malicia, sea por motivos esenciales a la naturaleza de las cosas. Dado que quienes se dedicaban a las ciencias no matemáticas y usaban los experimentos, no para ilustrar su filosofía sino para explorar la naturaleza, no disponían aún de teorías capaces de predecir y explicar lo que podía surgir, ${ }^{148}$ carecían de criterios para juzgar los resultados. Un problema frecuente era la incapacidad de reproducir lo que otros decían conseguir experimentalmente. Ello podía deberse

147 De ahí su esfuerzo por encontrar definiciones "esenciales" a priori capaces de funcionar como proposiciones primitivas en la derivación de teoremas. Por ejemplo, aunque le costó años, razonamientos y experimentos hallar que el incremento de la velocidad en la aceleración natural de los graves se realiza en función del tiempo y no del espacio, finalmente lo planteó en los Discorsi (Opere, VIII: 197) como algo lógicamente de cajón. En lugar de explicar cómo lo había descubierto con experimentos (algo contingente), lo presento como el modo de operar "primero, más simple y fácil" dada la "afinidad estrechísima que hay entre tiempo y movimiento". Por su lado, los experimentos servían no para descubrir sino para confirmar lo hallado a priori: hemos dado con la "esencia del movimiento naturalmente acelerado" porque "los síntomas demostrados a partir de ella parecen responder y concordar con lo que los experimentos naturales presentan a los sentidos" (Ibidem).

${ }^{148}$ En las ciencias matemáticas, donde existían teorías maduras desde la Antigüedad, las experiencias no arrojaban novedades inesperadas, sino valores concretos de un parámetro, una distancia, una fuerza o cualquier otra función. Aunque ello pudiera tener consecuencias revolucionarias, como la paralaje de Marte que creyó medir Tycho Brahe y que mostraba que en la oposición estaba más cerca de la Tierra que el Sol, la teoría de la medición de paralajes no lo era. 
a que no se explicaban bien los procedimientos, cosa que hacían mucho los alquimistas por motivos interesados. Pero aun cuando se explicasen bien los procedimientos, seguían produciéndose fallos en la repetición, lo que ponía seriamente en entredicho el método experimental de las ciencias baconianas frente a la subordinación teórica y la buena conducta de las mediciones de las matemáticas.

En 1661 Boyle publicó, junto con Certain Physiological Essays, un escrito titulado Two Essays Concerning the Unsuccessfulness of Experiments, ${ }^{149}$ tratando de investigar el problema. La replicación puede fallar por los materiales o por los procedimientos. Los materiales, los productos químicos usados, pueden contener impurezas incontroladas; pero incluso aunque no sea así y su rectificación y depuración se hayan hecho con mimo, pueden comportarse de modo distinto. Boyle piensa aquí que los reactivos químicos son como los especímenes animales o vegetales que pueden presentar diversas propiedades aún dentro de la misma especie. ${ }^{150} \mathrm{Y}$ del mismo modo que no hay dos enfermos iguales, como muestran los experimentos con polvo simpático que en unos resulta y en otros no, nunca podemos saber por qué los experimentos inorgánicos unas veces salen y otras no.

La cuestión se agrava porque, frente a lo que ocurre en las ciencias matemáticas, en las que se sabe qué hay que medir y controlar, en las ciencias baconianas se carece de criterios sobre cuáles son los factores relevantes, los cuales pueden pasar desapercibidos, como ocurre con los resultados de los injertos o con los ensayos de la vara de zahorí que sólo salen bien a veces, sin que sepamos por qué. ${ }^{151} \mathrm{Dada}$ la variabilidad esencial de la naturaleza y nuestro desconocimiento de los factores relevantes de los fenómenos, el principio de caridad recomienda conceder credibilidad a los informantes de experimentos que no nos salen a nosotros. Pero hay ciertas pistas que nos pueden ayudar a no aceptarlo todo.

${ }^{149}$ M. HUNTER \& E. B. DAVIS, The Works of Robert Boyle, II: 35-82.

150 "Aunque casi todo el mundo considera sin dudar que el antimonio (y lo mismo ha de entenderse del mercurio, el oro, el cobre, el estaño, etc.) ha de tenerse por ser todo él de la misma naturaleza y denominación, con todo... es posible discernir que hay entre los minerales del mismo tipo las mismas diferencias que se dan entre los animales y vegetales de la misma especien (Ibid., pág. 41).

151 Boyle no cree "bastante" en la influencia de los astros sobre la prueba de la vara de zahorí, aunque así se lo dijo un "famosísimo químico... muy solemnemente". "Mas de este experimento he de contentarme con señalar lo que acostumbro a decir cuando se me pide mi opinión sobre aquellas cosas que no me atrevo a rechazar perentoriamente, si bien no estoy convencido de ellas; a saber, que quienes las han visto pueden creer en ellas mucho más razonablemente que quienes no" (Ibid., pág. 69). Boyle es un caballero y está dispuesto a suspender el juicio antes que condenar a nadie por iluso o falsario. 
Una de ellas es el autoengaño y la sugestión (que andando el tiempo daría lugar a los experimentos ciegos ${ }^{152}$ ), y cita como ejemplo los experimentos consistentes en ver en las cristalizaciones de las cenizas y sales congeladas las imágenes de los vegetales de que procedían. Los observadores predispuestos pueden ver plantas en las múltiples formas que aparecen en los líquidos congelados, pero aunque por casualidad aparezca una imagen semejante a una vid, la repetición del experimento no la volverá a producir. Los efectos de la sugestión quedaron puestos de manifiesto con la broma que el fabricante de instrumentos Richard Reeves le gastó a un ingenuo diciéndole que con uno de sus telescopios de 9,14 $\mathrm{m}$ se veía en un molino a seis millas de distancia una araña en medio de su tela. Tras algunos titubeos iniciales, acabó confesando que la veía con tanta nitidez que se asombraba de no haberla captado inmediatamente. ${ }^{153}$

Ahora bien, eliminados los efectos del autoengaño, en caso de que ello sea posible, nos quedamos con la credibilidad del autor como único criterio epistemológico, asentado en los valores cristianos de equidad y caridad. Si el autor es persona digna de crédito, hemos de aceptar sus informes aunque a nosotros no nos salga lo mismo, pues hay muchas causas de tal variabilidad. ${ }^{154} \mathrm{El}$ problema es que la credibilidad de una persona debe medirse por la exactitud de sus informes, con lo que el pobre Boyle está cogido en un círculo un tanto vicioso.

${ }^{152}$ En el caso del polvo simpático, Boyle reconoce de pasada la necesidad de controlar la sugestión tomando como especialmente significativo un resultado positivo con una persona que no crela en él: "lejos de contribuir con su imaginación al efecto del polvo, se reía de aquellos a quienes veía aplicarlo..." (Ibid. pág. 74). Sobre la confirmación de los efectos del polvo simpático por parte de C. Wren en la Royal Society, véase C. Solfs, "Alicuius in verba: Tenerife y la Royal Society", citado en la nota 44.

${ }^{153} \mathrm{Ibid}$., pág. 62. Aunque no menciona a Kircher, éste era muy aficionado a los árboles metálicos obtenidos por cristalizaciones salinas amén de a la reconstrucción de vegetales calcinados en virtud de un principio seminal intacto en ellas. Pueden verse varios ejemplos en el Capítulo 6 del Libro X de Mundus subterraneus. Sobre la crítica a la forma formatriz o seminal y la explicación mecánica de estas las cristalizaciones, véase la Observación XX de la Micrografia de R. HoOKE.

154 "Cuando estoy convencido de la habilidad y circunspección de un escritor que informa de una cuestión de hecho sobre la base de su propio conocimiento, no rechazo su observación como no verdadera ni mucho menos condeno a la propia persona como mentirosa cuando hallo que parece ser contradicha por una observación contraria o más indubitable... Y tengo como razón para esta indulgencia para con un autor inteligente que a veces se producen irregularidades contrarias al curso usual de las cosas, como es evidente en el caso de los monstruos; que a veces la hipótesis aceptada, aunque quizá no haya de rechazarse en general, no rige universalmente como la gente supone; y que también a veces la contradicción entre las observaciones puede ser sólo aparente (debido a la ausencia de ciertas circunstancias desapercibidas necesarias para tornarlas consistentes) por lo que puede que ambas sean verdaderas" (Ibid. pág. 80). 
Con todo hay casos extremos en los que "si un autor acostumbra a ser fabuloso o plagiario y a ofrecer confiadamente cosas de oídas sin decir a sus lectores cuándo es así, entonces si al repetir sus experimentos éstos no salen, podemos sentirnos autorizados a imputarle a él la falta de éxito más bien que a nosotros mismos o al azar». ${ }^{155}$ Difícilmente podría darse una descripción más exacta del proceder de Kircher, aunque el piadoso Boyle no lo diga explícitamente y lo cite cuatro veces en este ensayo tildándolo de diligente e industrioso. Pero eso era en 1661 antes de que crecieran los motivos para dudar de su diligencia e industria, tal y como se pondría especialmente de relieve con la publicación del Mundus subterraneus en 1665, aunque es improbable que incluso entonces cometiese la grosería de dudar de su integridad (su piedad) y no sólo de su capacidad, como hacía Huygens padre.

\section{Conclusión}

La ciencia de Kircher obedecía a un modelo erudito renacentista que estaba en contradicción con el que se estaba forjando e imponiendo en el siglo XVII, en detrimento de lo maravilloso aceptado con poco espíritu crítico. Naturalmente este nuevo modelo bebía en parte de aquél, en el que diferentes perspectivas filosóficas se conjugaban con la experiencia y la práctica de una manera que el modelo triunfante diagnosticaría como irracional e ilógico. Kircher estaba en el lado de allá de la demarcación que separaba a su concepción del saber de las diferentes modalidades promocionadas por sus críticos y que acabarían recabando para sí la condición de genuino saber natural. Pero la discrepancia no se observaba tanto en los contenidos doctrinales (nada hay más similar a las interacciones mágicas que la gravitación a distancia de Newton) cuanto en la articulación lógicomatemática de las teorías y su control experimental estricto. En este sentido la experientia y los experimenta de Kircher se parecen más al estilo laxo y esotérico de los autores herméticos que al público, detallado y reproducible de los académicos del Cimento o de Boyle. La filosofía "magnética" de Kircher conecta las partes del cosmos mediante simpatías y analogías emblemáticas o simbólicas poco aptas para la articulación matemática de las teorías físicas traída de la mano del copernicanismo. La impostación matemática de Kircher se parece así más a la de R. Fludd que a la de J. Kepler y no sirve para el cómputo preciso de efectos bien definidos que puedan contraponerse luego con las mediciones, tal como

155 Ibid., pág. 77. 
hacían los practicantes de las ciencias matemáticas del tipo de Galileo, Pascal o Huygens. Por otro lado, su uso laxo de la experiencia tampoco servía para la recopilación baconiana de novedades y para la exploración de los nuevos campos abiertos a la ciencia por los experimentalistas, como los británicos Gilbert o Boyle o los florentinos de la Accademia del Cimento, donde la ausencia de criterios teóricos estrictos obligaba a proceder con circunspección y máxima cautela. Pero la vaga filosofía atomista y mecánico corpuscular que ayudaba en su tarea a los experimentadores heurísticos era un peligro para el alma y la eucaristía, como ya señalamos. Frente a todo ello, en Kircher un experimento es una ocasión para entretener e ilustrar vagamente una pretensión teórica frecuentemente mal articulada; es más una ayuda sensual para la memoria que una pieza de la demostración o la construcción de teorías.

La confusión kircheriana poseía una función en el contexto de la ciencia jesuítica y papista tras la condena de Galileo en 1633, pocos meses antes de la llegada de Kircher a Roma. La implicación de la Compañía en la condena de Galileo y su defensa de la inmovilidad de la Tierra y de la escolástica aristotélica puso a la avanzada papista en una posición muy desairada ante la República de las Letras. La salida ficcionalista para compatibilizar los viejos dogmas con los elementos de juicio pro-copernicanos (la omnipotencia divina puede hacer que todo parezca como si la Tierra se moviese sin que realmente sea así) inducía un escepticismo acerca de la capacidad del intelecto humano muy poco concurrente con la prometedora investigación científica en busca de la verdadera estructura de la naturaleza y del cosmos. El papismo deseaba un imposible, disfrutar de las ventajas de las nuevas artes de la medicina, de las matemáticas, de la mecánica y la química sin comprometerse con los peligros que entrañaban para el alma el copernicanismo, la iatroquímica y la química paracelsiana o el mecanicismo atomista. Quería los resultados prácticos con una visión del mundo fundamentalista en la doctrina y escéptica en filosofía. Pero el escepticismo lleva a ausencia de criterios y ésta, a la credulidad y a la erudición acrítica.

Kircher era una expresión extrema de todo ello, capaz de lanzar una cortina de humo que hiciese parecer ante Europa que la Iglesia Católica fomentaba la ciencia, cuando en realidad intentaba someterla y acallarla. Trataba de usar la ciencia como una diversión cortesana, como un arte de la tramoya. Sus libros poseían el atractivo del mundo de lo oculto y lo prohibido que el lector podía recorrer de la mano de Kircher sin peligro para el alma, de la misma manera que el visitante del Museo Kircheriano asistía a la visión de aquellas maravillas y expe- 
riencias mágicas con los ojos como platos y sin entender una palabra, dejando las cosas en manos de tan sesudos padres.

La obra de Kircher era un ataque preventivo a la ciencia moderna; o, para decirlo con Julio Cortázar, era una aplicación de la técnica de la toma del velorio. ${ }^{156}$ Fingiendo interés por la cosmología, la astronomía, el magnetismo o la química, en realidad trataba de evitar que pudiesen decirnos cómo es realmente el mundo, tarea que habría de quedar para los teólogos y filósofos del Papa. Lo dice muy bien Paula Findlen: "En manos de los jesuitas, los instrumentos que conferían autoridad a las afirmaciones de la nueva ciencia se tornaron en instrumentos con los que insertar dudas sobre la validez de las nuevas ideas». ${ }^{157} \mathrm{Con}$ sus museos, laboratorios, redes de informantes y colegios, los jesuitas pagaban tributo verbal a las matemáticas y a la experimentación modernas, pero no les permitían determinar nuestra ontología ni nuestra visión de la naturaleza. Como siempre existe una brecha entre los experimentos particulares y las tesis teóricas generales, los jesuitas pretendían apropiarse de las técnicas experimentales y matemáticas para arrojar dudas sobre los resultados cuando incomodaban a sus dogmas predilectos, mostrándose más laxos y relajados cuando no era así. A fin de no verse sorprendidos por las novedades científicas, como había acontecido con los descubrimientos telescópicos de Galileo, pusieron todo su empeño en las nuevas técnicas instrumentales y trabajaron especialmente en las nuevas áreas del magnetismo, la observación telescópica, la óptica o la pneumática, donde descubrieron algunos fenómenos importantes pero no construyeron nada.

En este contexto encaja bien la estrambótica y lujosa obra de Kircher que se apropia del prestigio del saber oculto de Paracelso, Bruno o los Rosacruces sin permitirle constituirse en una nueva religión mundana; absorbe y exhibe el saber de van Helmont y otros herméticos, acepta la transmutación de los elementos, pero castiga a Paracelso, a los alquimistas y a la transmutación de los metales; ${ }^{158}$ juega con las novedades cósmicas de Tycho o Galileo, con las manchas solares,

156 Véase "Conducta en los velorios" (Cuentos Completos 1, Madrid: Alfaguara, 1994: 43336), donde su familia acude a los velorios ajenos en los que plane y llora más que nadie y acaba por desplazar a los verdaderos deudos del muerto.

157 "Scientific Spectacle in Baroque Rome: Athanasius Kircher and the Roman College Museum", en M. FEINGOLD (Ed.), Jesuit Science and the Republic of Letters, MIT Press, 2003: 225-284; página 257.

158 Cf. M. BALDWIN, "Alchemy in the Sociery of Jesus", en Z. von Martels (Ed.), Alchemy Revisited, Leiden: Brill, 1990: 182-87. 
los océanos lunares o con la infinitud de los mundos de Bruno, pero niega el heliocentrismo y afirma a la Tierra en el centro el universo; bebe de los experimentos magnéticos de Gilbert con la calamita pero niega con J. Grandami que el magnetismo pueda hacer rotar la Tierra; alardea de experimentos pneumáticos y utiliza los de $\mathrm{O}$. von Guericke, pero niega la existencia del vacío epicureísta. Caminar por el borde del precipicio entrañaba riesgos, como vimos con la censura del Itinerarium, pero ofrecía ventajas propagandísticas en un momento de descrédito del Papa por la oposición a la nueva ciencia. Por eso sus esfuerzos fueron respaldados por la Compañáa y por la Iglesia. Pero la tarea no tenía futuro y todo era teatro: veramente questo frate è un gran buffone. 